Supporting Information for:

\title{
The Resolution of Vaulted Biaryl Ligands via Borate Esters of Quinine and Quinidine
}

\author{
Xiaopeng Yin, Li Zheng, Aliakbar Mohammadlou, Brian Cagnon and William D. Wulff* \\ Department of Chemistry, Michigan State University, East Lansing, MI 48824 \\ Email: wulff@chemistry.msu.edu
}

\section{List of Contents}

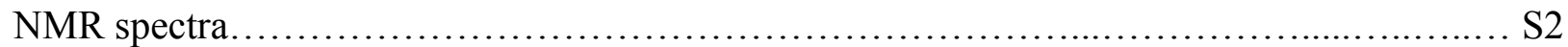




\section{NMR Spectra}

5-Bromo-3-phenyl-1-naphthol 19a:

${ }^{1} \mathrm{H} \mathrm{NMR}\left(500 \mathrm{MHz}, \mathrm{CDCl}_{3}\right)$

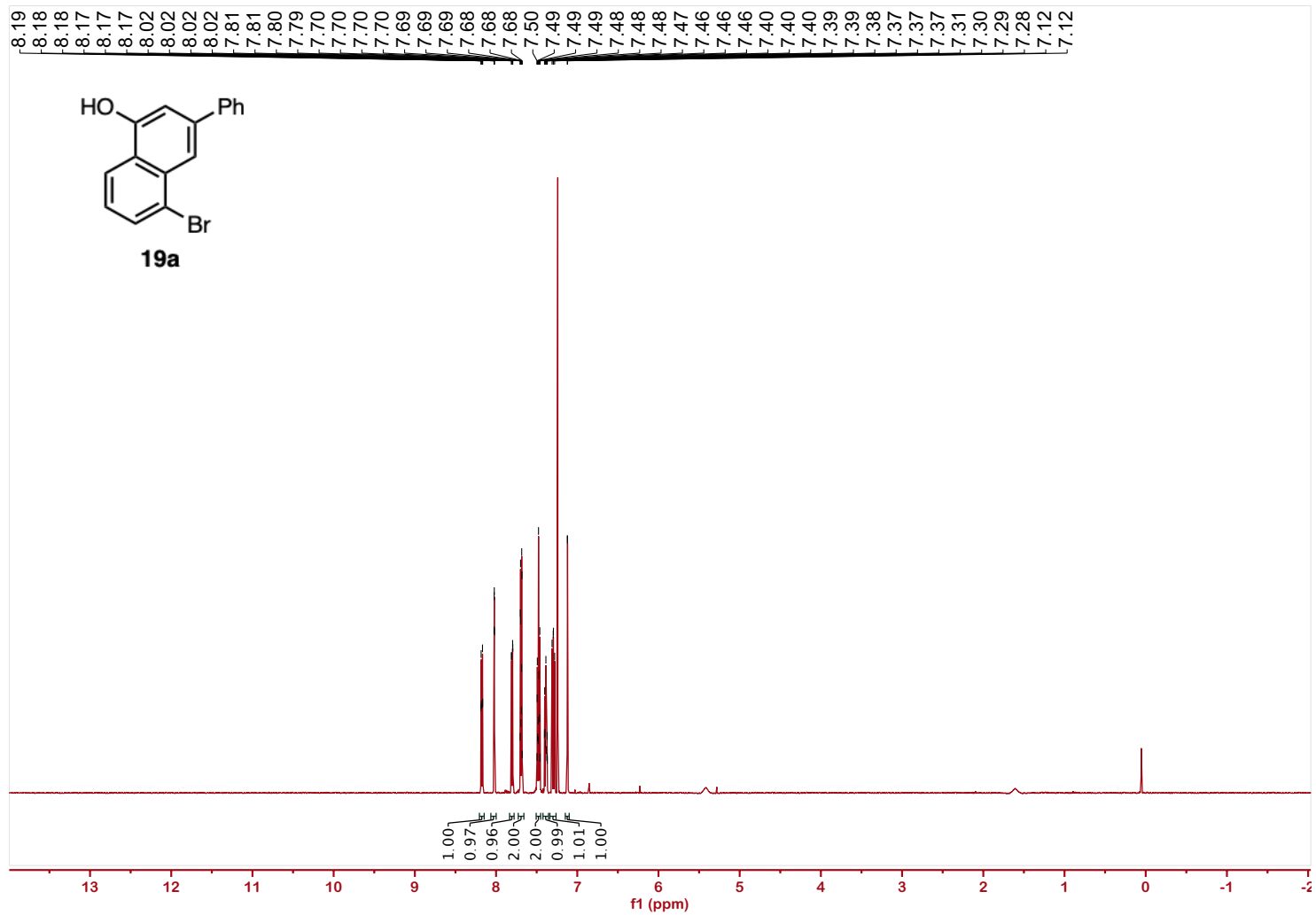

${ }^{13} \mathrm{C}\left\{{ }^{1} \mathrm{H}\right\}$ NMR $\left(126 \mathrm{MHz}, \mathrm{CDCl}_{3}\right)$<smiles>Oc1cccc2cccc(Br)c12</smiles>

19a
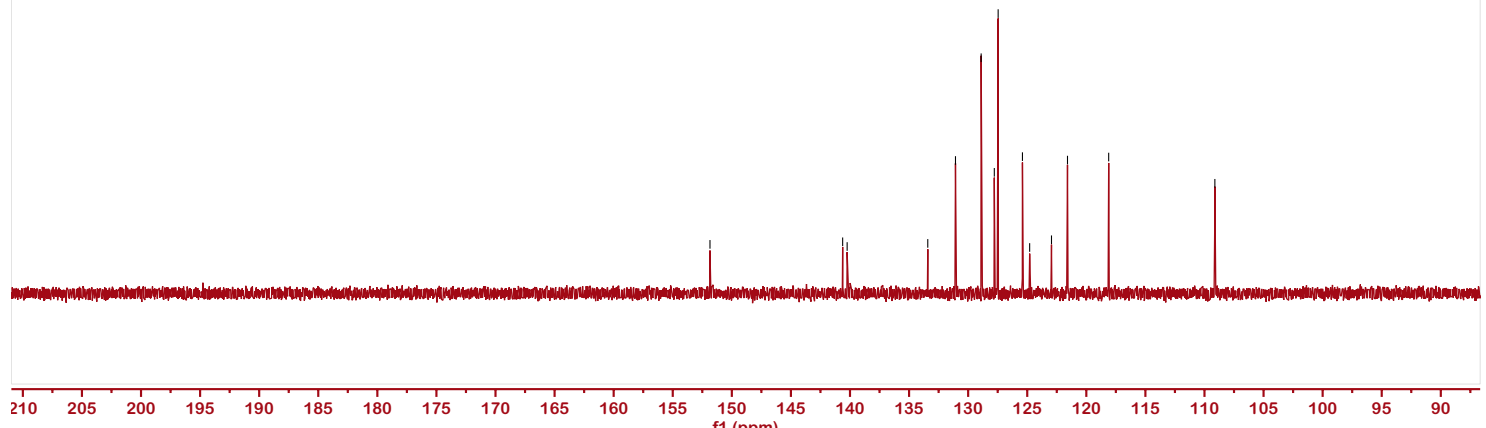


\section{5,5'-Br2VANOL 12a:}

${ }^{1} \mathrm{H}$ NMR (500 MHz, $\mathrm{CDCl}_{3}$ )

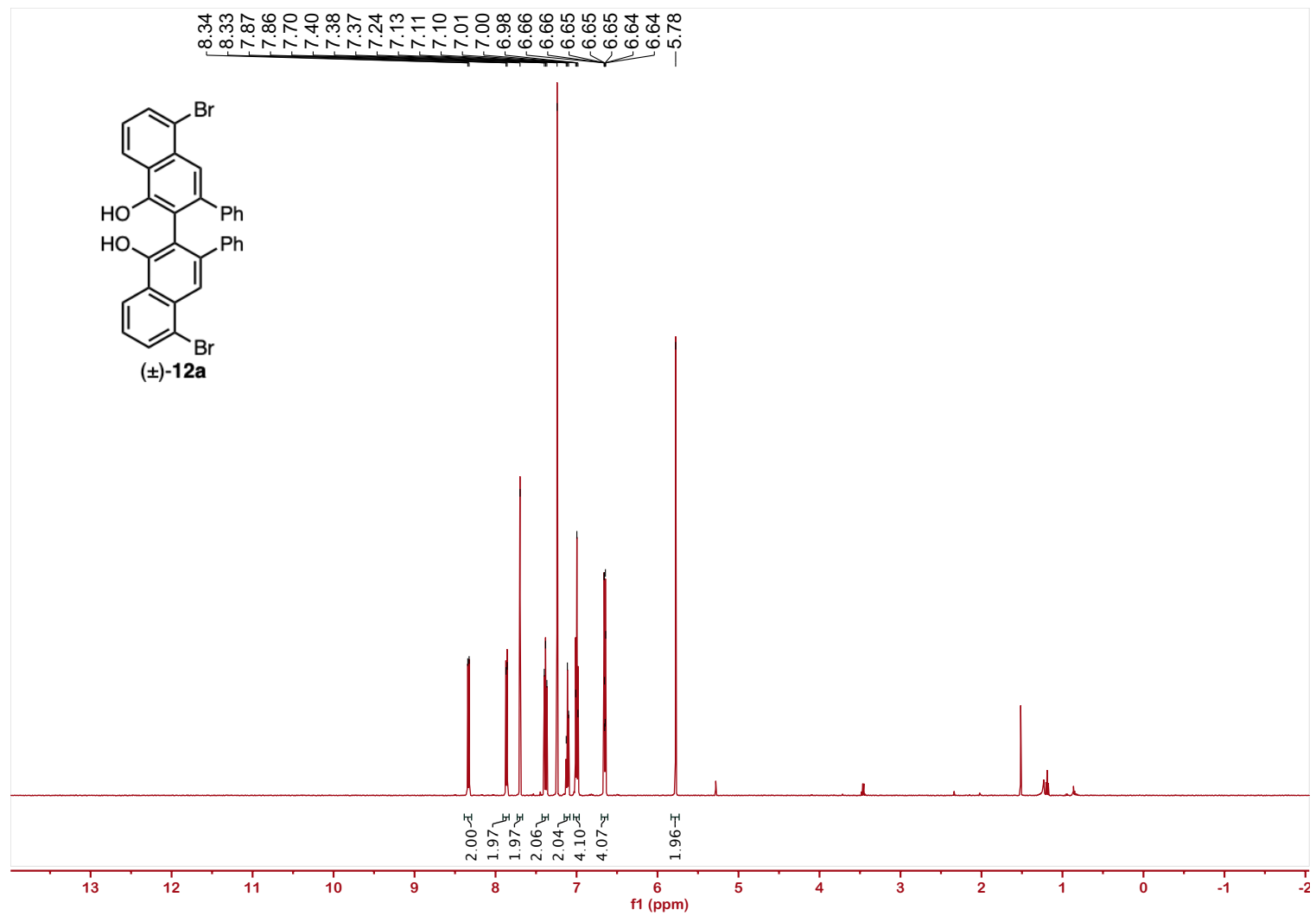

${ }^{13} \mathrm{C}\left\{{ }^{1} \mathrm{H}\right\}$ NMR $\left(126 \mathrm{MHz}, \mathrm{CDCl}_{3}\right)$

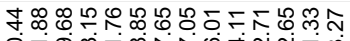

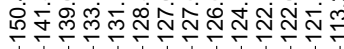

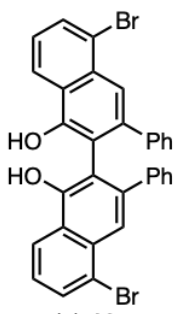

(士)-12a

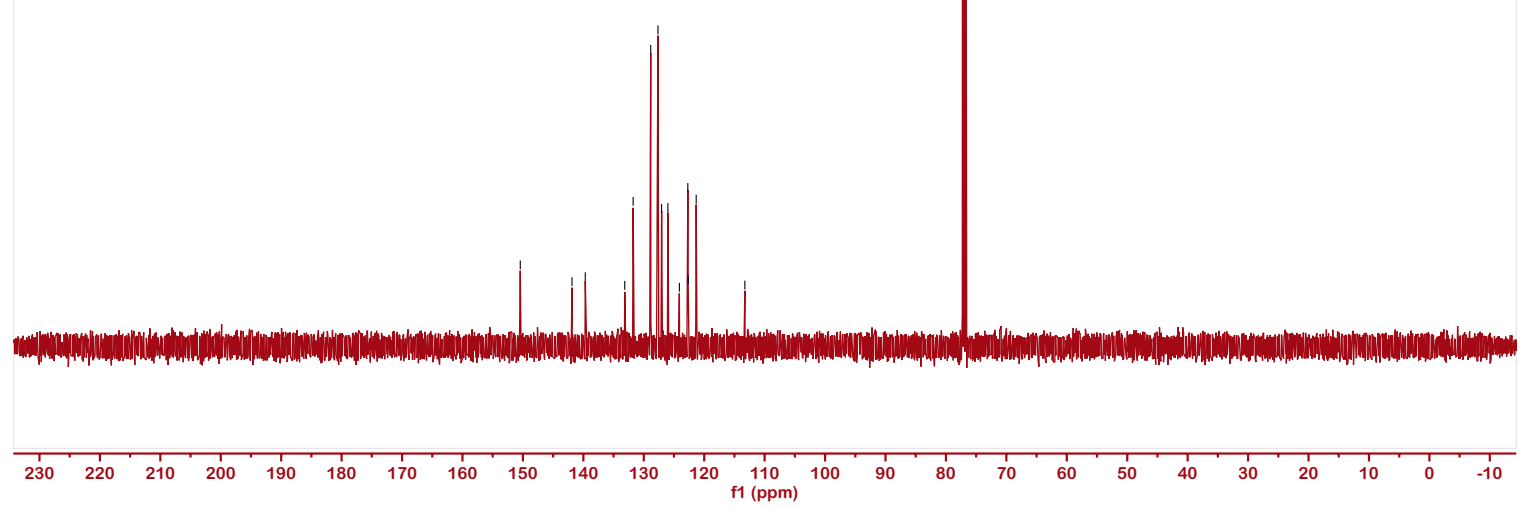


5-Chloro-3-phenyl-1-naphthol 19b:

${ }^{1} \mathrm{H}$ NMR $\left(500 \mathrm{MHz}, \mathrm{CDCl}_{3}\right)$

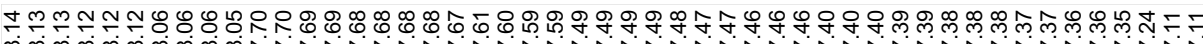

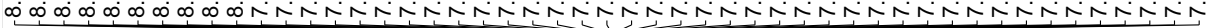

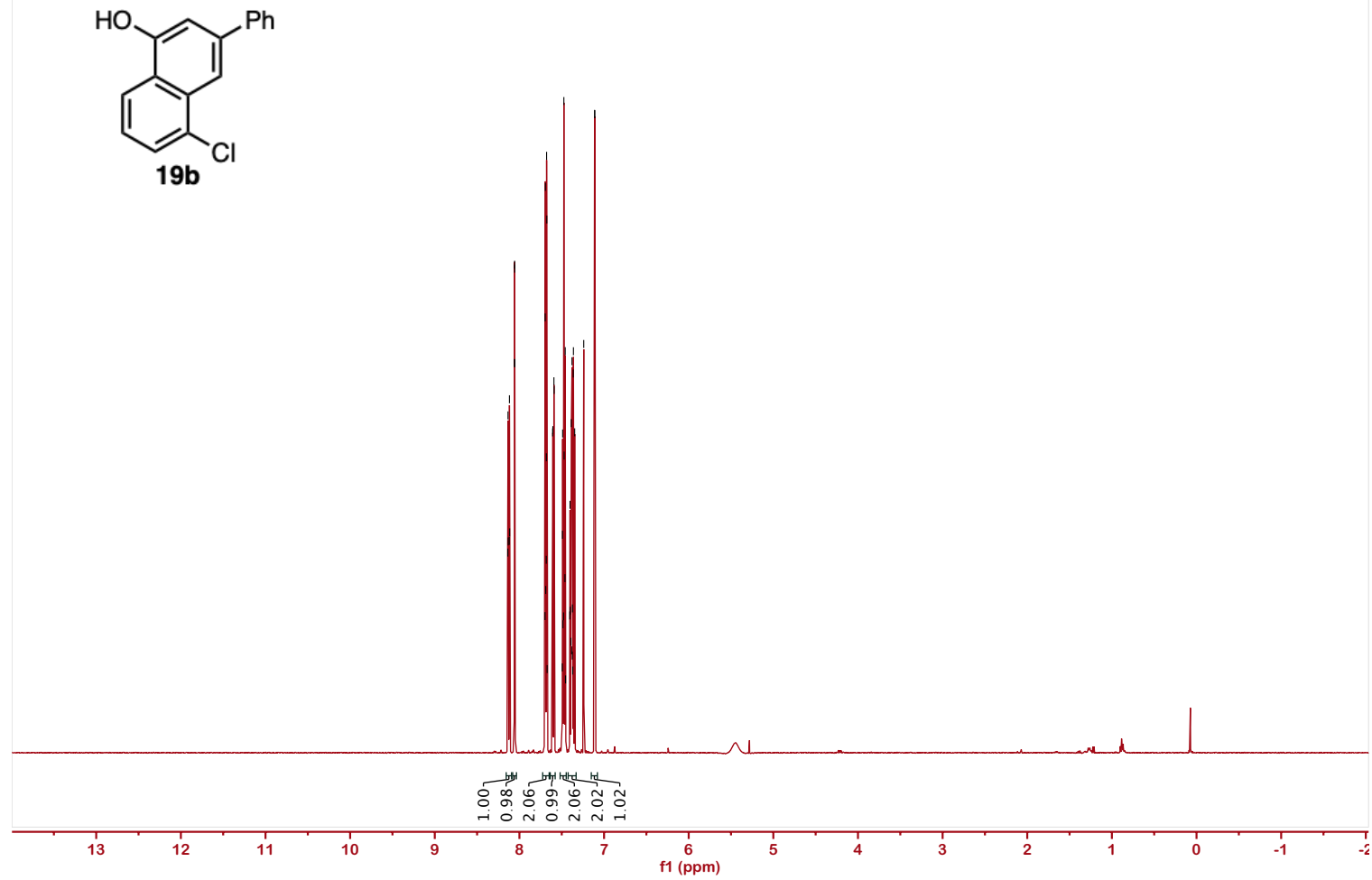

${ }^{13} \mathrm{C}\left\{{ }^{1} \mathrm{H}\right\}$ NMR $\left(126 \mathrm{MHz}, \mathrm{CDCl}_{3}\right)$

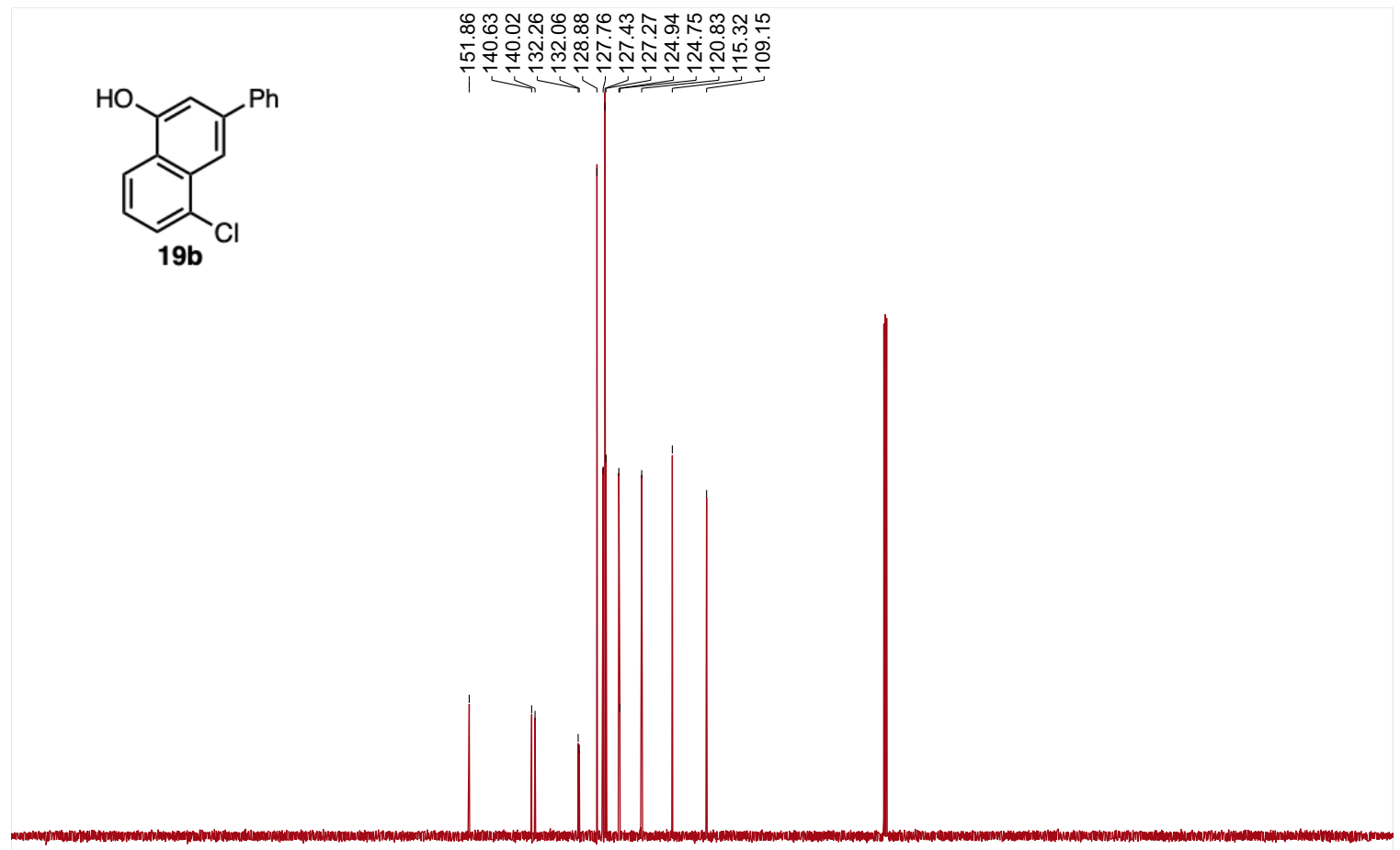

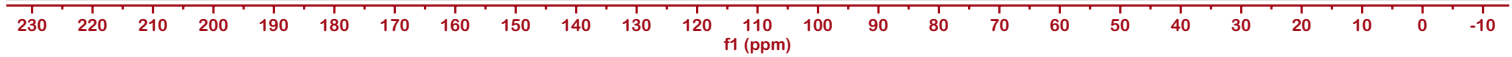




\section{5,5'- $\mathrm{Cl}_{2}$ VANOL $\mathbf{1 2 b}$ :}

${ }^{1} \mathrm{H}$ NMR $\left(500 \mathrm{MHz}, \mathrm{CDCl}_{3}\right)$

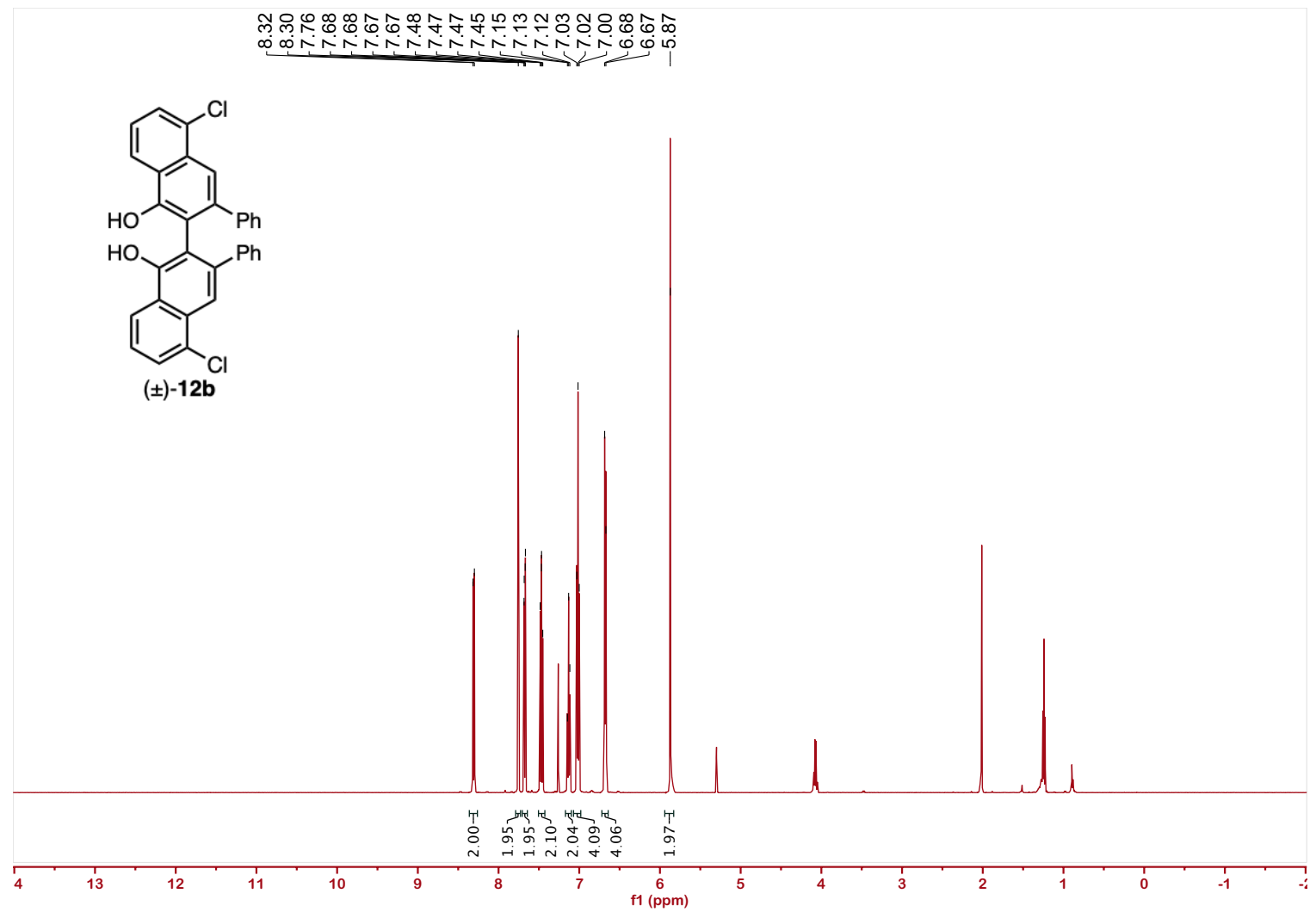

${ }^{13} \mathrm{C}\left\{{ }^{1} \mathrm{H}\right\} \mathrm{NMR}\left(126 \mathrm{MHz}, \mathrm{CDCl}_{3}\right)$

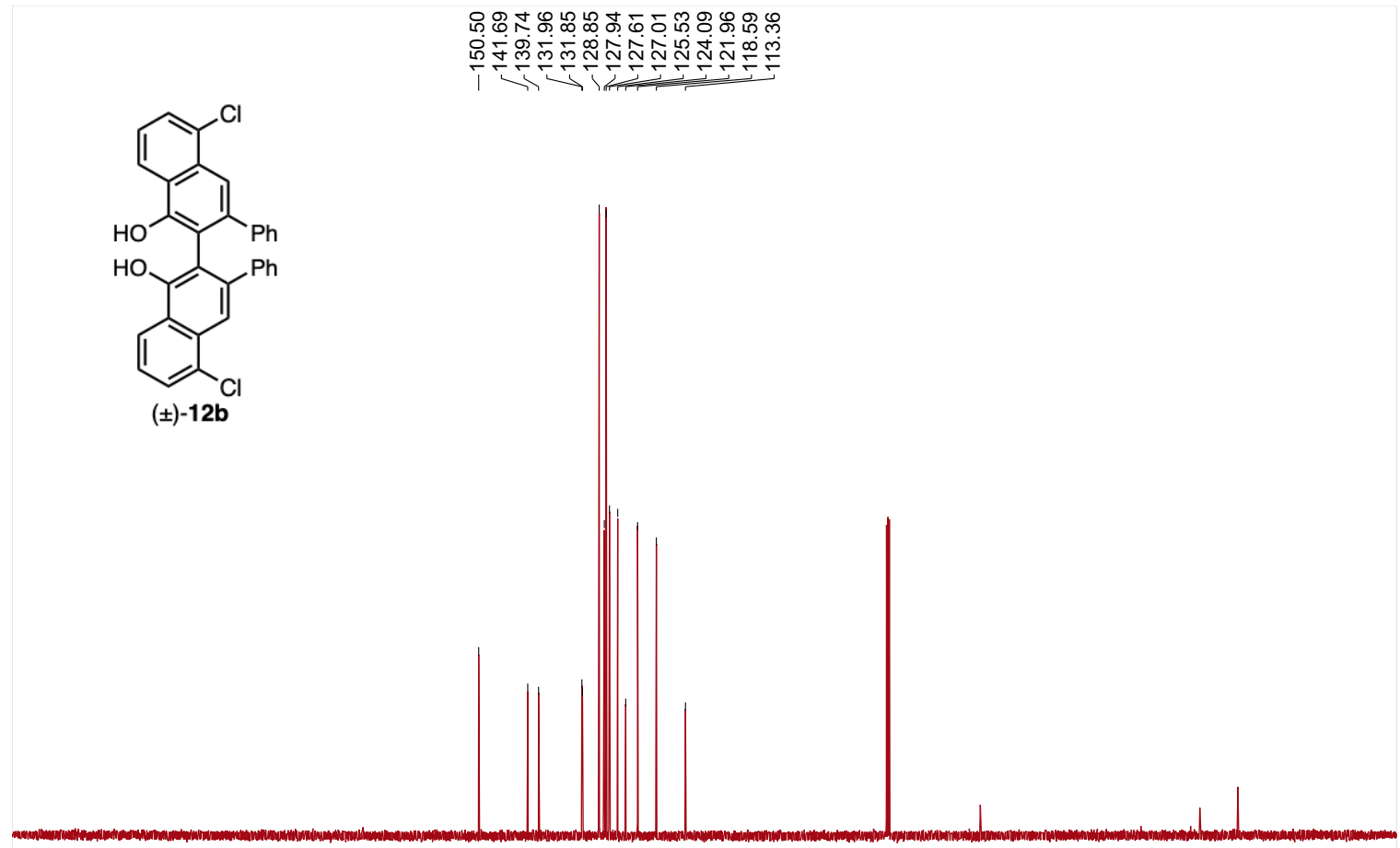

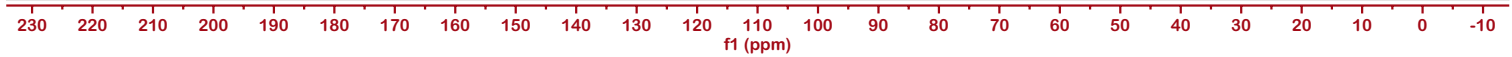


5-Methyl-3-phenyl-1-naphthol 19c:

${ }^{1} \mathrm{H}$ NMR $\left(500 \mathrm{MHz}, \mathrm{CDCl}_{3}\right)$

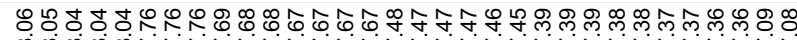

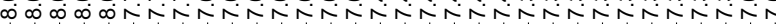

$\stackrel{i}{i}$<smiles>Cc1cccc2c(O)cc(-c3ccccc3)cc12</smiles>

19c

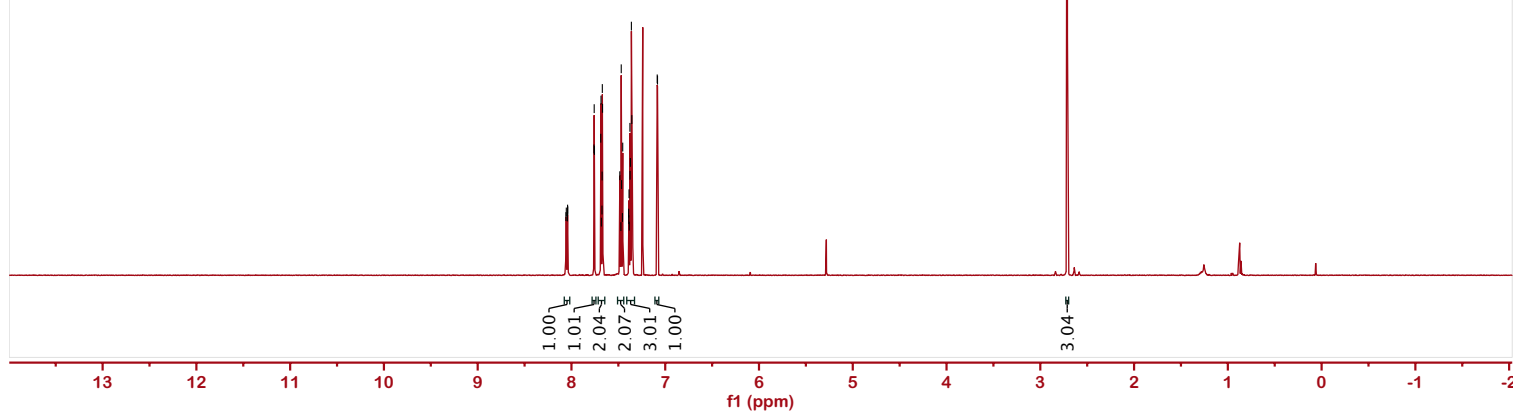

${ }^{13} \mathrm{C}\left\{{ }^{1} \mathrm{H}\right\} \mathrm{NMR}\left(126 \mathrm{MHz}, \mathrm{CDCl}_{3}\right)$

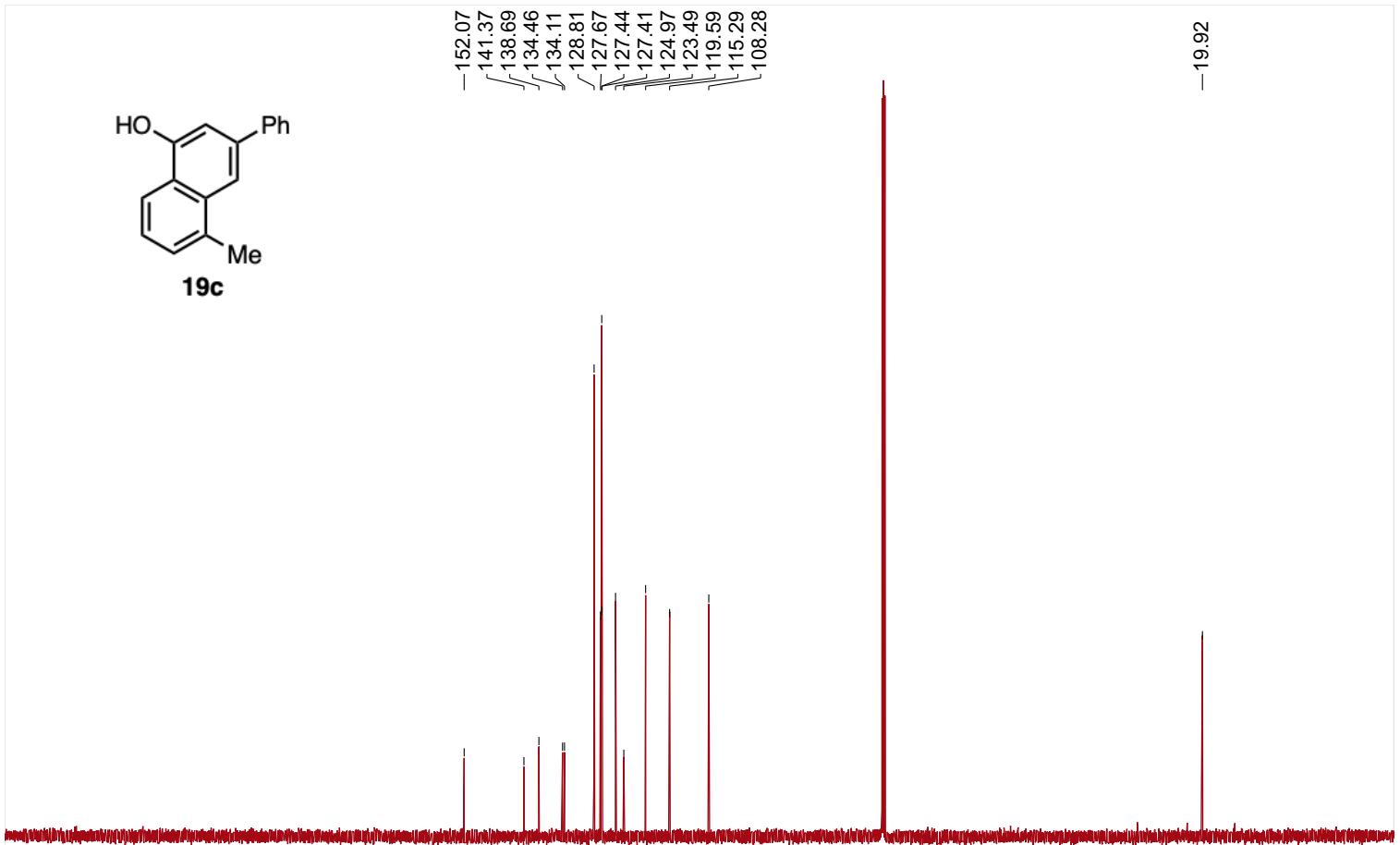

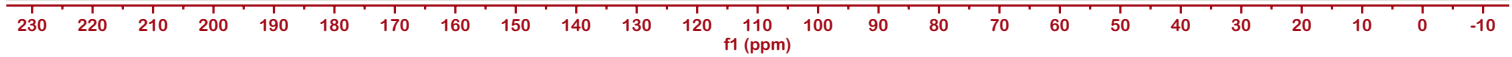




\section{5,5'-Me ${ }_{2}$ VANOL 12c:}

${ }^{1} \mathrm{H}$ NMR $\left(500 \mathrm{MHz}, \mathrm{CDCl}_{3}\right)$

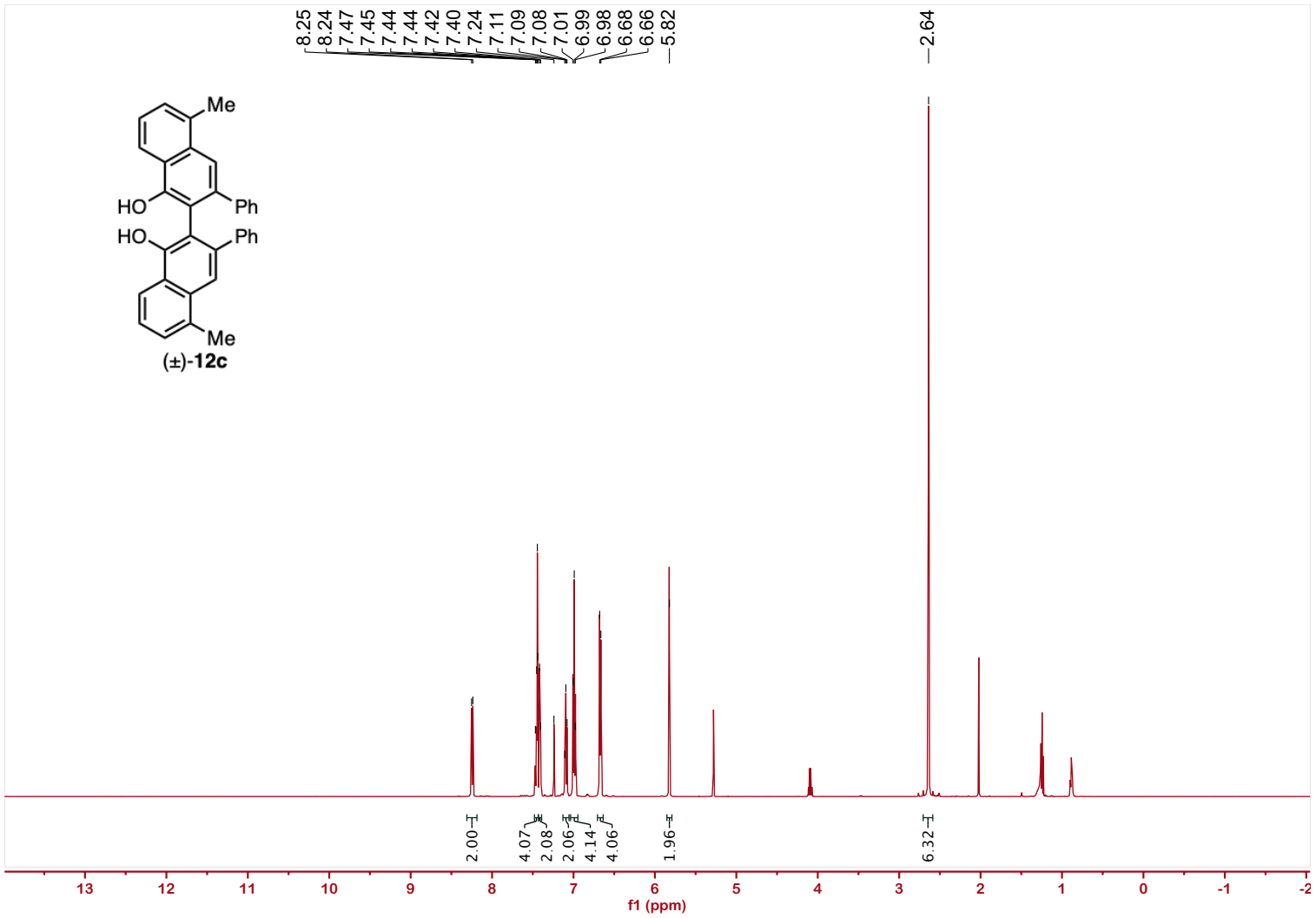

${ }^{13} \mathrm{C}\left\{{ }^{1} \mathrm{H}\right\}$ NMR $\left(126 \mathrm{MHz}, \mathrm{CDCl}_{3}\right)$

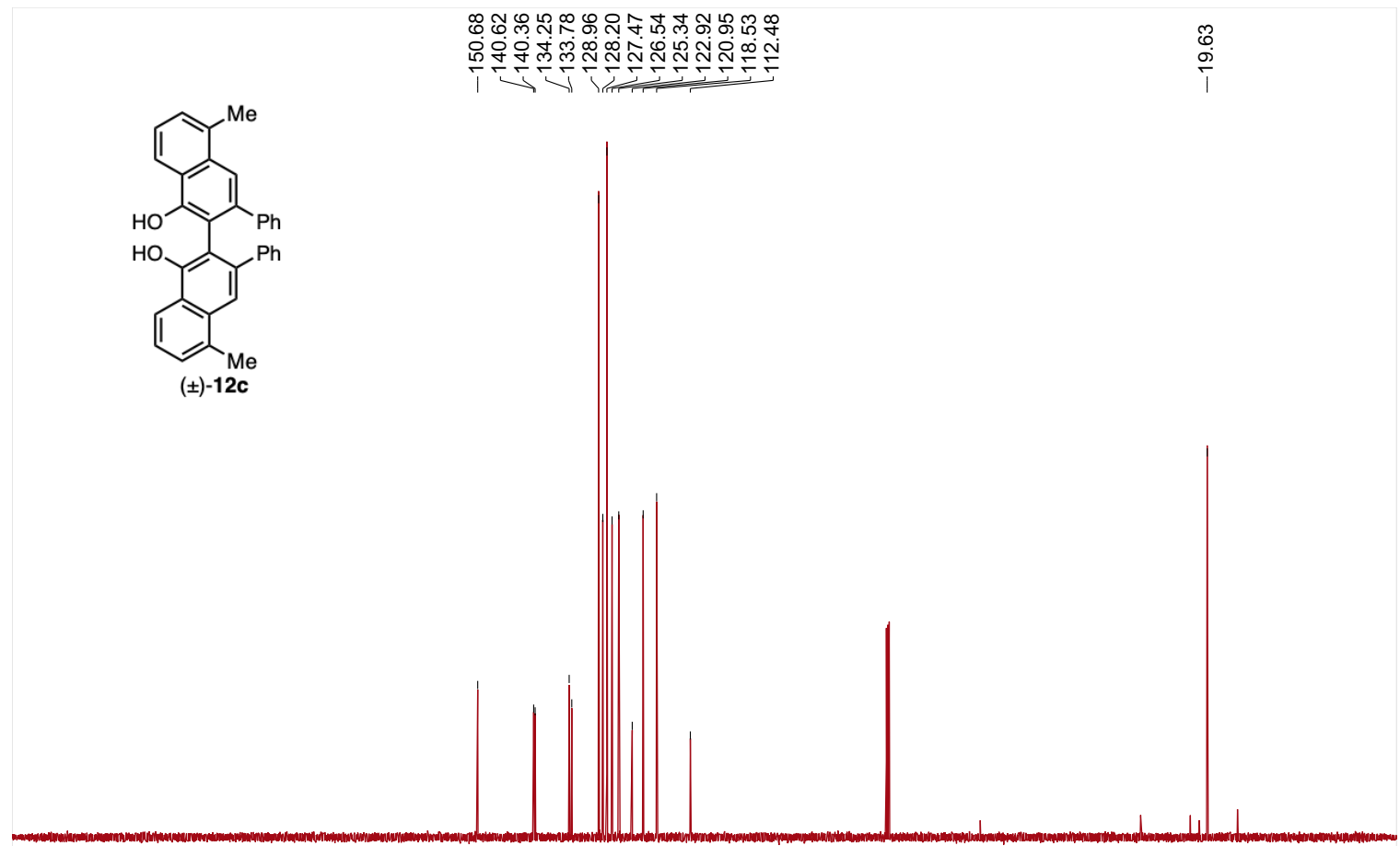

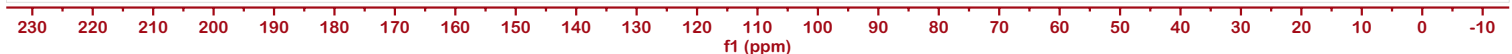


5-Methoxy-3-phenyl-1-naphthol 19d:

${ }^{1} \mathrm{H}$ NMR $\left(500 \mathrm{MHz}, \mathrm{CDCl}_{3}\right)$

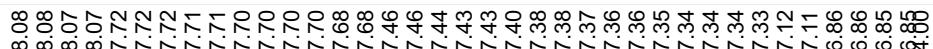

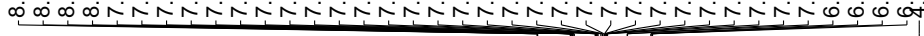

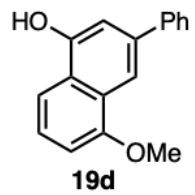

$19 d$

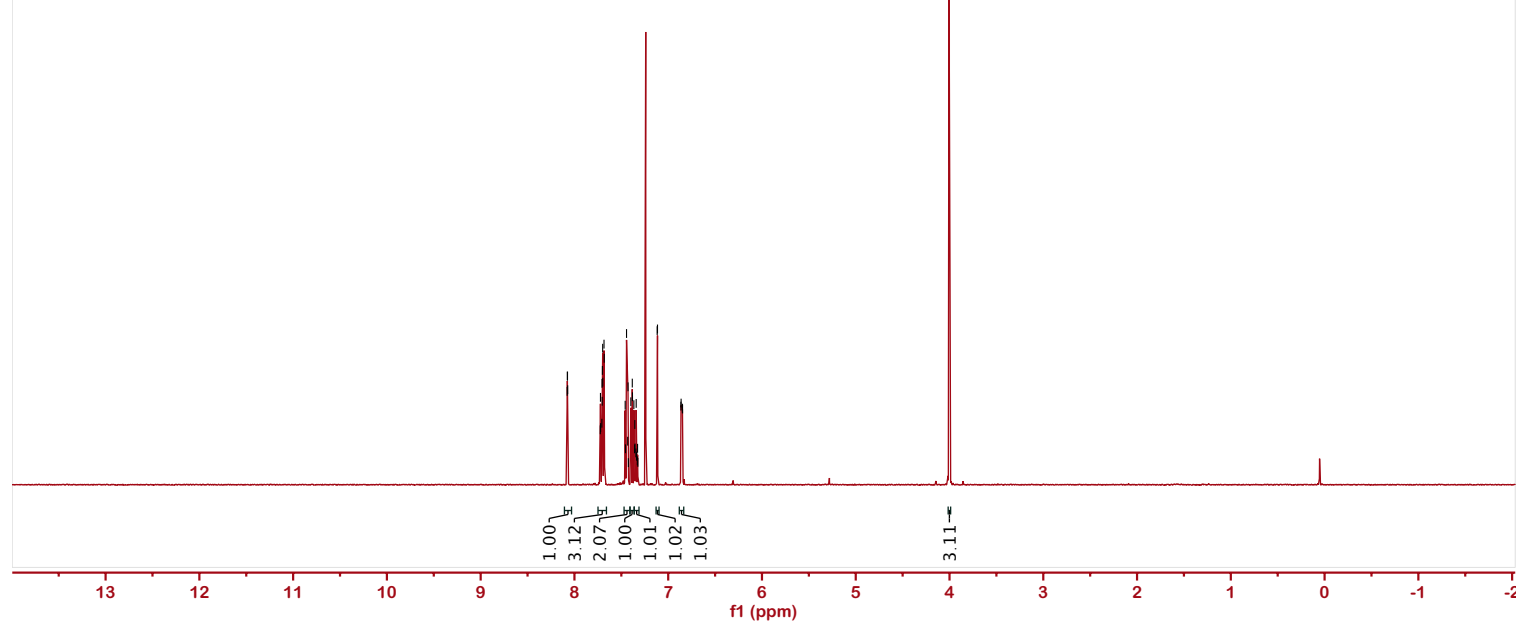

${ }^{13} \mathrm{C}\left\{{ }^{1} \mathrm{H}\right\}$ NMR $\left(126 \mathrm{MHz}, \mathrm{CDCl}_{3}\right)$

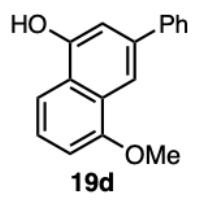

每

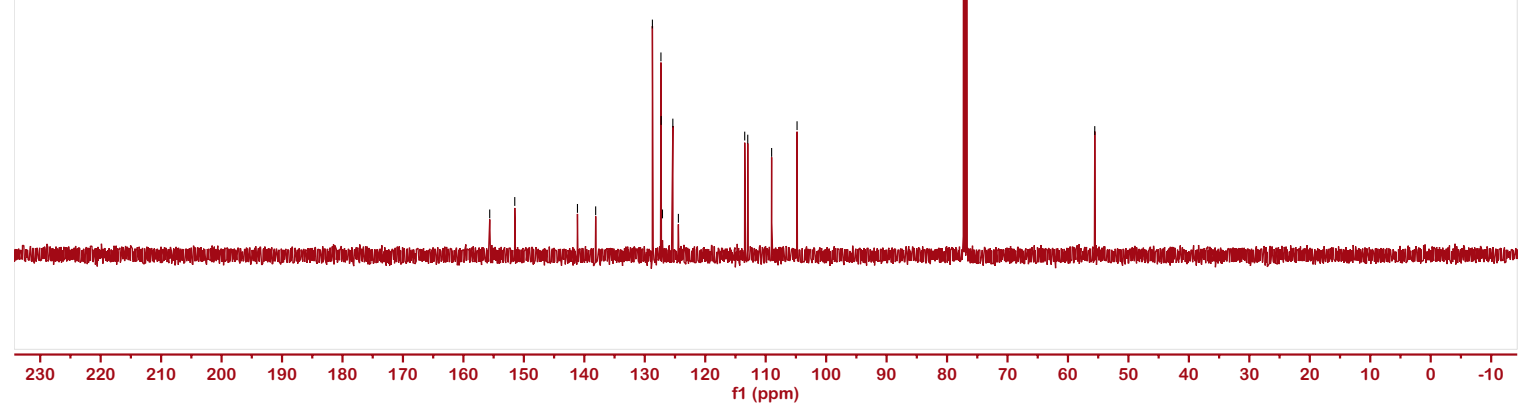


5,5'-OMe 2 VANOL 12d:

${ }^{1} \mathrm{H}$ NMR (500 MHz, $\mathrm{CDCl}_{3}$ )

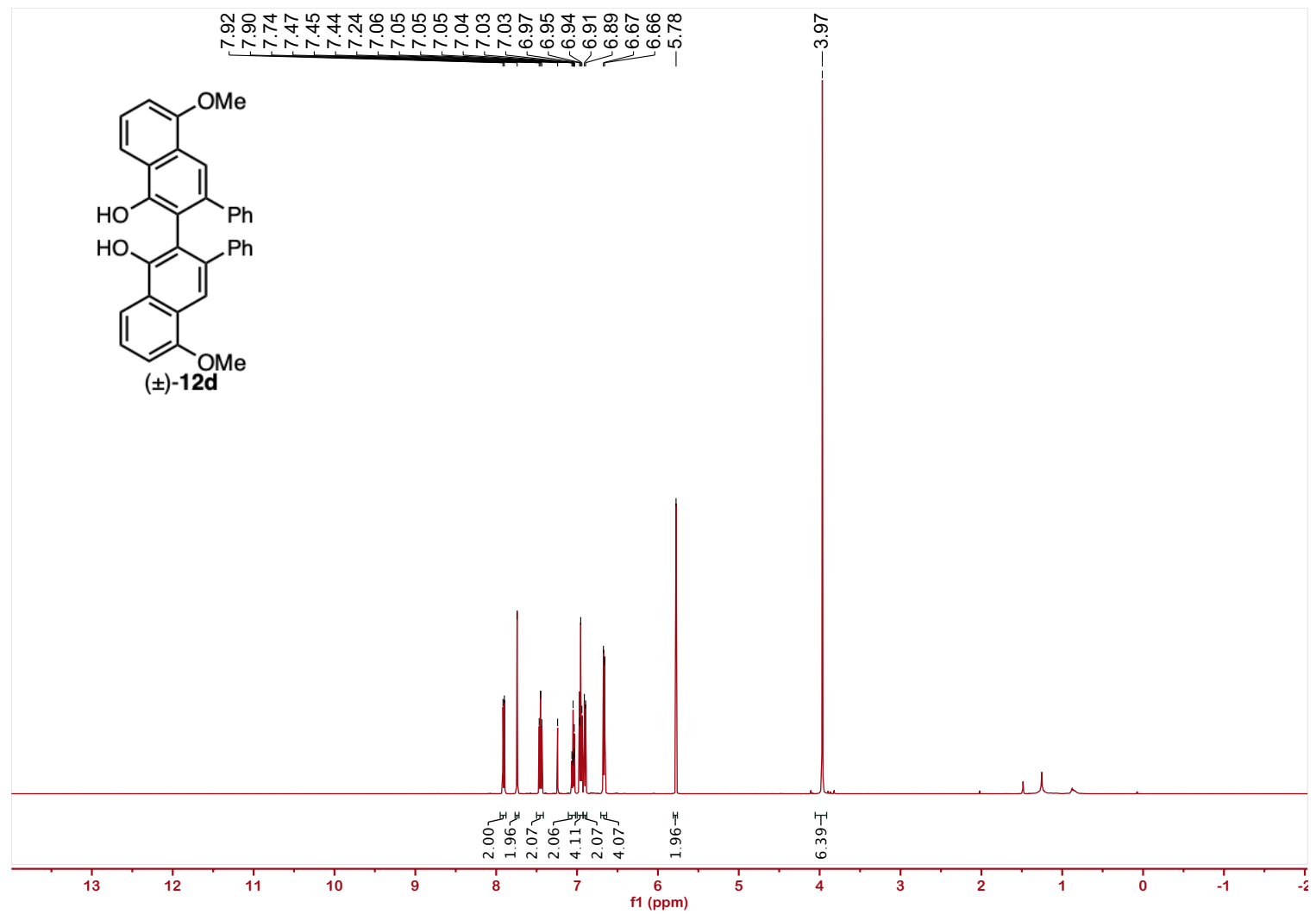

${ }^{13} \mathrm{C}\left\{{ }^{1} \mathrm{H}\right\}$ NMR $\left(126 \mathrm{MHz}, \mathrm{CDCl}_{3}\right)$
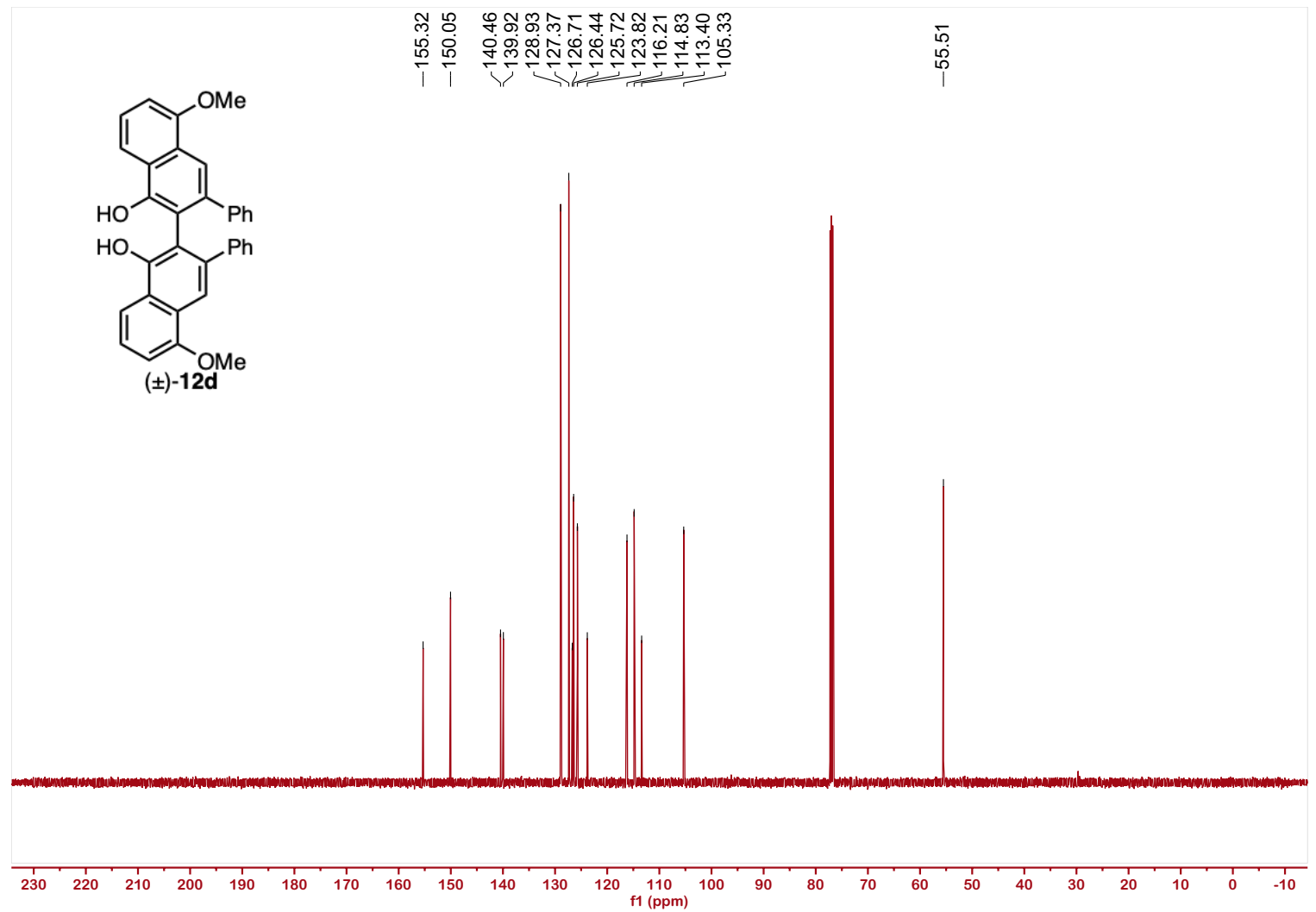
5-Trifluoromethyl-3-phenyl-1-naphthol 19e:

${ }^{1} \mathrm{H}$ NMR $\left(500 \mathrm{MHz}, \mathrm{CDCl}_{3}\right)$
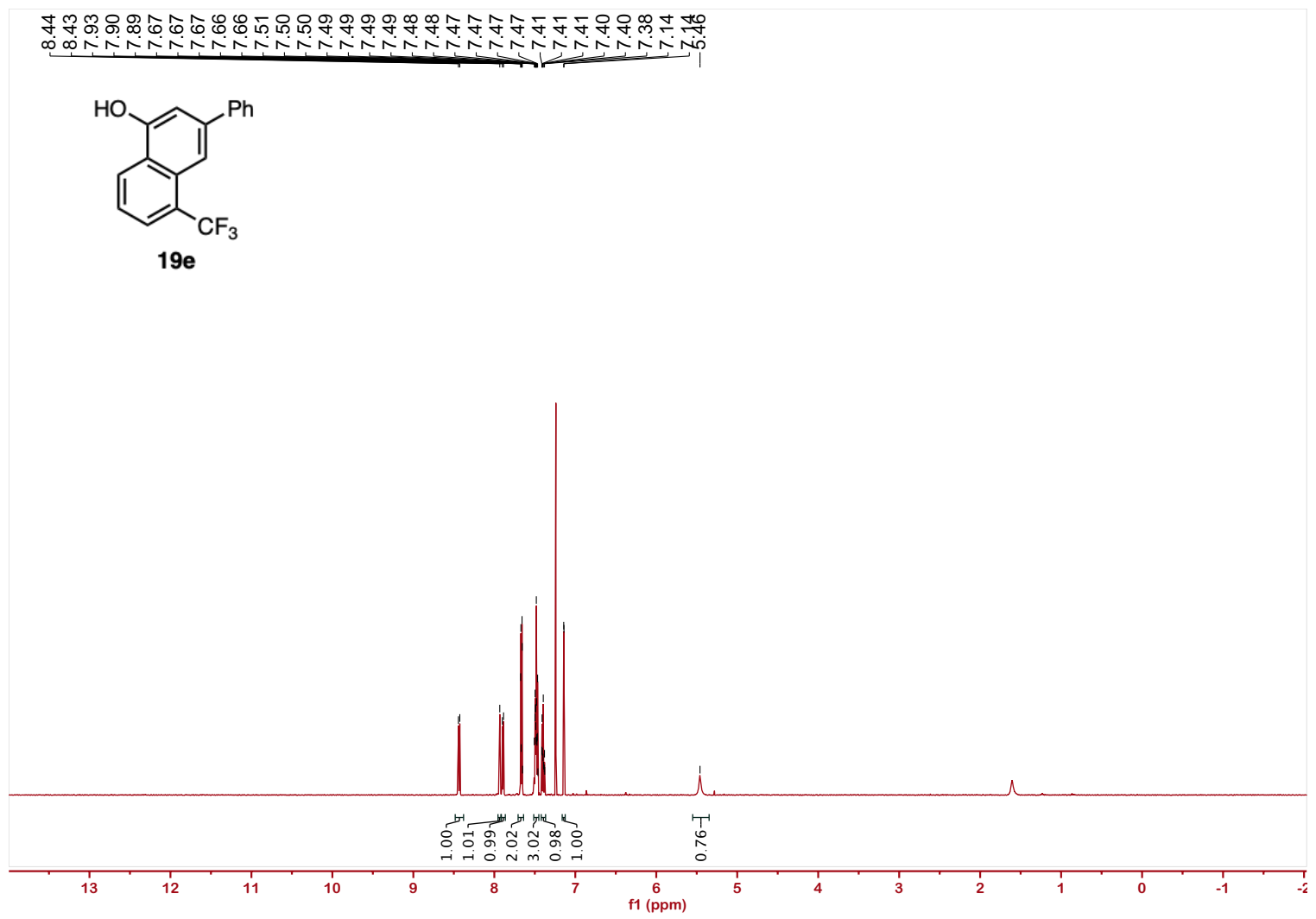

${ }^{13} \mathrm{C}\left\{{ }^{1} \mathrm{H}\right\}$ NMR $\left(126 \mathrm{MHz}, \mathrm{CDCl}_{3}\right)$

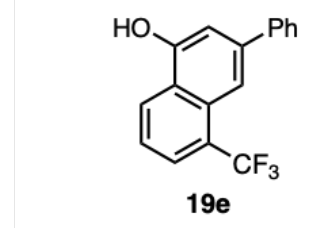

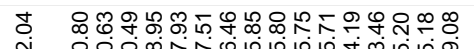

崔
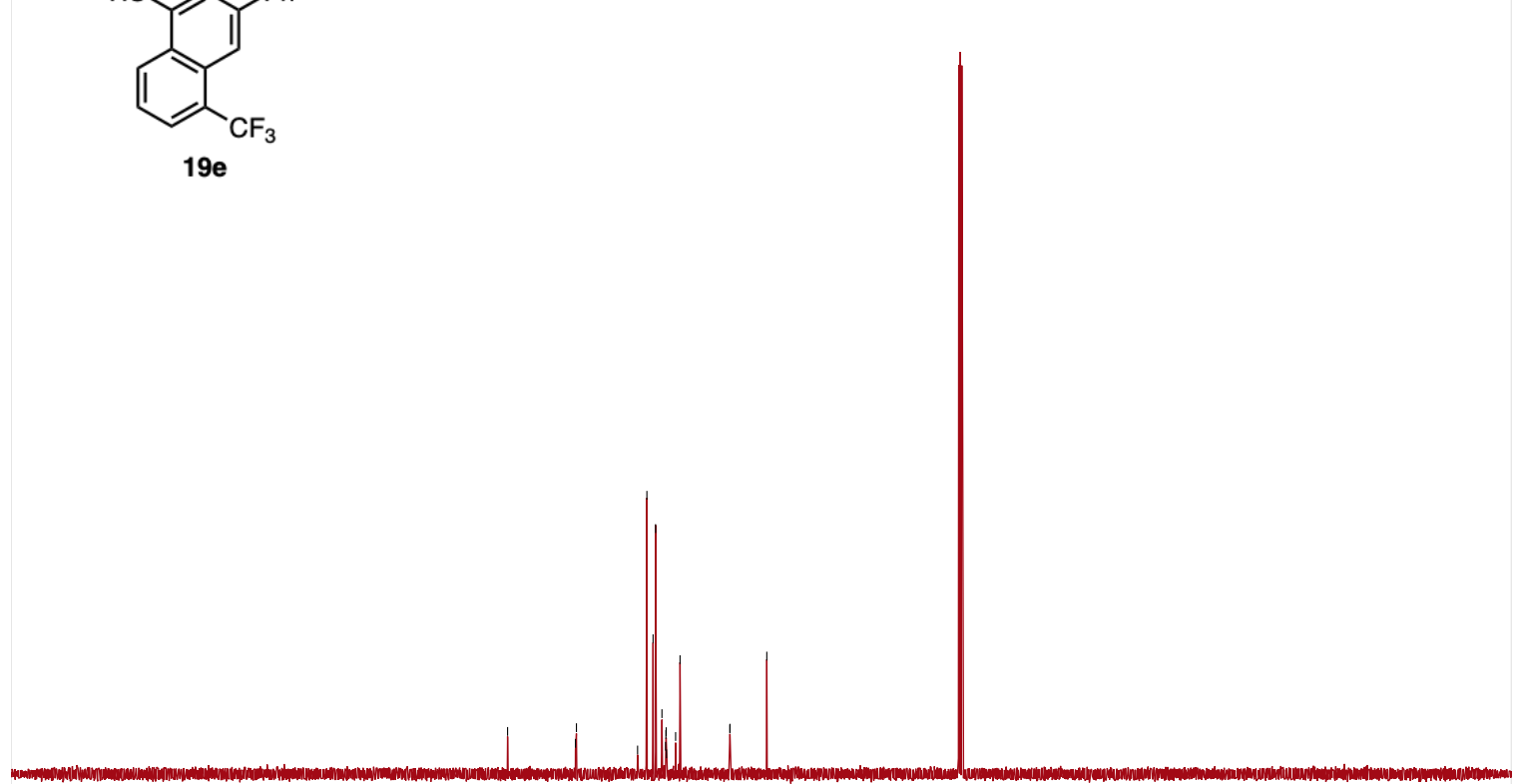

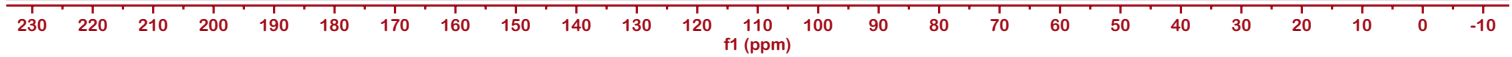




\section{5,5'-( $\left(\mathrm{CF}_{3}\right)_{2}$ VANOL 12e:}

${ }^{1} \mathrm{H}$ NMR $\left(500 \mathrm{MHz}, \mathrm{CDCl}_{3}\right.$ )

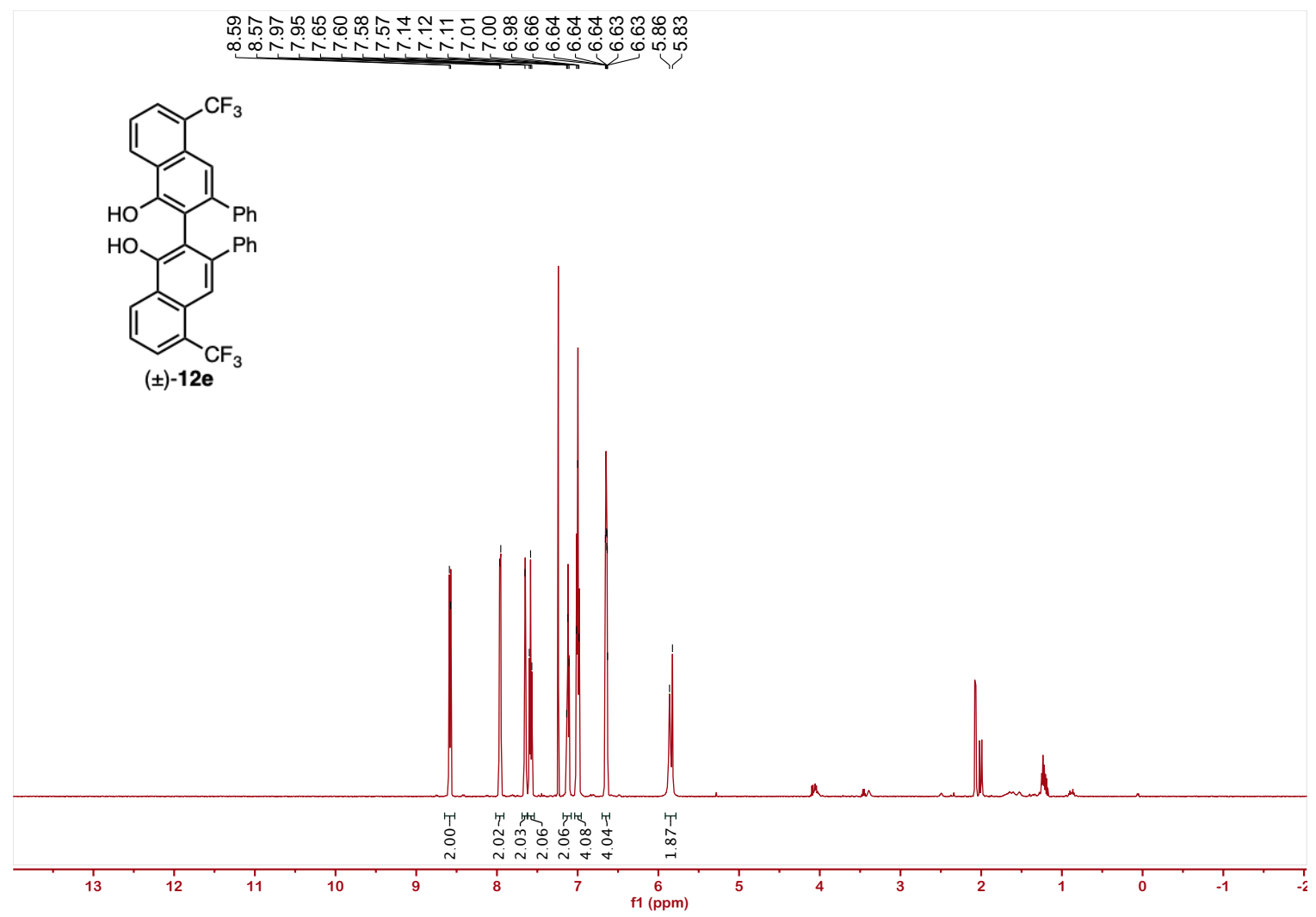

${ }^{19} \mathrm{~F}$ NMR $\left(470 \mathrm{MHz}, \mathrm{CDCl}_{3}\right)$
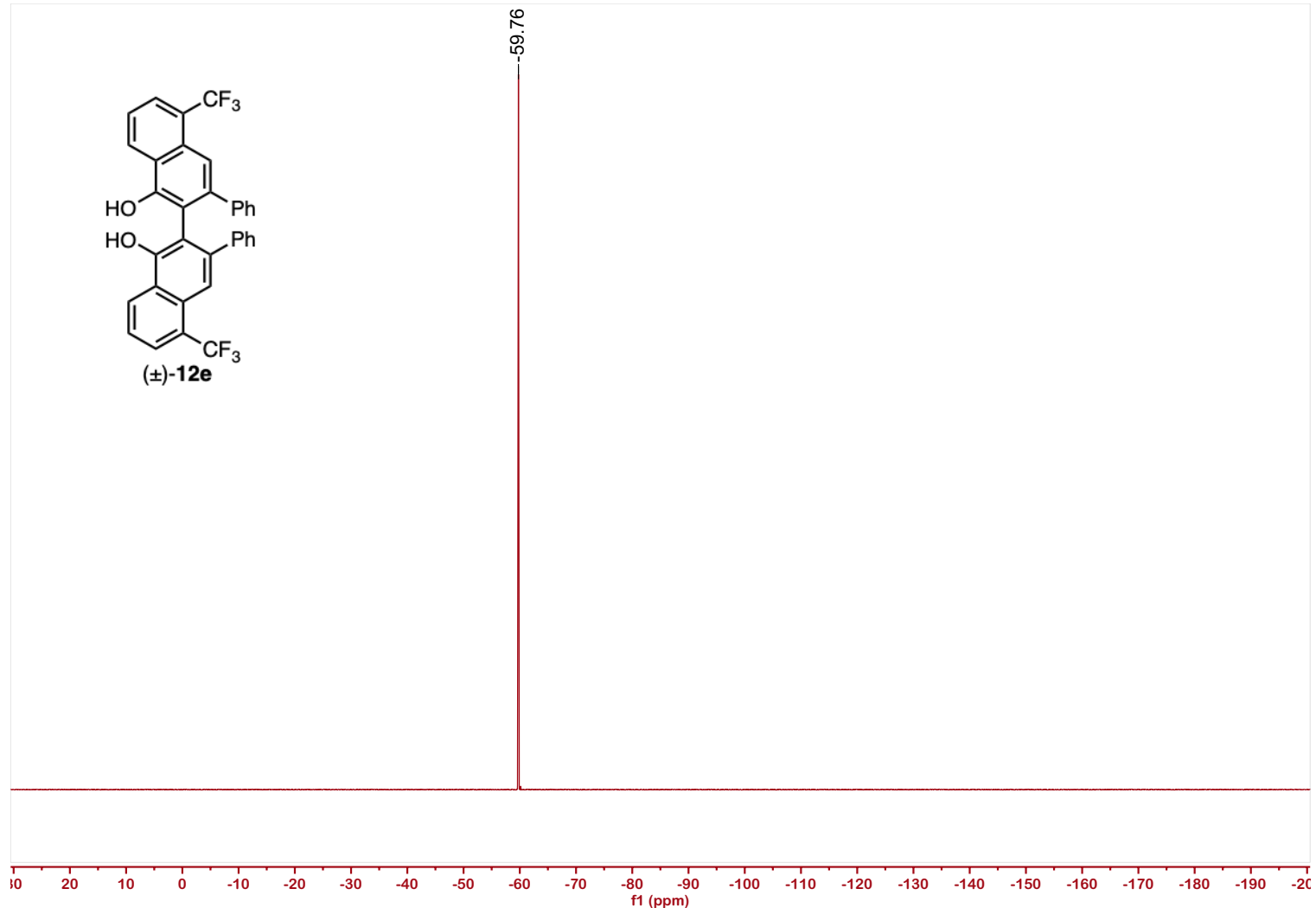
${ }^{13} \mathrm{C}\left\{{ }^{1} \mathrm{H}\right\} \mathrm{NMR}\left(126 \mathrm{MHz}, \mathrm{CDCl}_{3}\right)$

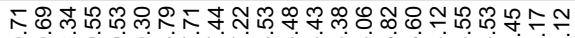

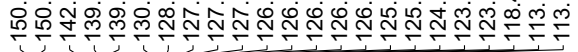<smiles>OC1=c2ccccc2=C(O)c2c(-c3ccccc3)c(-c3ccccc3)cc3c(C(F)(F)F)ccc1c23</smiles>

(士)-12e

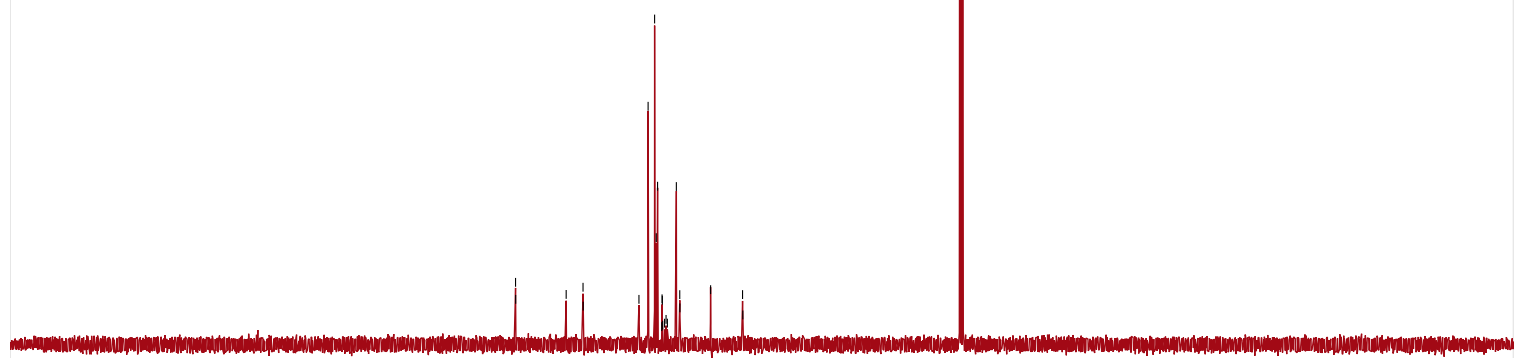

\begin{tabular}{llllllllllllllllllllllllllll}
\hline 1 & 1 \\
230 & 220 & 210 & 200 & 190 & 180 & 170 & 160 & 150 & 140 & 130 & 120 & $\begin{array}{c}110 \\
\mathrm{f} 1(\mathrm{ppm})\end{array}$ & 100 & 90 & 80 & 70 & 60 & 50 & 40 & 30 & 20 & 10 & 0 & -10
\end{tabular} 
3-(4-Ethylphenyl)-1-naphthol 21a:

${ }^{1} \mathrm{H}$ NMR $\left(500 \mathrm{MHz}, \mathrm{CDCl}_{3}\right)$

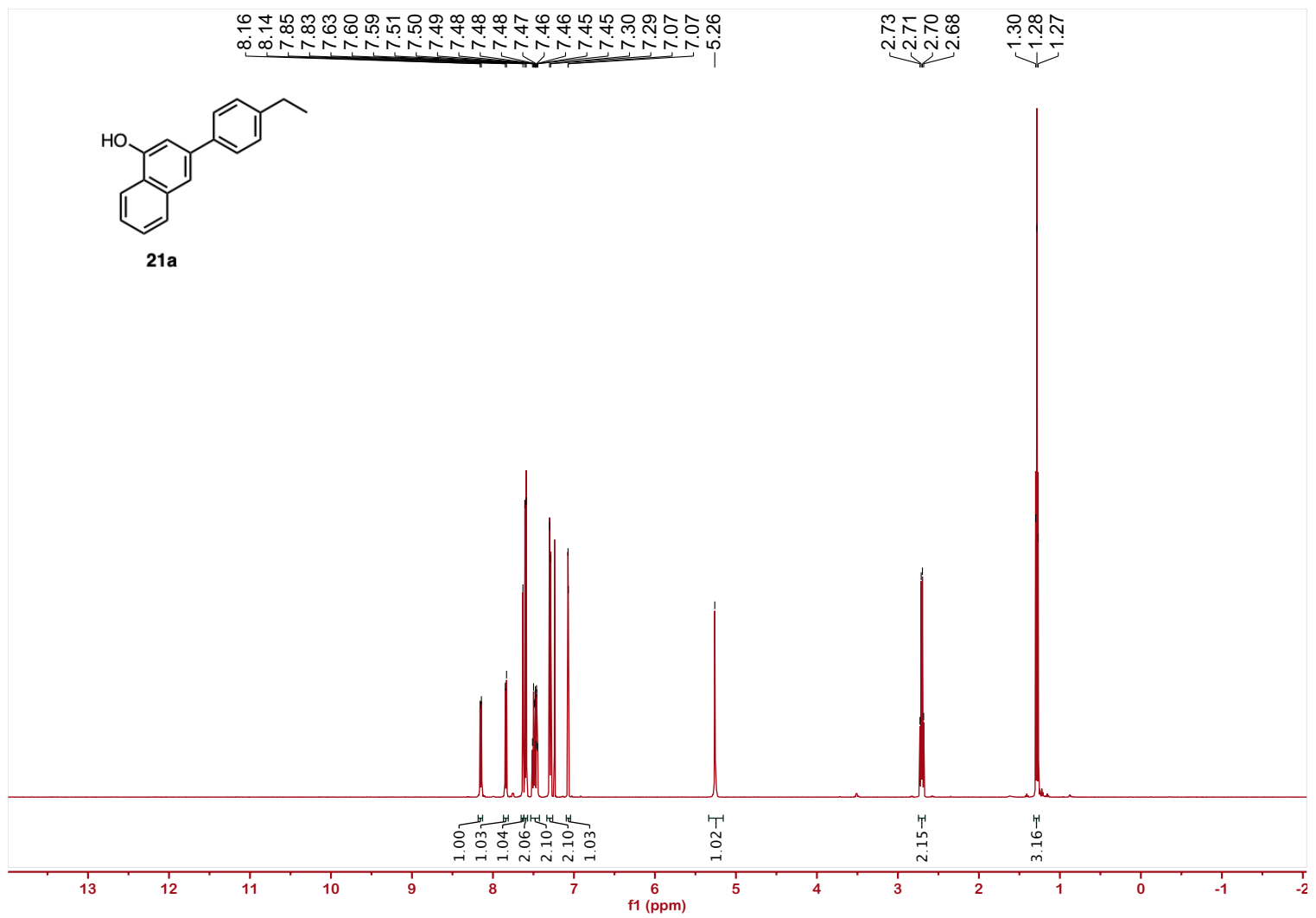

${ }^{13} \mathrm{C}\left\{{ }^{1} \mathrm{H}\right\}$ NMR $\left(126 \mathrm{MHz}, \mathrm{CDCl}_{3}\right)$

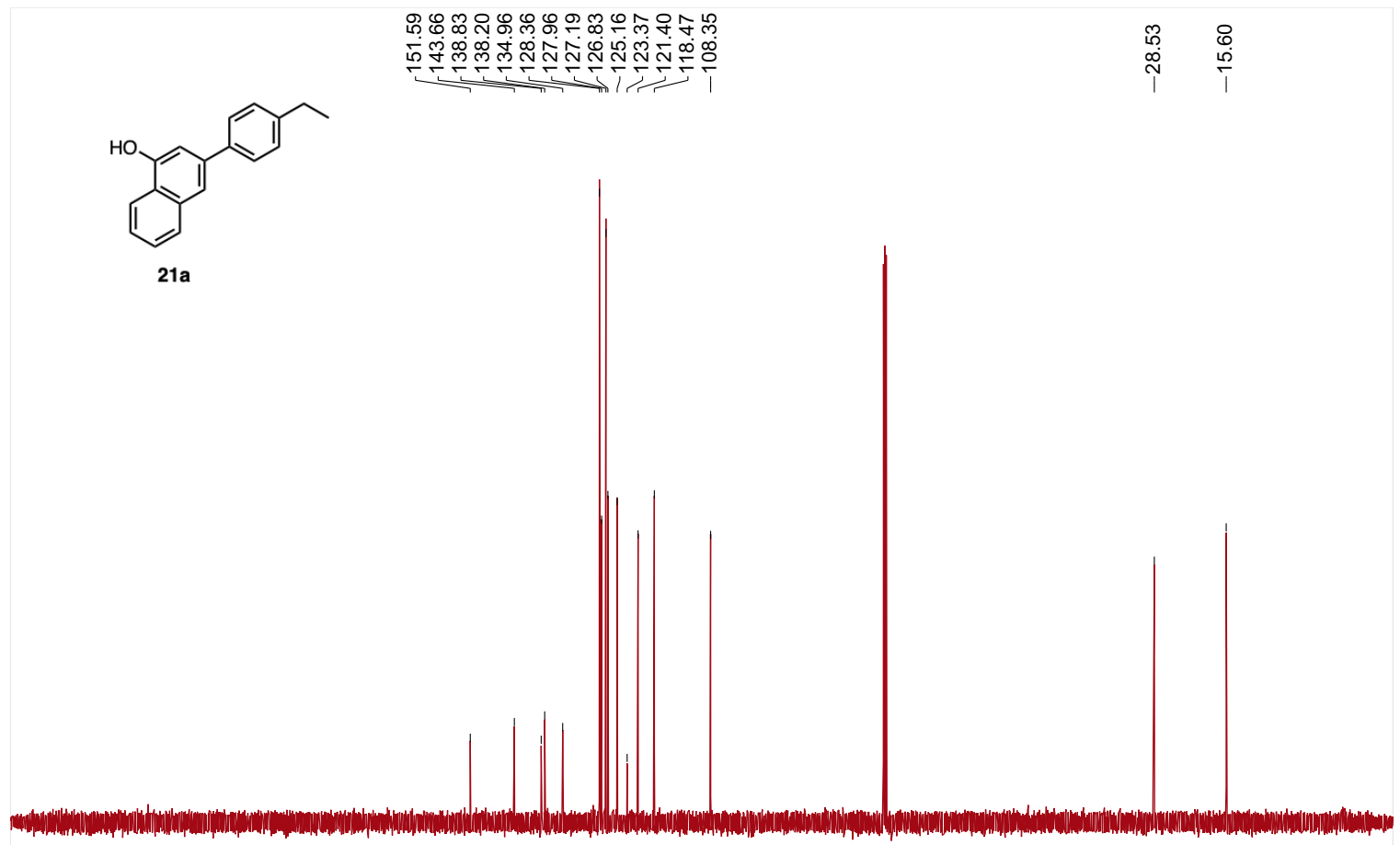

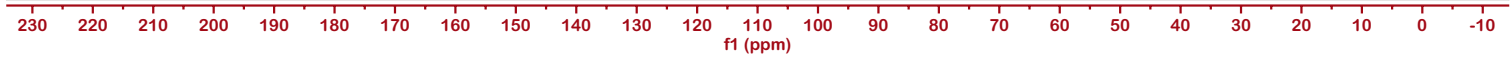




\section{3,3'- $p \mathrm{EtPh}_{2}$ VANOL 11a:}

${ }^{1} \mathrm{H}$ NMR $\left(500 \mathrm{MHz}, \mathrm{CDCl}_{3}\right)$

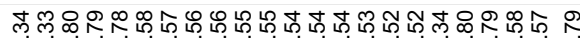

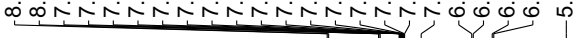

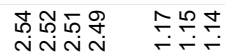

กูก<smiles>CCc1ccc(-c2cc3ccccc3c(O)c2-c2ccc(CC)cc2)cc1</smiles>

$( \pm)-11 \mathrm{a}$

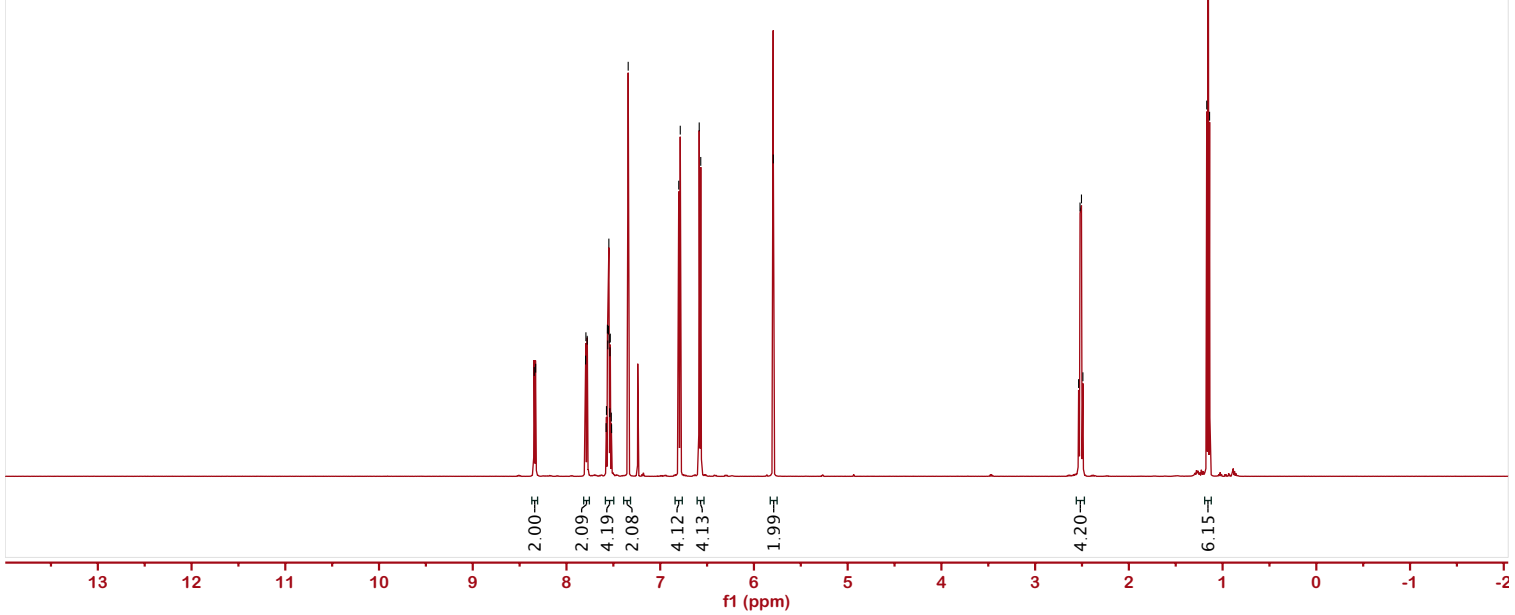

${ }^{13} \mathrm{C}\left\{{ }^{1} \mathrm{H}\right\}$ NMR $\left(126 \mathrm{MHz}, \mathrm{CDCl}_{3}\right)$

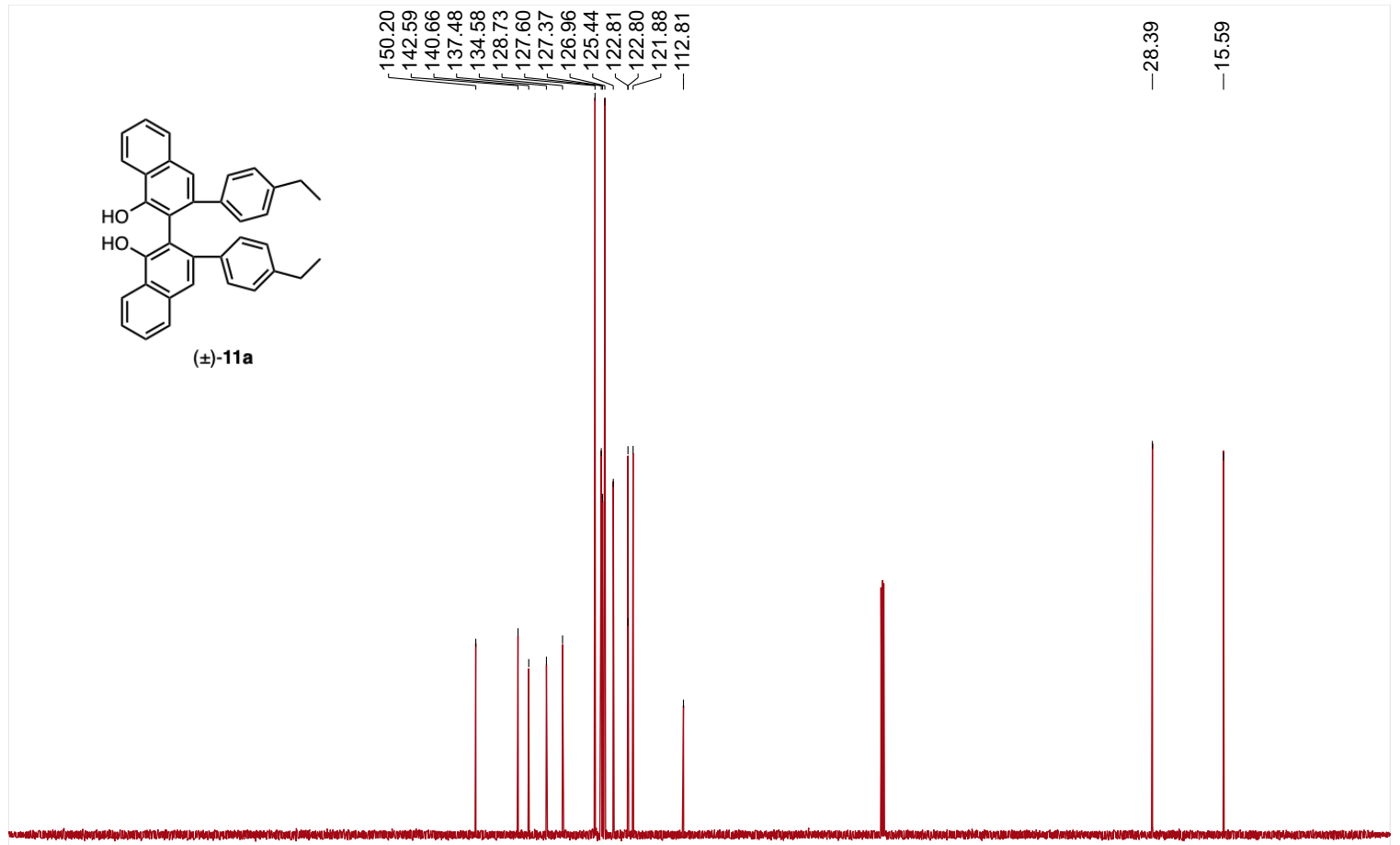

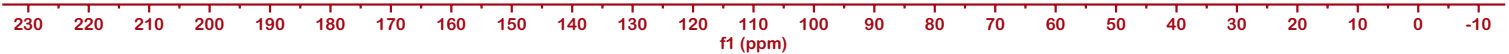


3-(4-Methoxyphenyl)-1-naphthol 21b:

${ }^{1} \mathrm{H}$ NMR $\left(500 \mathrm{MHz}, \mathrm{CDCl}_{3}\right.$ )

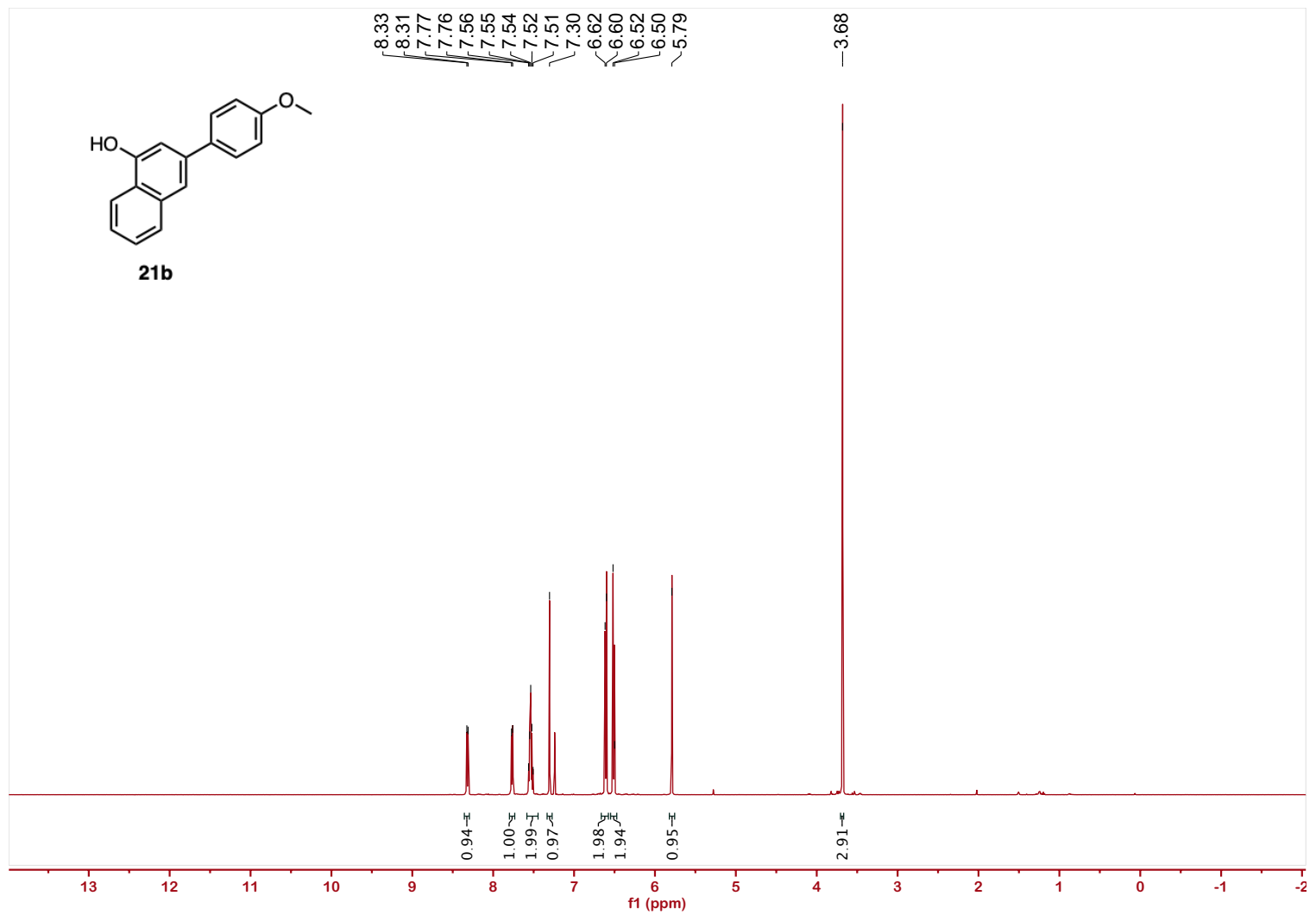

${ }^{13} \mathrm{C}\left\{{ }^{1} \mathrm{H}\right\}$ NMR $\left(126 \mathrm{MHz}, \mathrm{CDCl}_{3}\right)$

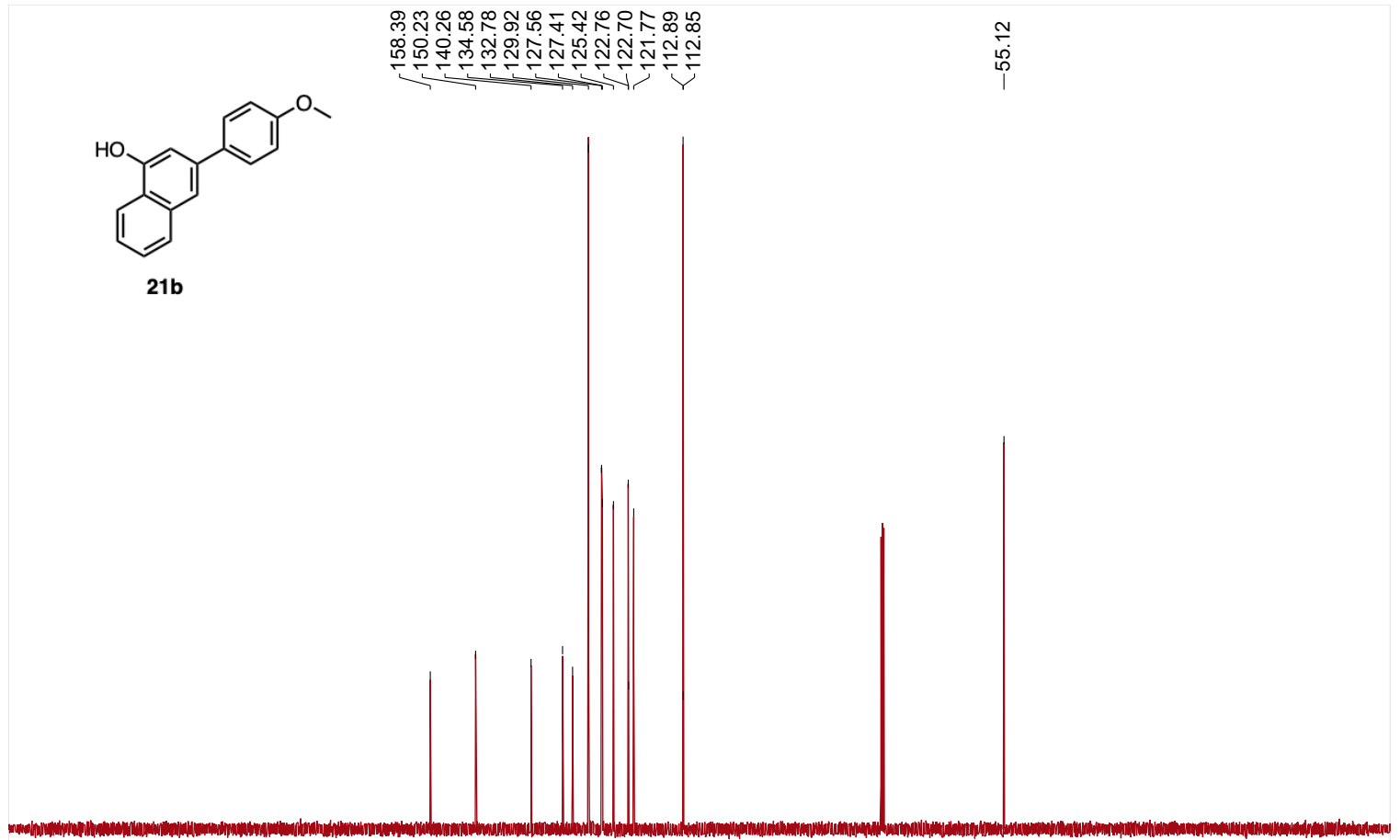

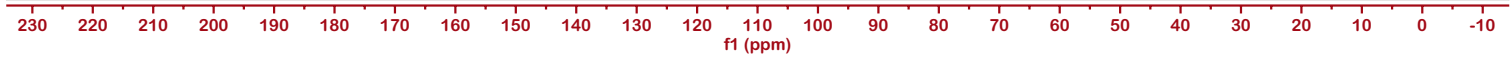




\section{3,3'- $p \mathrm{OMePh}_{2}$ VANOL 11b:}

${ }^{1} \mathrm{H}$ NMR $\left(500 \mathrm{MHz}, \mathrm{CDCl}_{3}\right.$ )

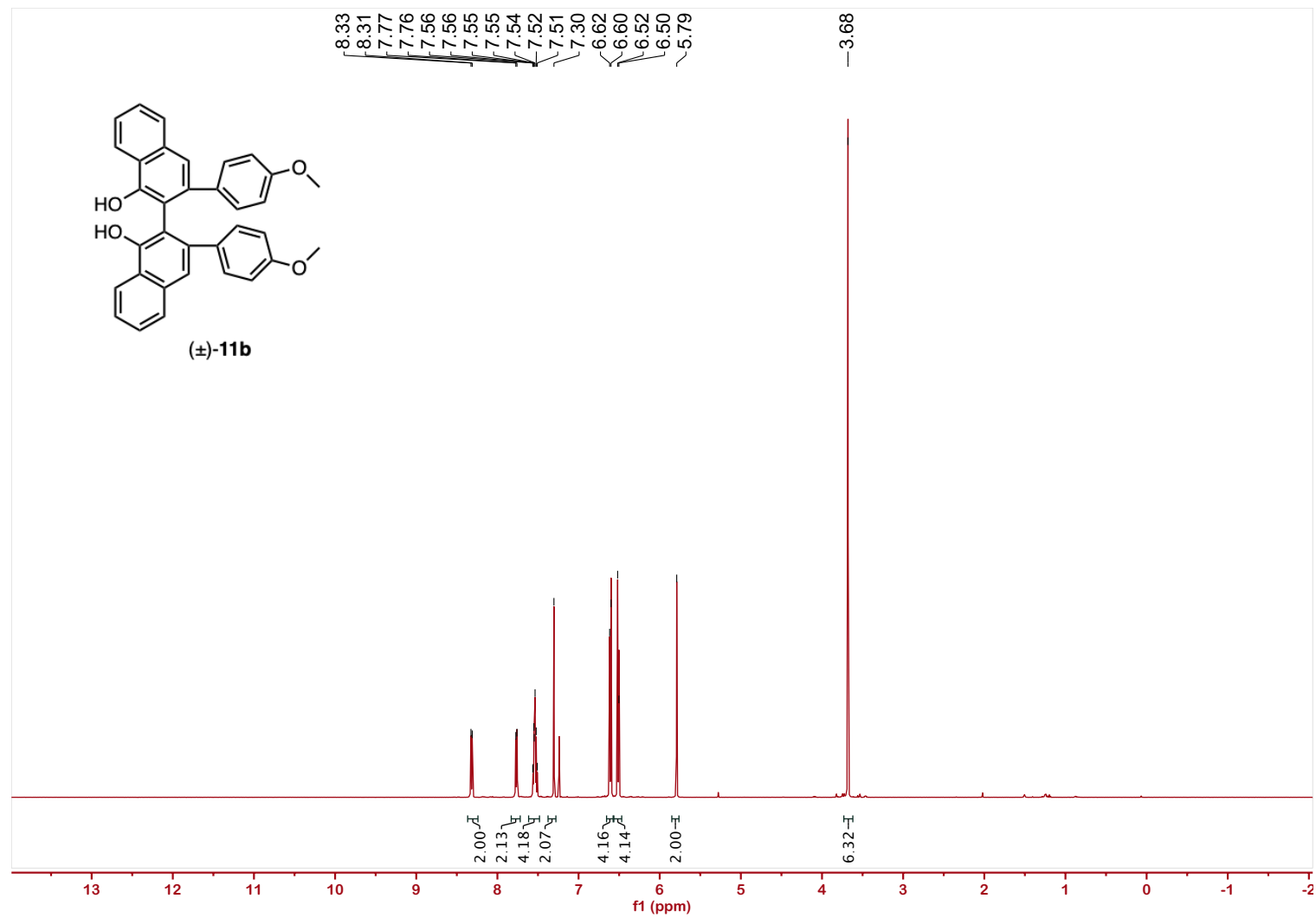

${ }^{13} \mathrm{C}\left\{{ }^{1} \mathrm{H}\right\}$ NMR $\left(126 \mathrm{MHz}, \mathrm{CDCl}_{3}\right)$

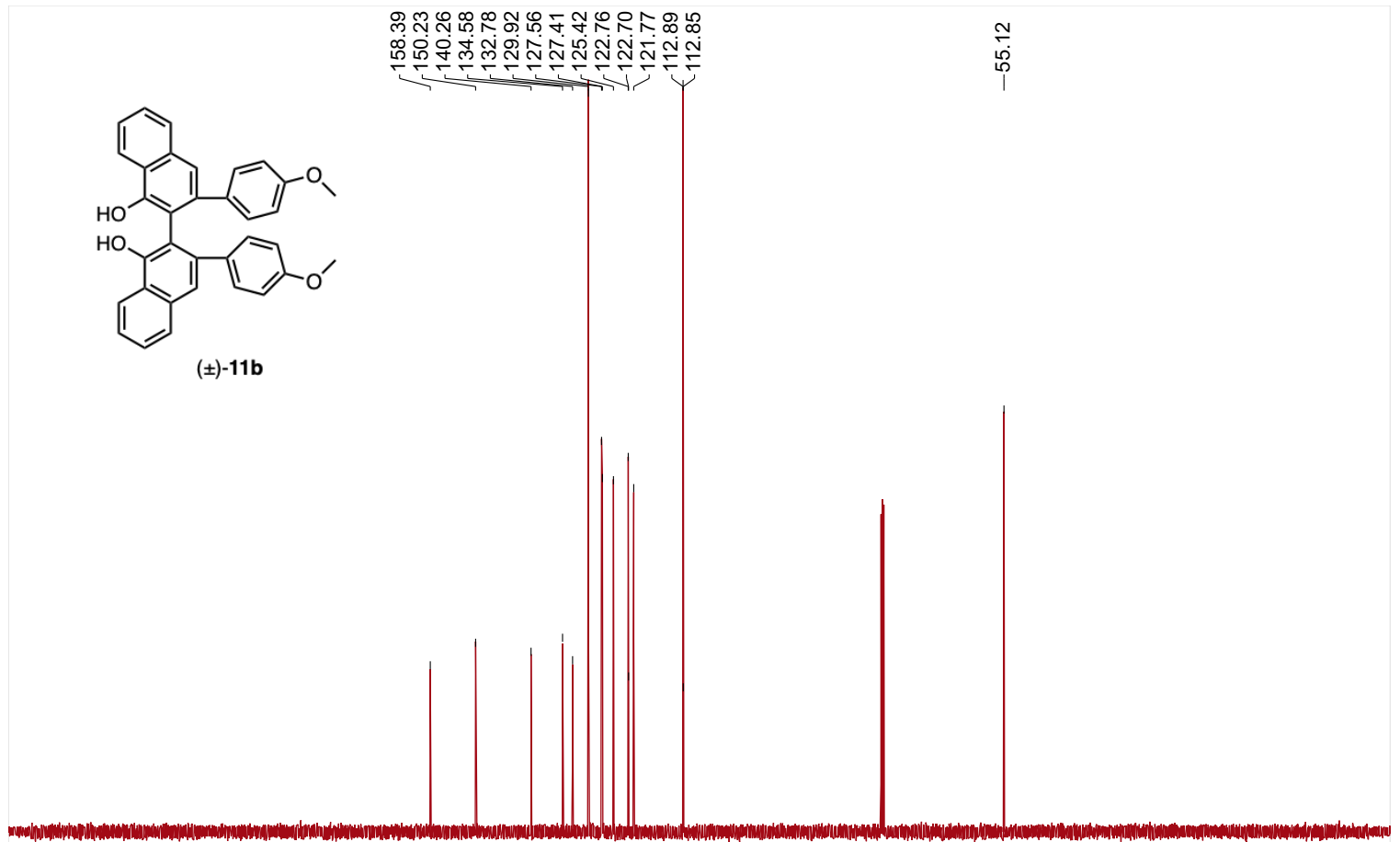

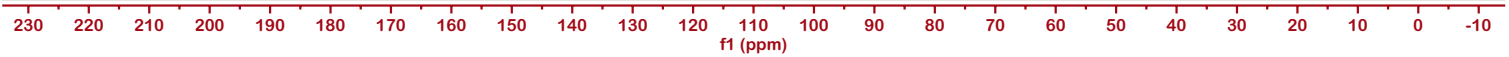


3-(4-Butylphenyl)-1-naphthol 21c:

${ }^{1} \mathrm{H}$ NMR $\left(500 \mathrm{MHz}, \mathrm{CDCl}_{3}\right.$ )

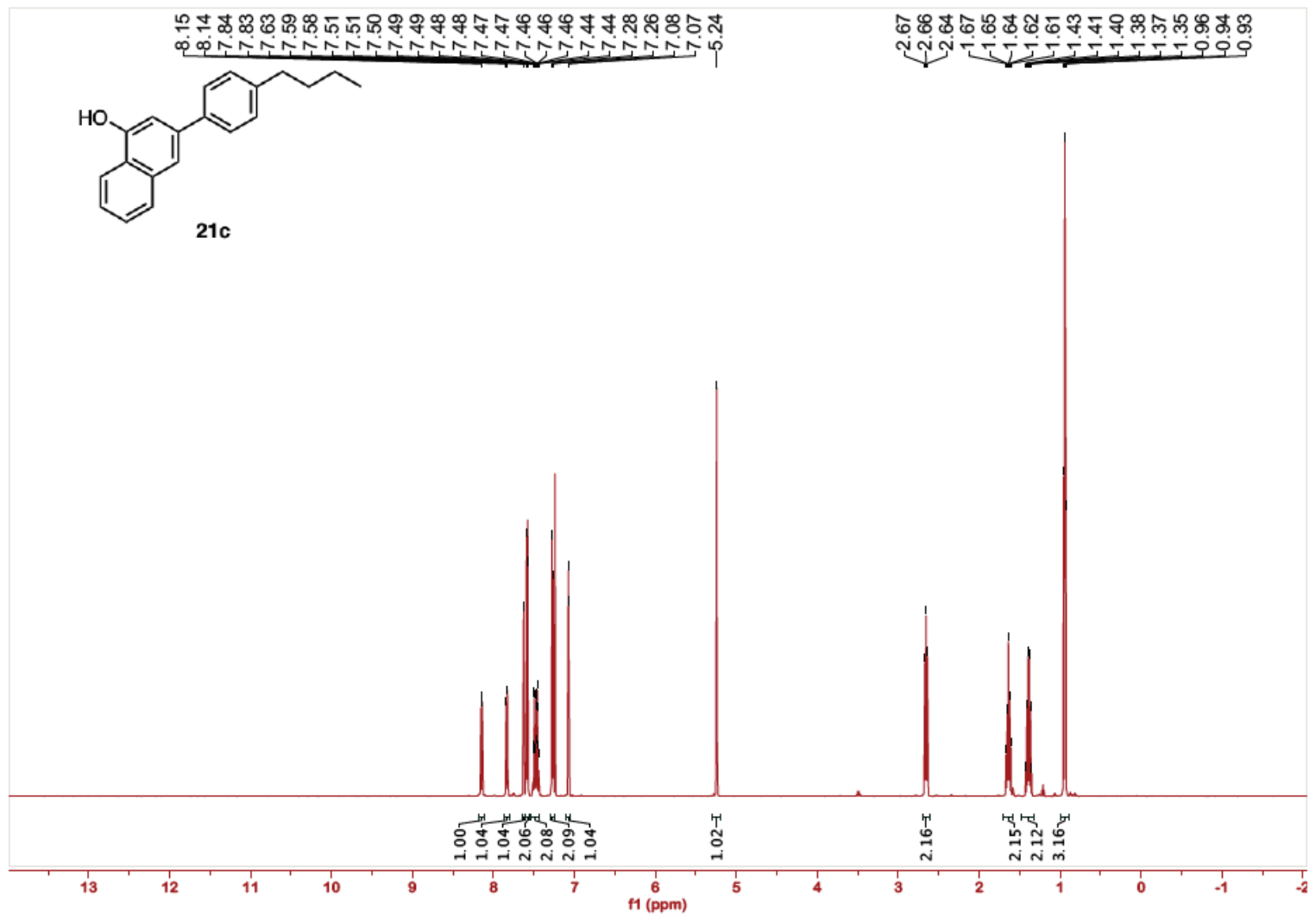

${ }^{13} \mathrm{C}\left\{{ }^{1} \mathrm{H}\right\}$ NMR $\left(126 \mathrm{MHz}, \mathrm{CDCl}_{3}\right)$

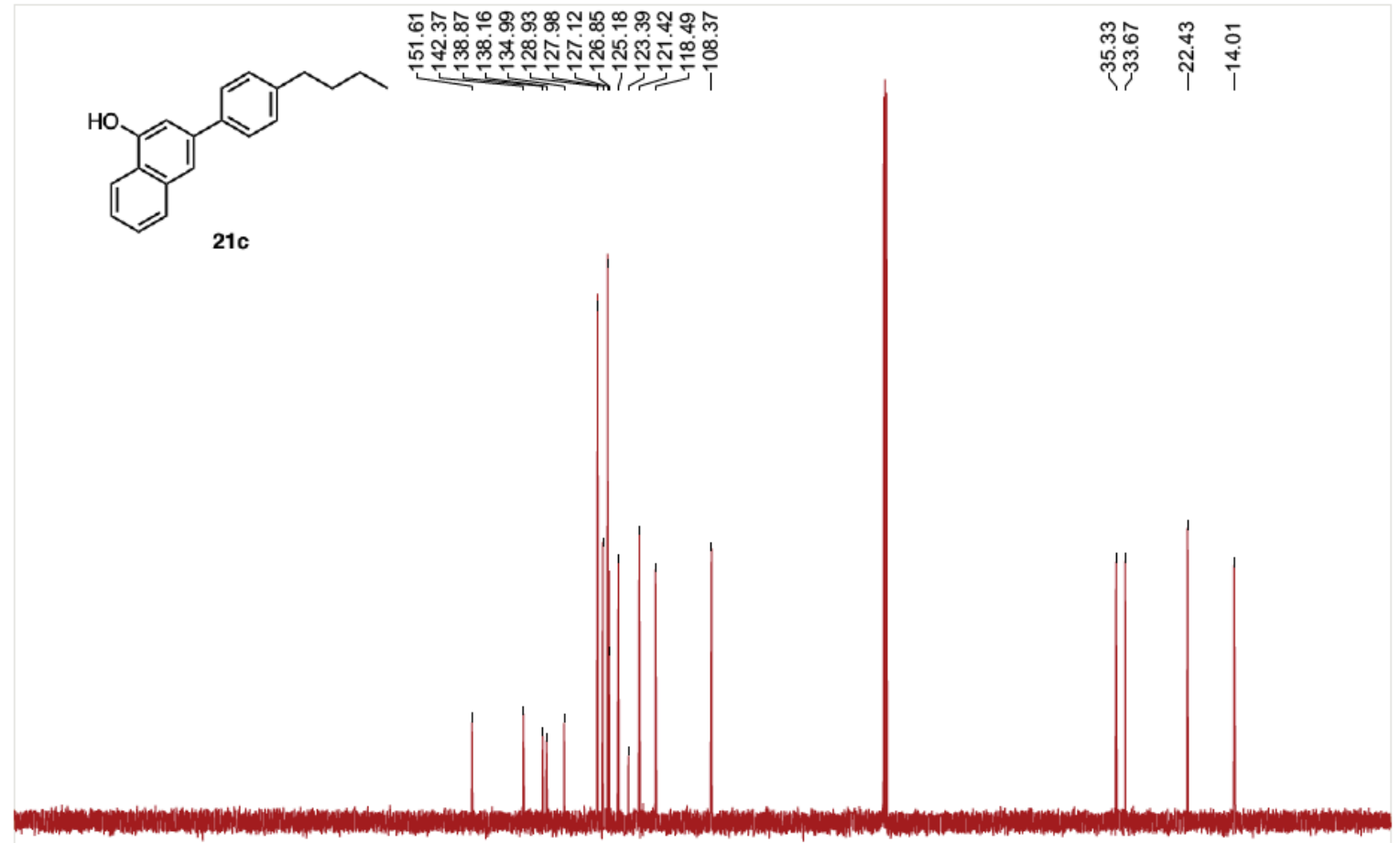

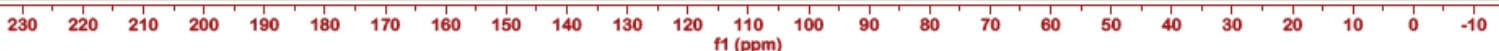


3,3'- $p \mathrm{BuPh}_{2}$ VANOL 11c:

${ }^{1} \mathrm{H}$ NMR $\left(500 \mathrm{MHz}, \mathrm{CDCl}_{3}\right.$ )

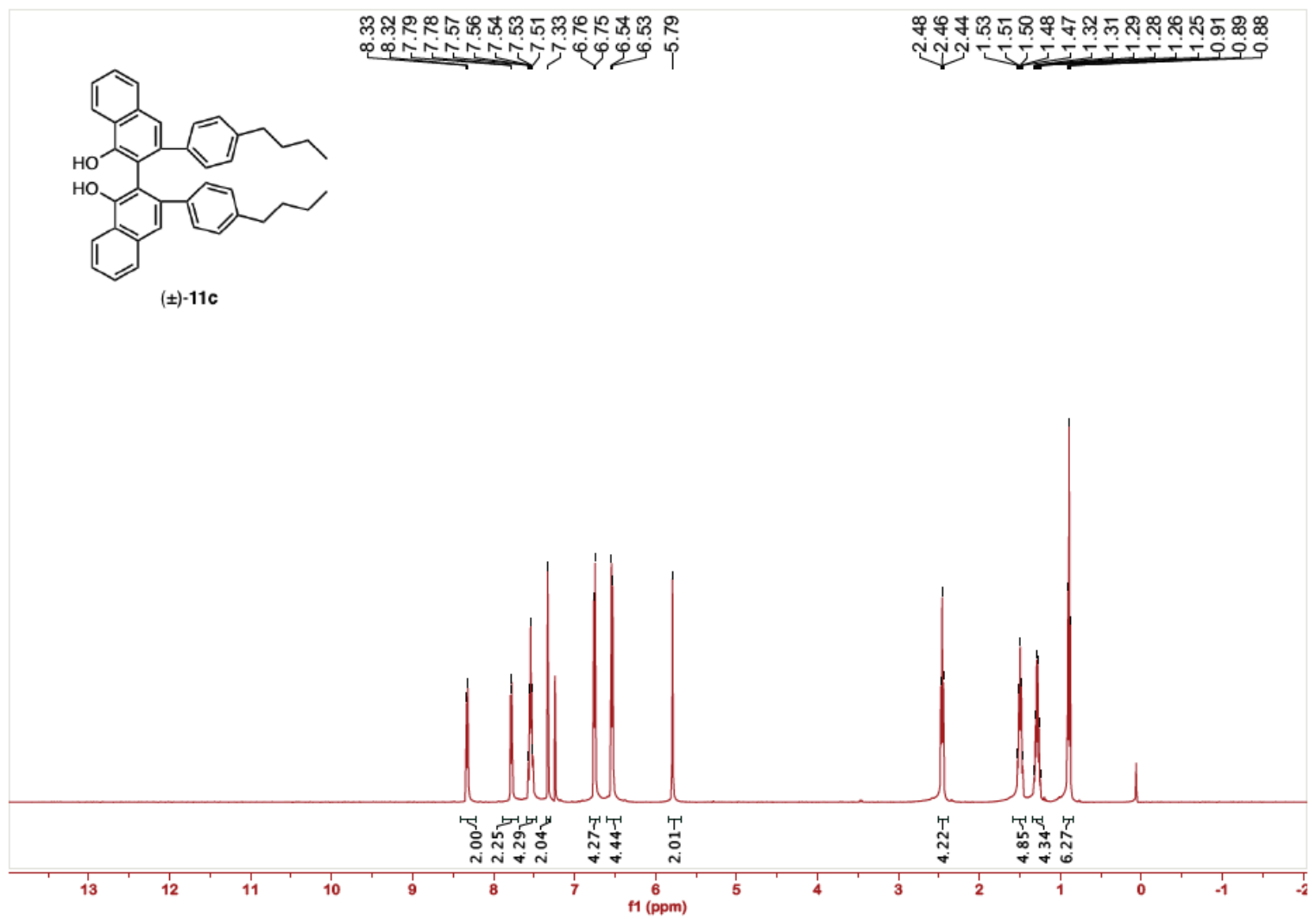

${ }^{13} \mathrm{C}\left\{{ }^{1} \mathrm{H}\right\}$ NMR (126 MHz, $\left.\mathrm{CDCl}_{3}\right)$

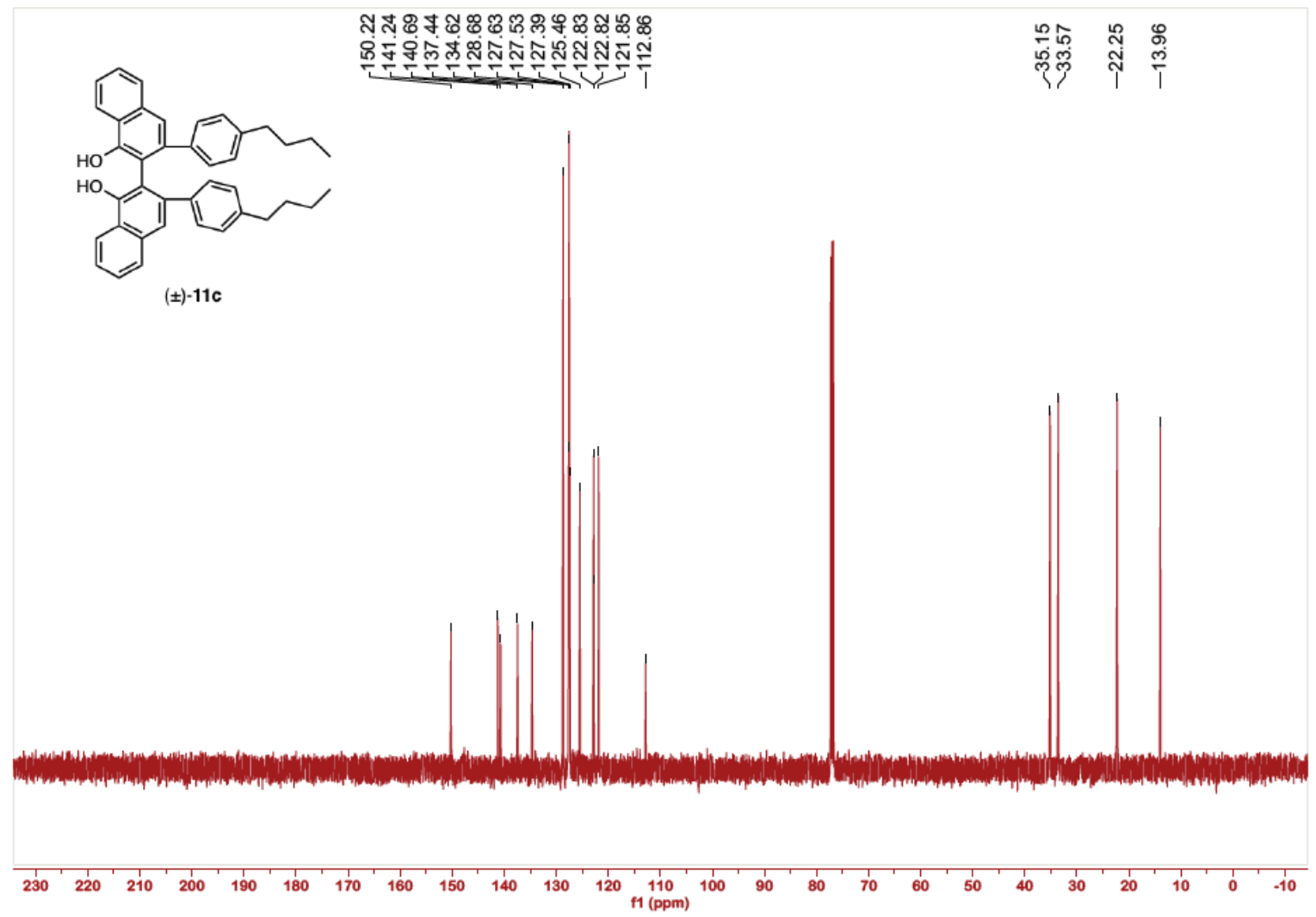


1-Phenyladamantane 23:

${ }^{1} \mathrm{H}$ NMR (500 MHz, $\mathrm{CDCl}_{3}$ )

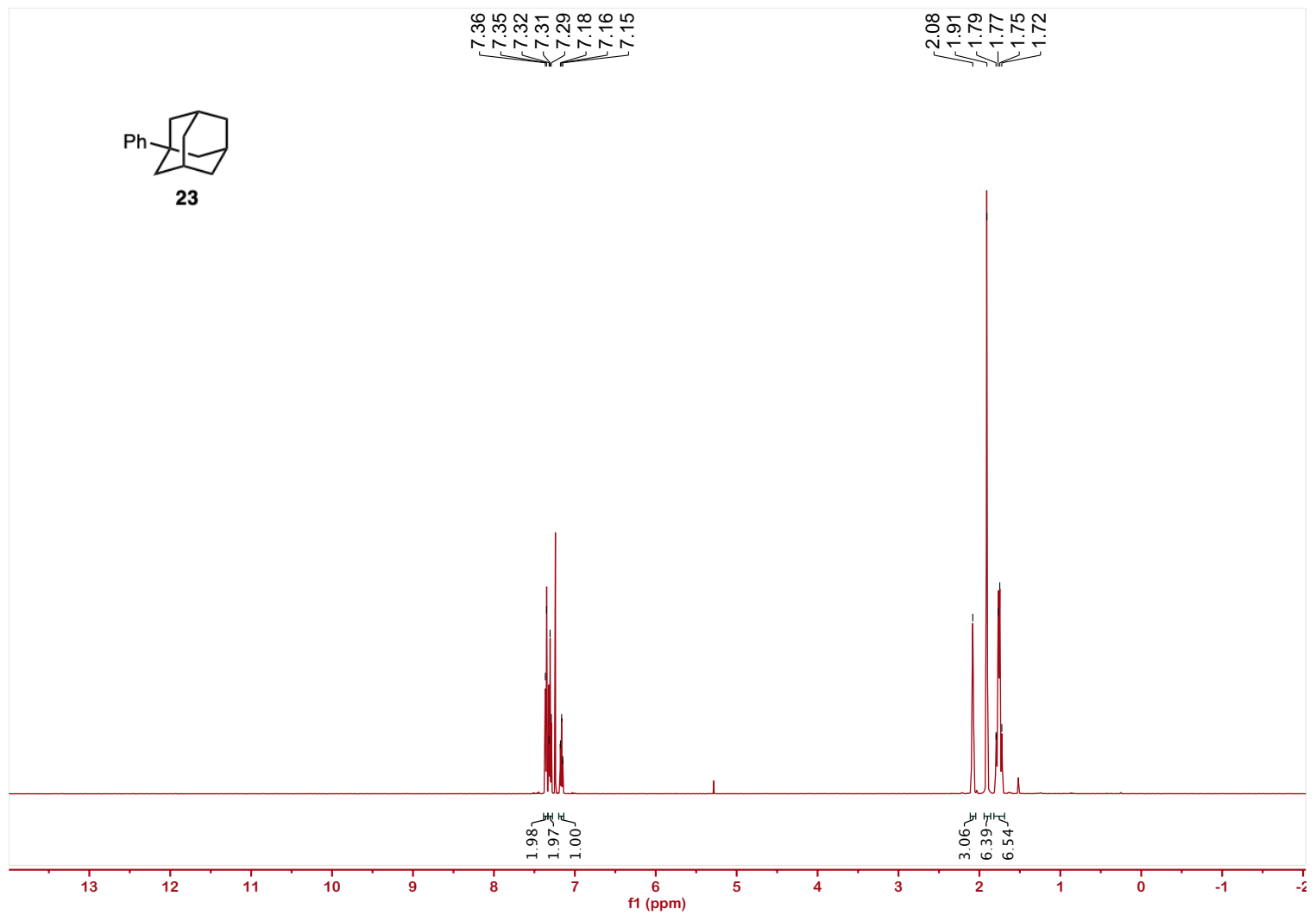

${ }^{13} \mathrm{C}\left\{{ }^{1} \mathrm{H}\right\}$ NMR $\left(126 \mathrm{MHz}, \mathrm{CDCl}_{3}\right)$

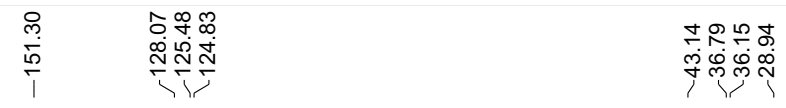

Pn

23

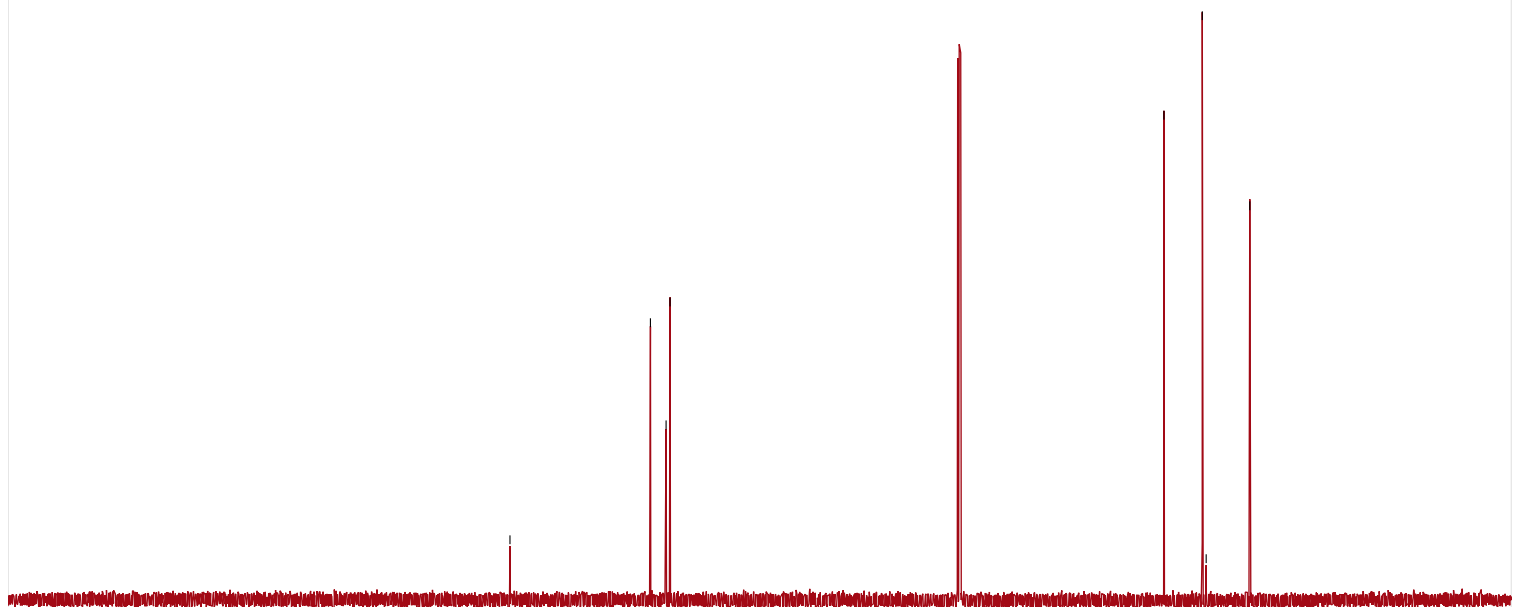

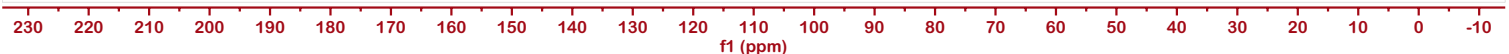


4-Adamantylacetophenone 24:

${ }^{1} \mathrm{H}$ NMR (500 MHz, $\mathrm{CDCl}_{3}$ )

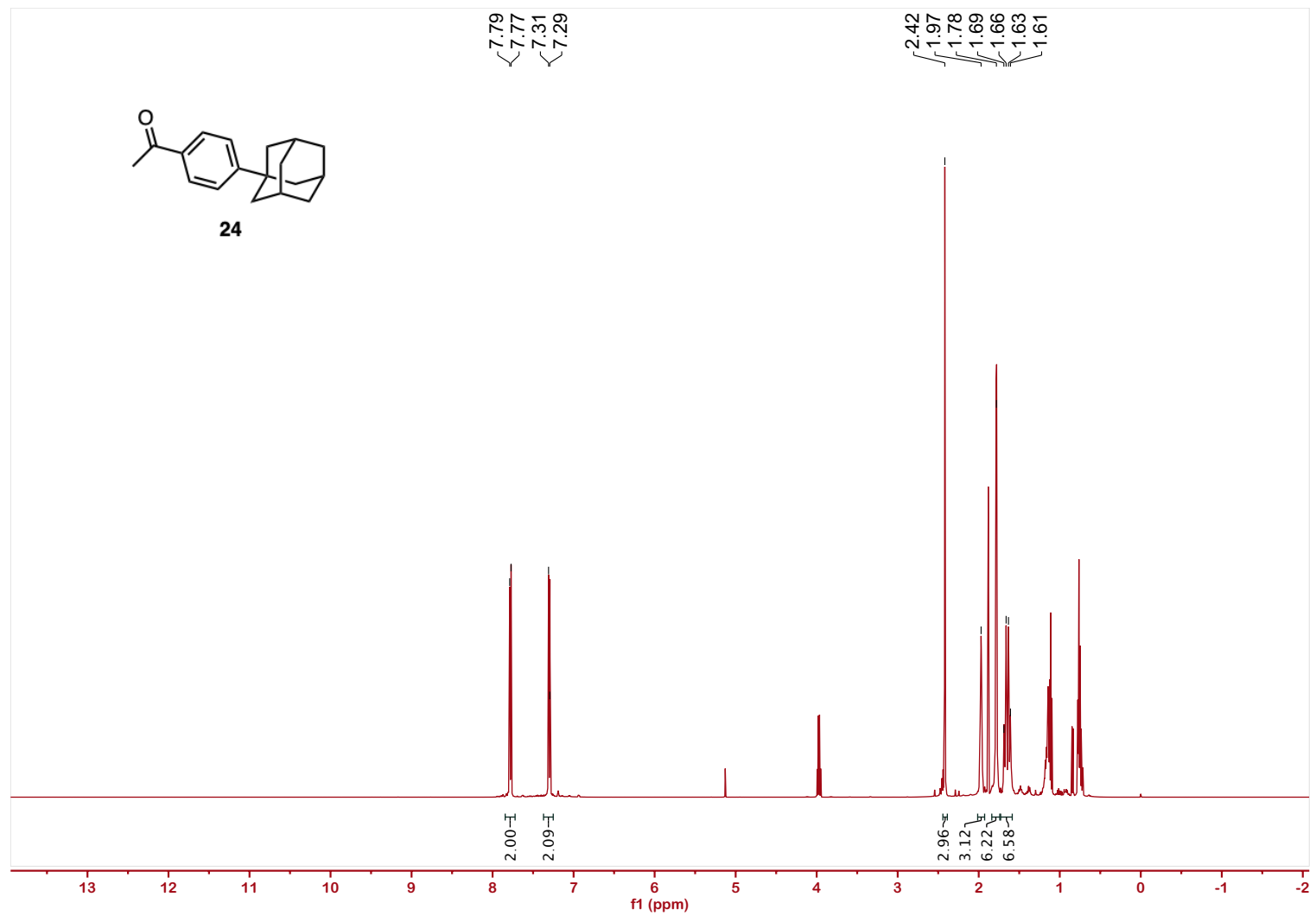

${ }^{13} \mathrm{C}\left\{{ }^{1} \mathrm{H}\right\}$ NMR $\left(126 \mathrm{MHz}, \mathrm{CDCl}_{3}\right)$

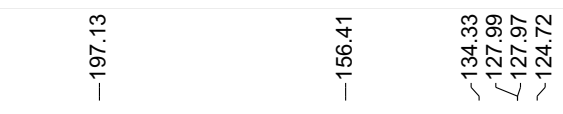

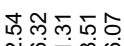

भ่

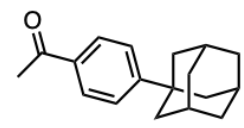

24

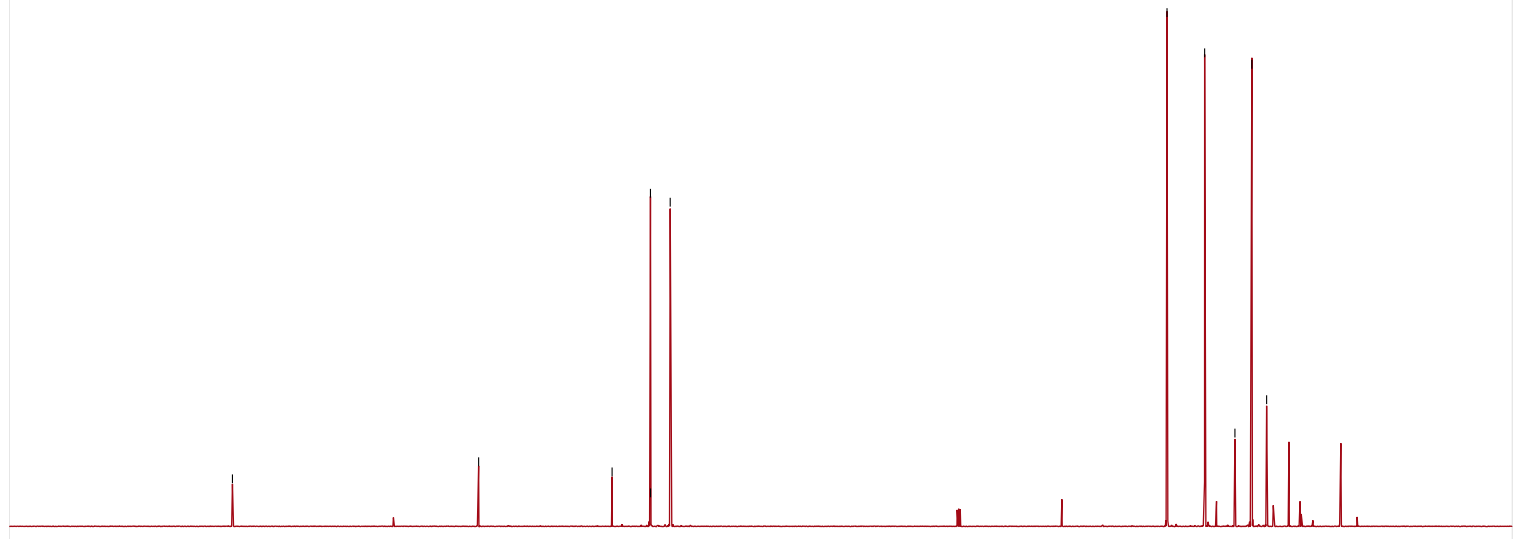

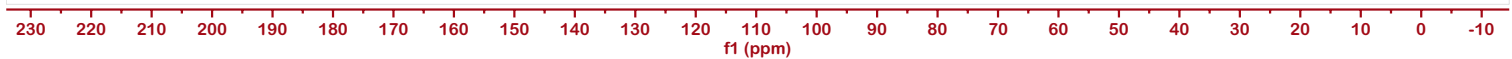


1-Morpholino-2-(4-adamantylphenyl) ethane-1-thione 25:

${ }^{1} \mathrm{H}$ NMR (500 MHz, $\mathrm{CDCl}_{3}$ )
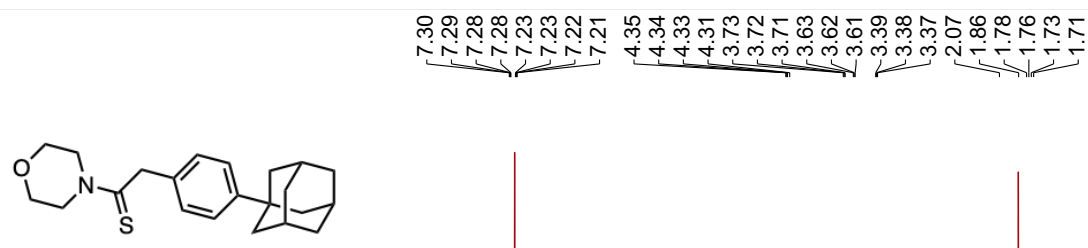

25

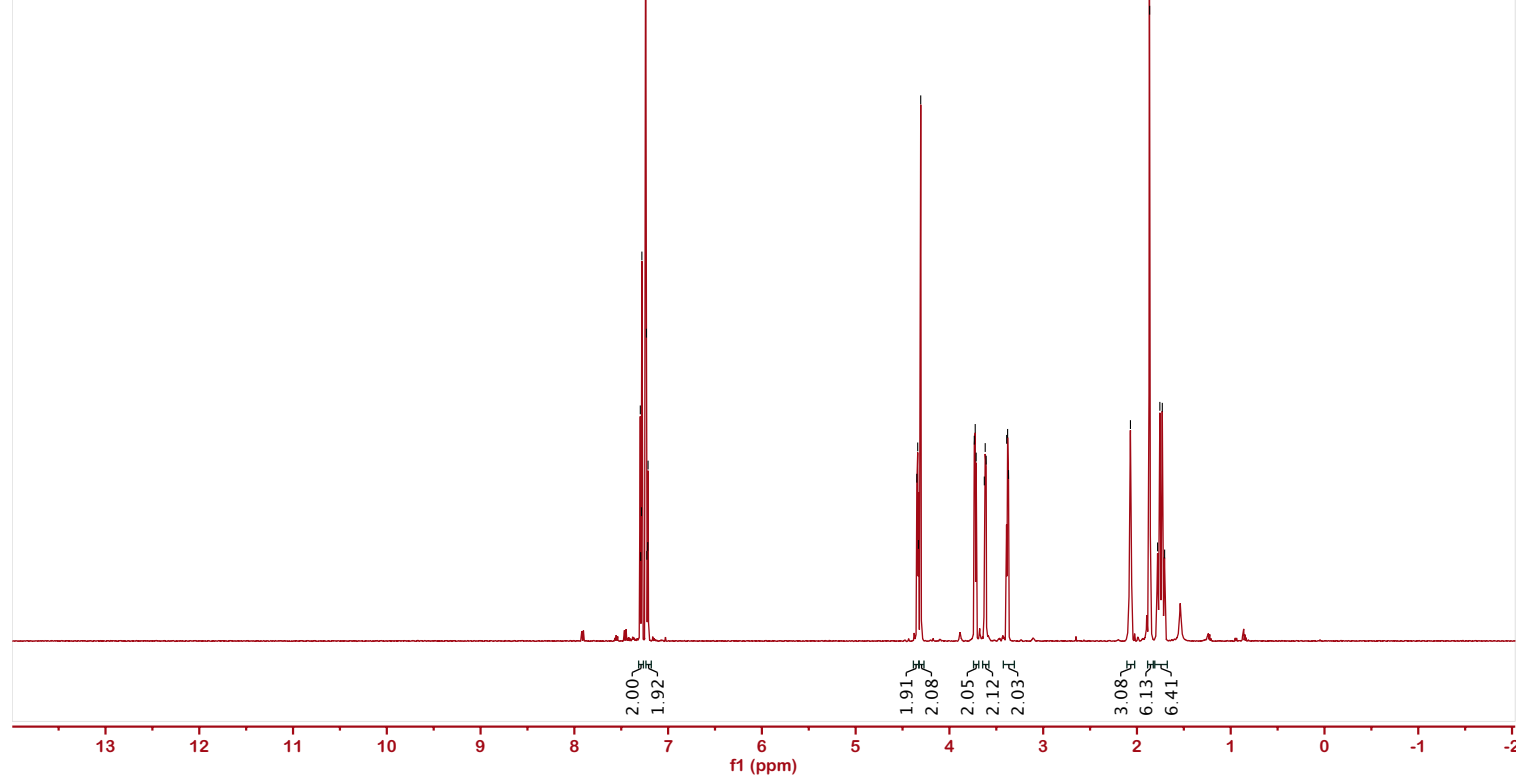

${ }^{13} \mathrm{C}\left\{{ }^{1} \mathrm{H}\right\}$ NMR $\left(126 \mathrm{MHz}, \mathrm{CDCl}_{3}\right)$

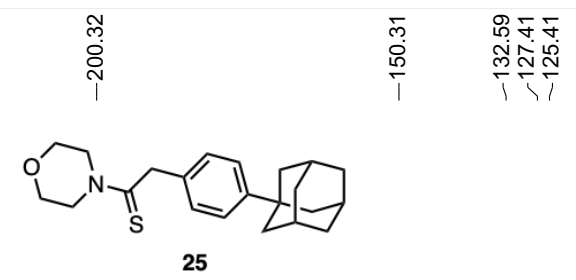

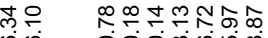

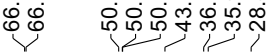

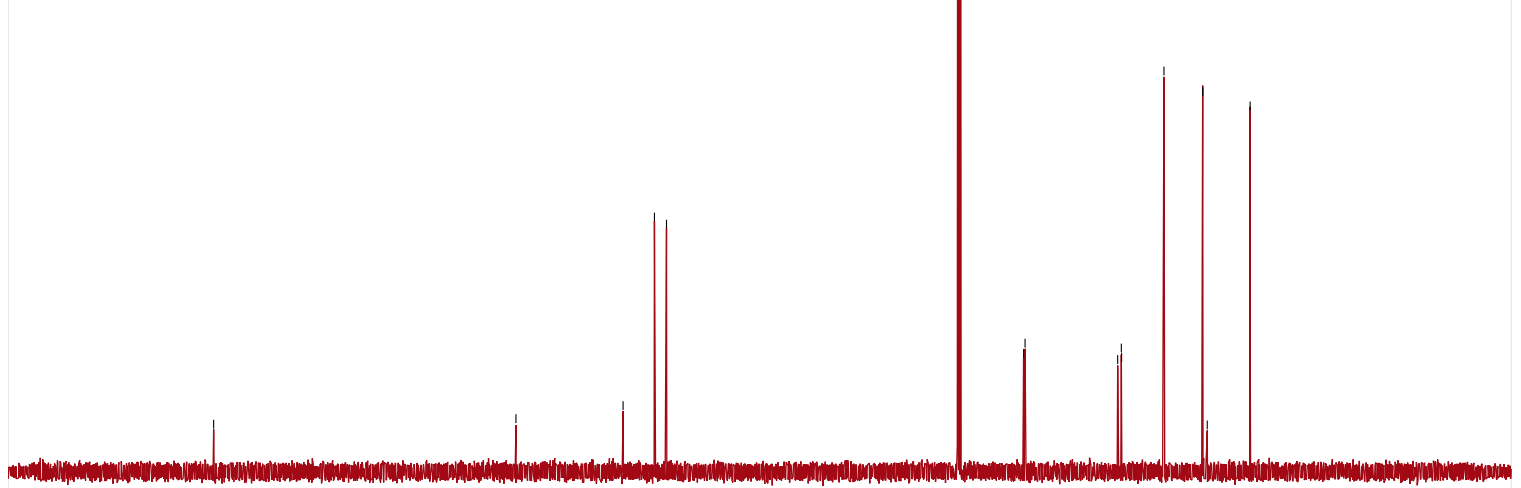

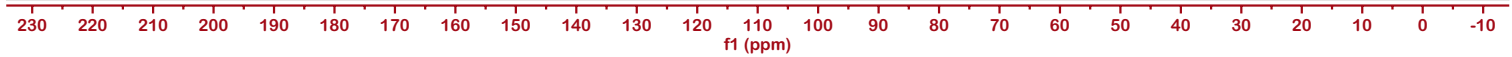


2-(4-Adamantylphenyl)acetic acid 26e:

${ }^{1} \mathrm{H}$ NMR $\left(500 \mathrm{MHz}, \mathrm{CDCl}_{3}\right)$

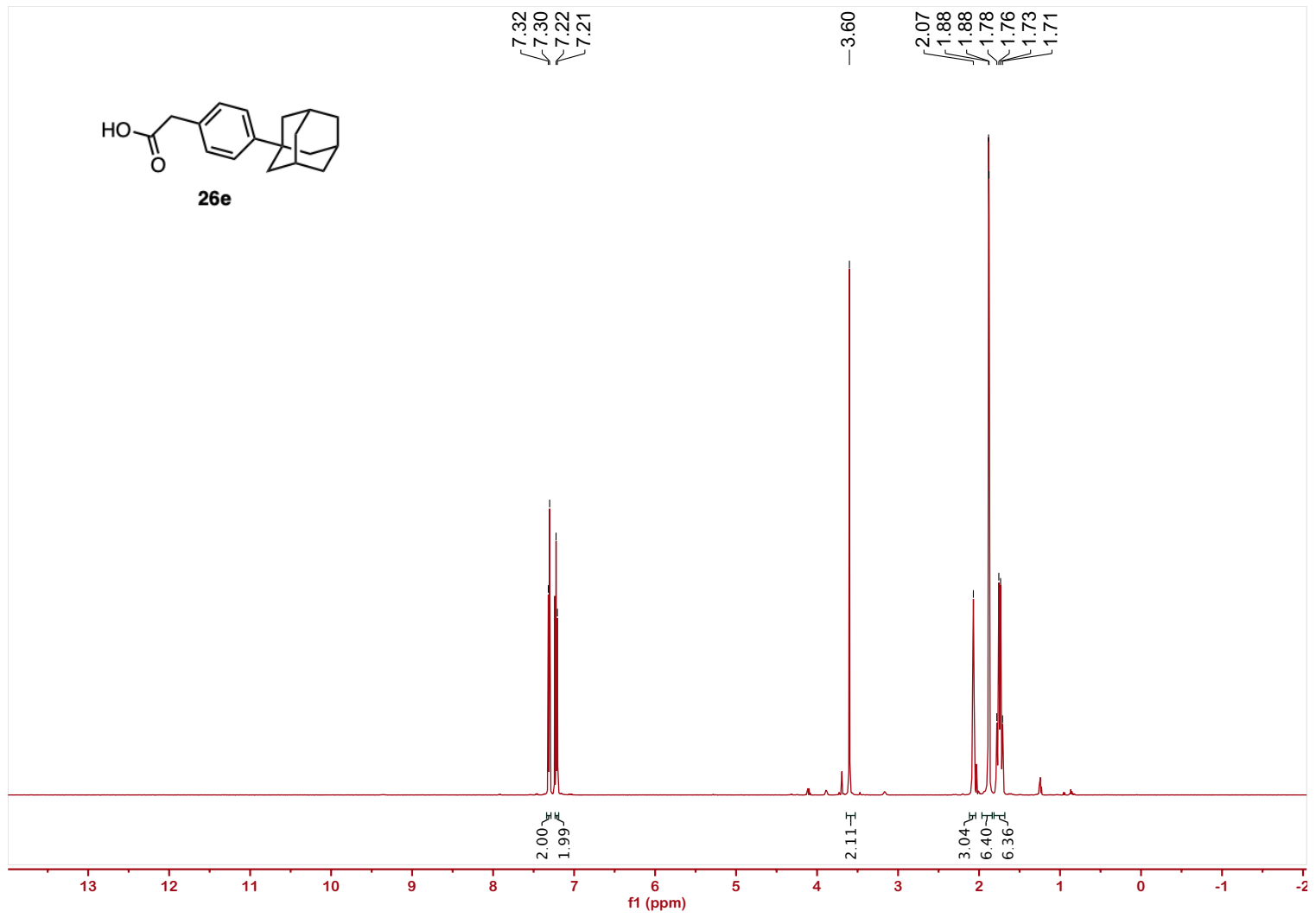

${ }^{13} \mathrm{C}\left\{{ }^{1} \mathrm{H}\right\}$ NMR $\left(126 \mathrm{MHz}, \mathrm{CDCl}_{3}\right)$

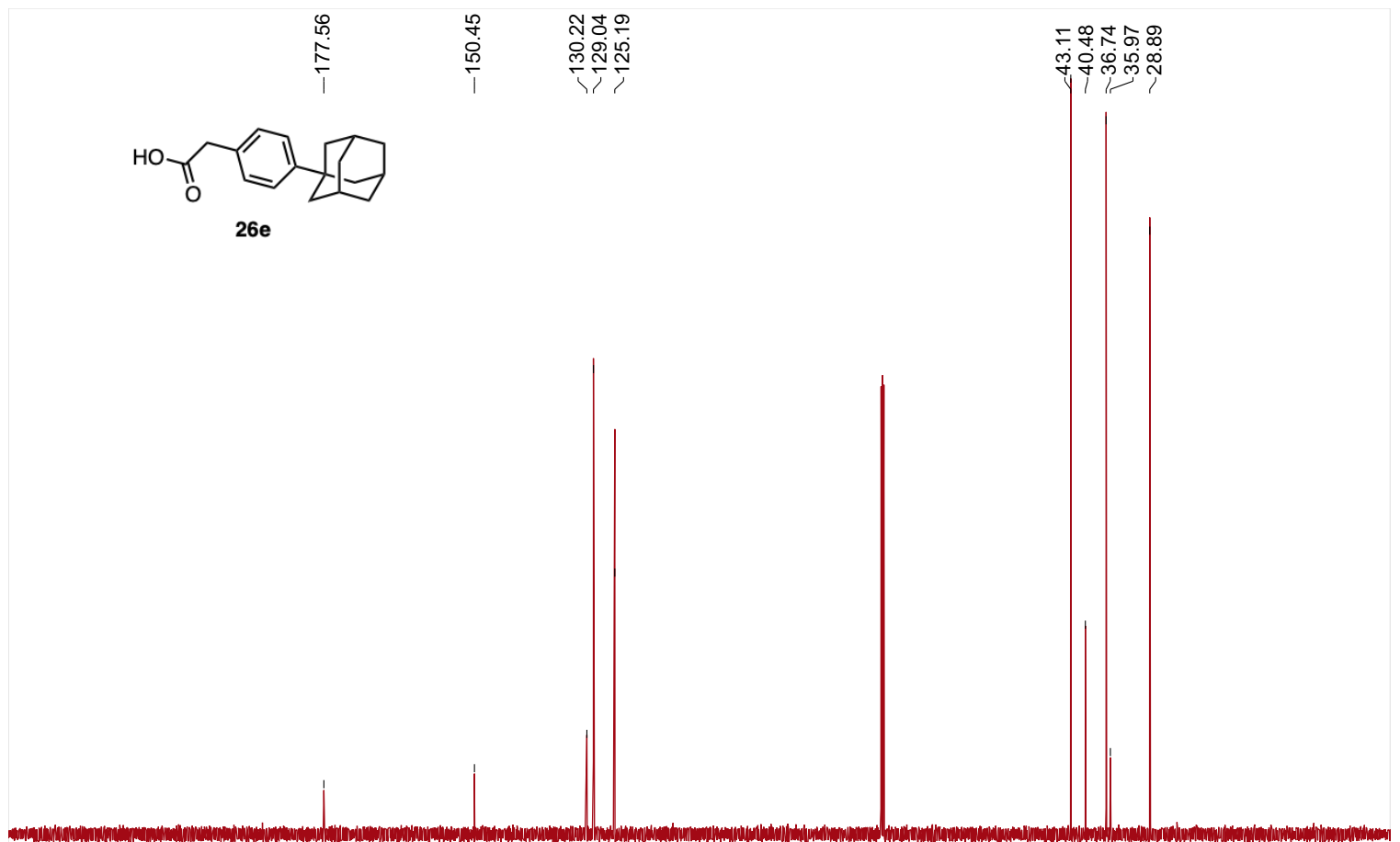

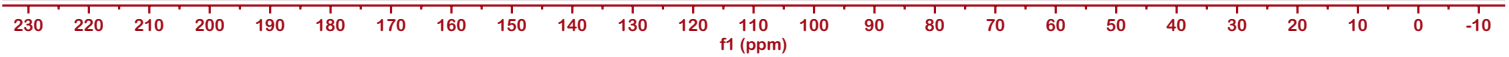


2-(4-(tert-Butyl)phenyl)acetic acid 26a:

${ }^{1} \mathrm{H}$ NMR $\left(500 \mathrm{MHz}, \mathrm{CDCl}_{3}\right.$ )

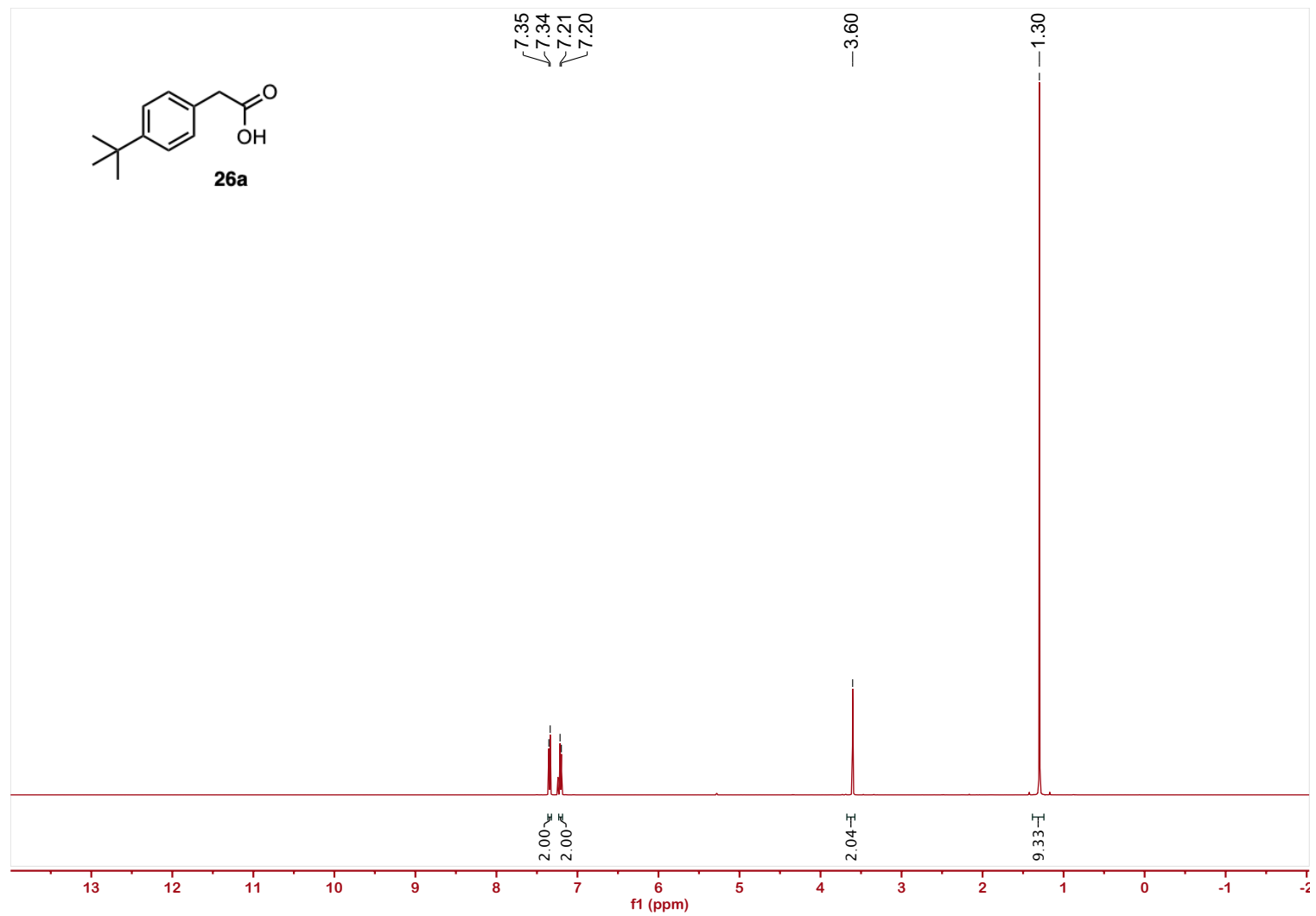

${ }^{13} \mathrm{C}\left\{{ }^{1} \mathrm{H}\right\}$ NMR $\left(126 \mathrm{MHz}, \mathrm{CDCl}_{3}\right)$

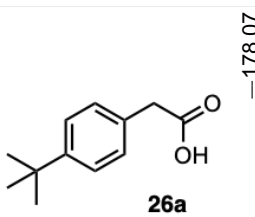

ำ

$26 a$

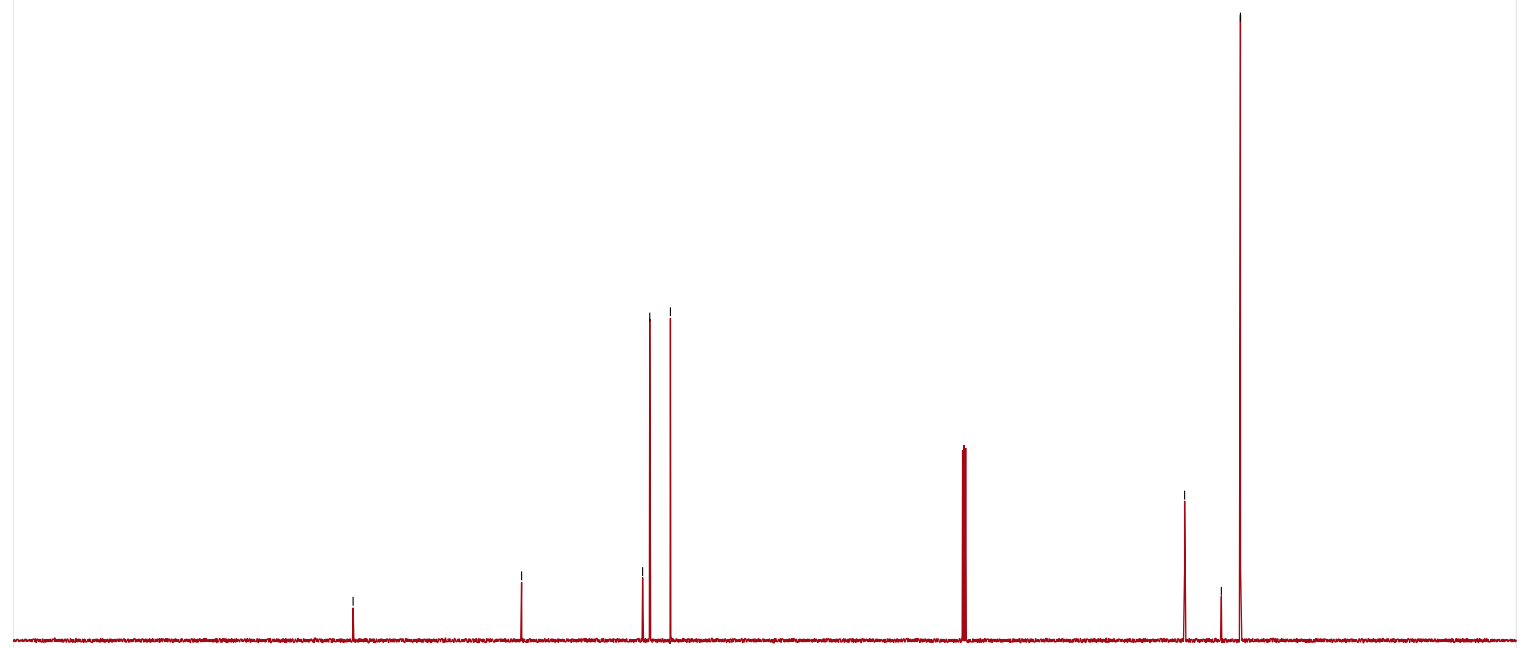

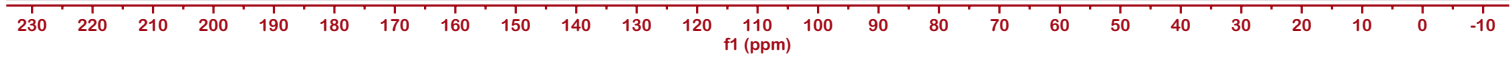


7-(tert-Butyl)-3-phenyl-1-naphthol 29a:

${ }^{1} \mathrm{H} \mathrm{NMR}\left(500 \mathrm{MHz}, \mathrm{CDCl}_{3}\right)$

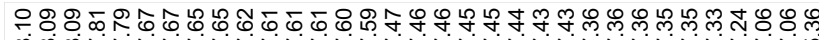

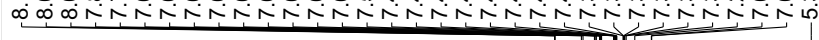<smiles>CC(C)(C)c1ccc2cc(-c3ccccc3)cc(O)c2c1</smiles>

29a

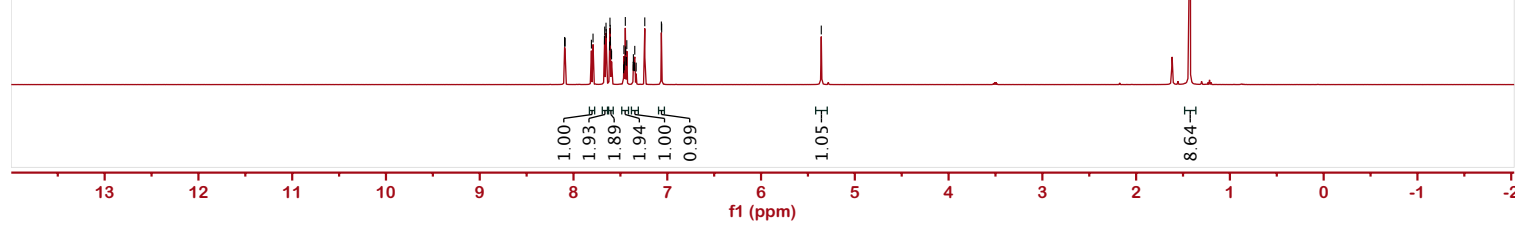

${ }^{13} \mathrm{C}\left\{{ }^{1} \mathrm{H}\right\} \mathrm{NMR}\left(126 \mathrm{MHz}, \mathrm{CDCl}_{3}\right)$

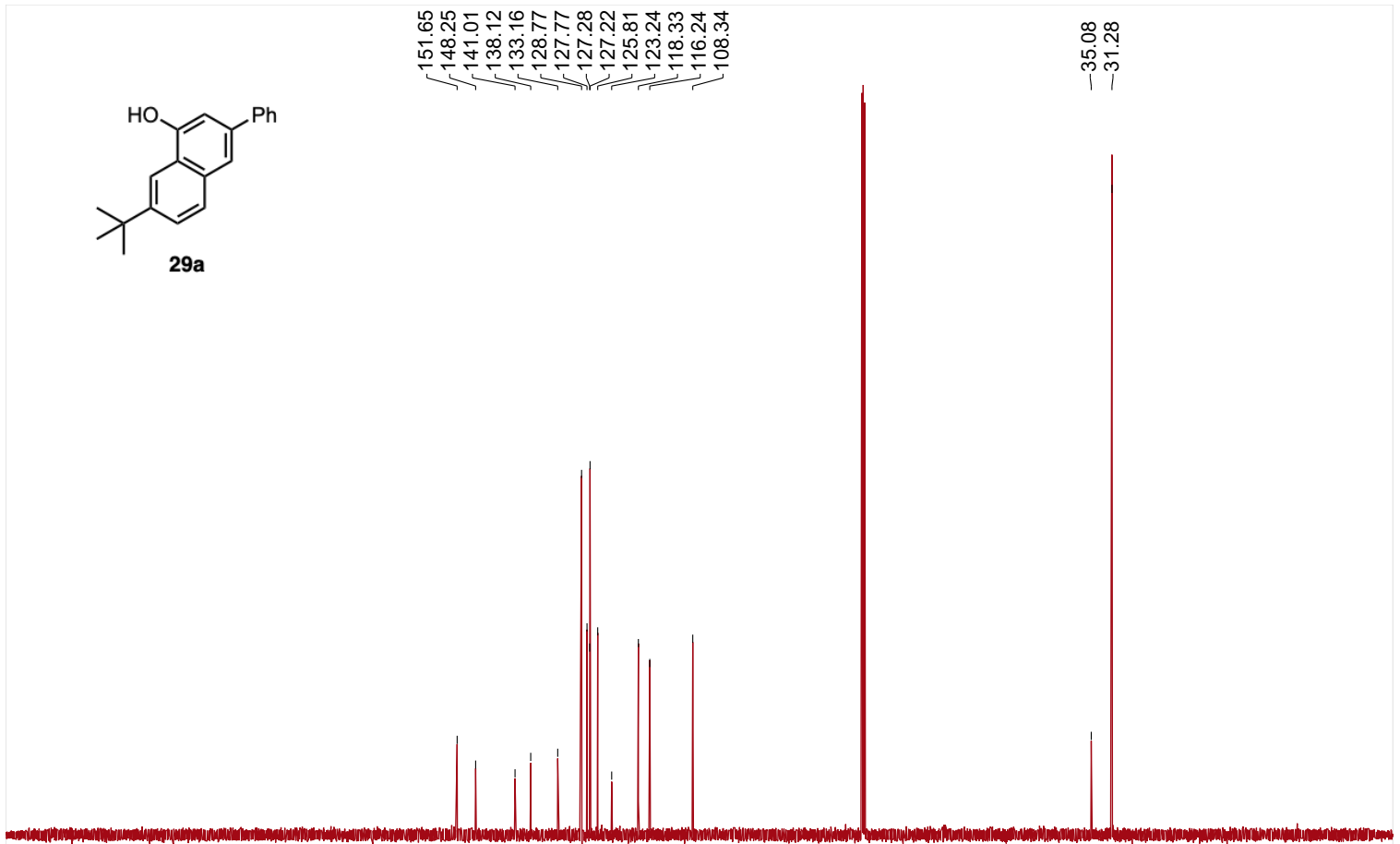

\begin{tabular}{lllllllllllllllllllllllllllllll}
\hline 230 & 220 & 210 & 200 & 190 & 180 & 170 & 160 & 150 & 140 & 130 & 120 & $\begin{array}{c}110 \\
f 1(\mathrm{ppm})\end{array}$ & 90 & 80 & 70 & 60 & 50 & 40 & 30 & 20 & 10 & 0 & -10 & -2
\end{tabular} 
7,7'-Di-tert-butyl-3,3'-diphenyl-[2,2'-binaphthalene]-1,1'-diol (7,7'-tBu $\left.{ }_{2} \mathrm{VANOL}\right)$ 13a:

${ }^{1} \mathrm{H}$ NMR $\left(500 \mathrm{MHz}, \mathrm{CDCl}_{3}\right)$

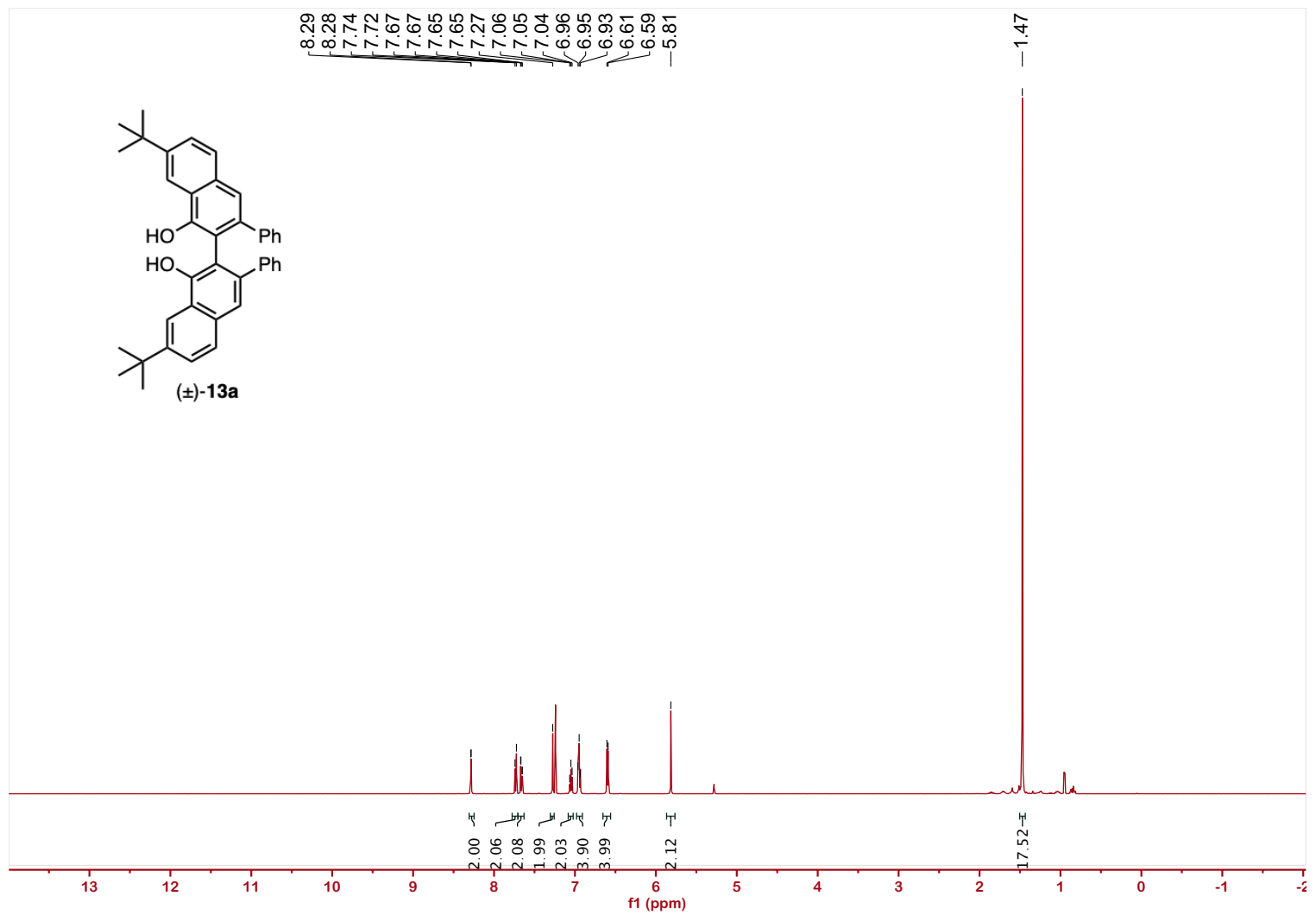

${ }^{13} \mathrm{C}\left\{{ }^{1} \mathrm{H}\right\}$ NMR $\left(126 \mathrm{MHz}, \mathrm{CDCl}_{3}\right)$

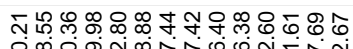

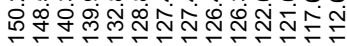

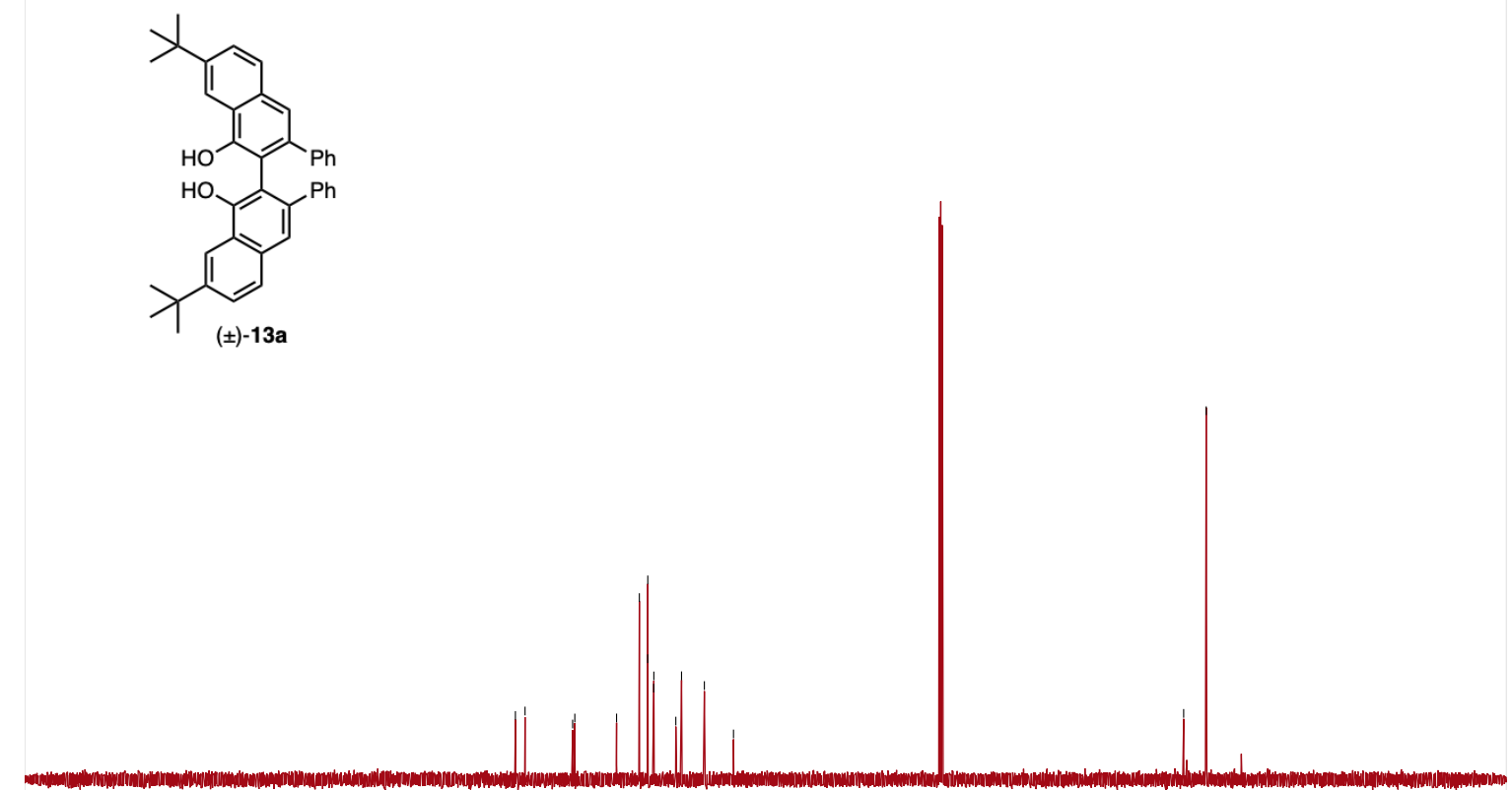

일

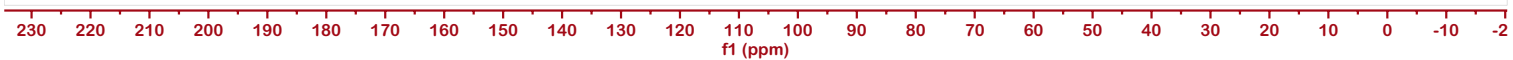


7-Bromo-3-phenyl-1-naphthol 29b:

${ }^{1} \mathrm{H}$ NMR $\left(500 \mathrm{MHz}, \mathrm{CDCl}_{3}\right.$ )

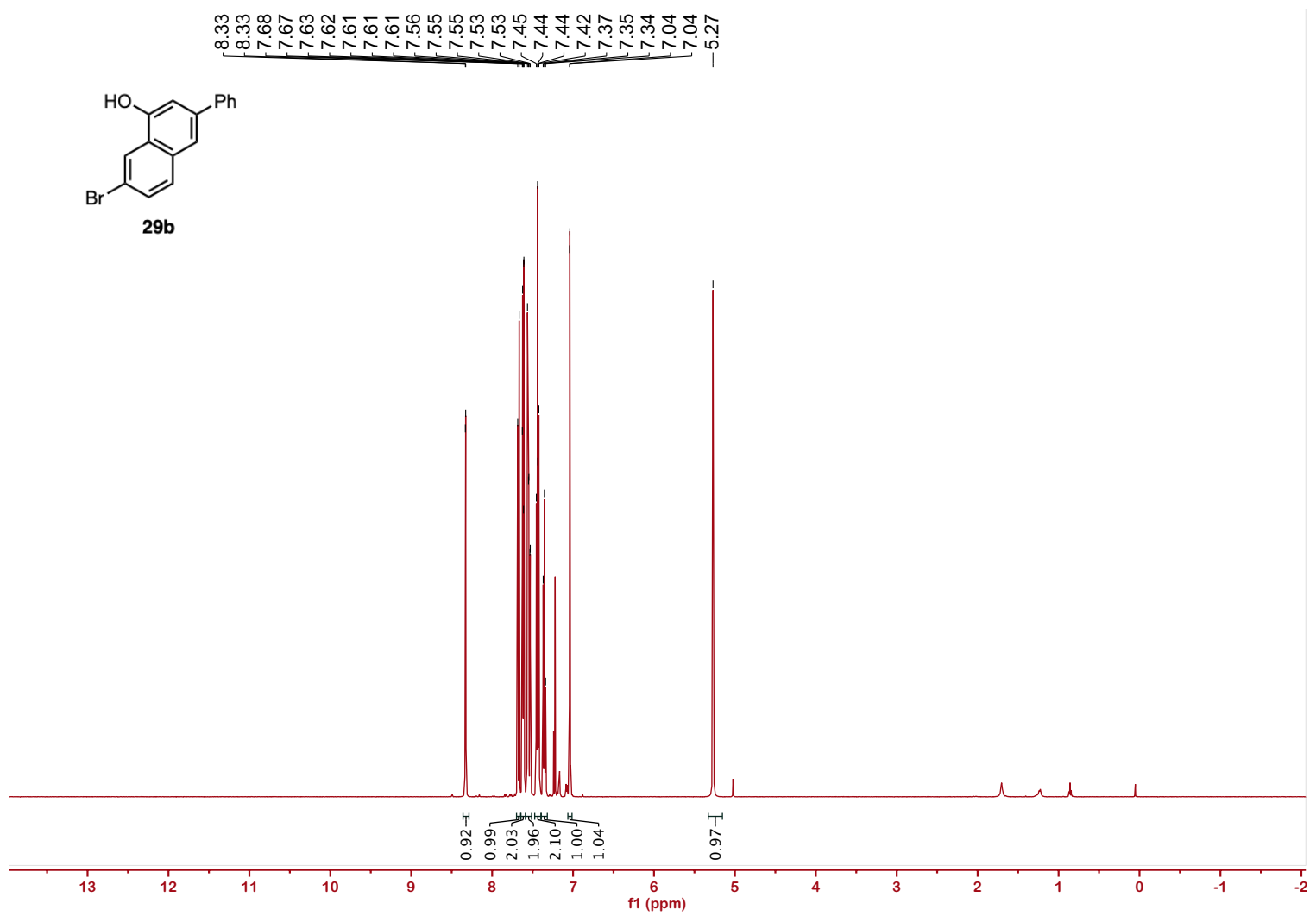

${ }^{13} \mathrm{C}\left\{{ }^{1} \mathrm{H}\right\}$ NMR $\left(126 \mathrm{MHz}, \mathrm{CDCl}_{3}\right)$

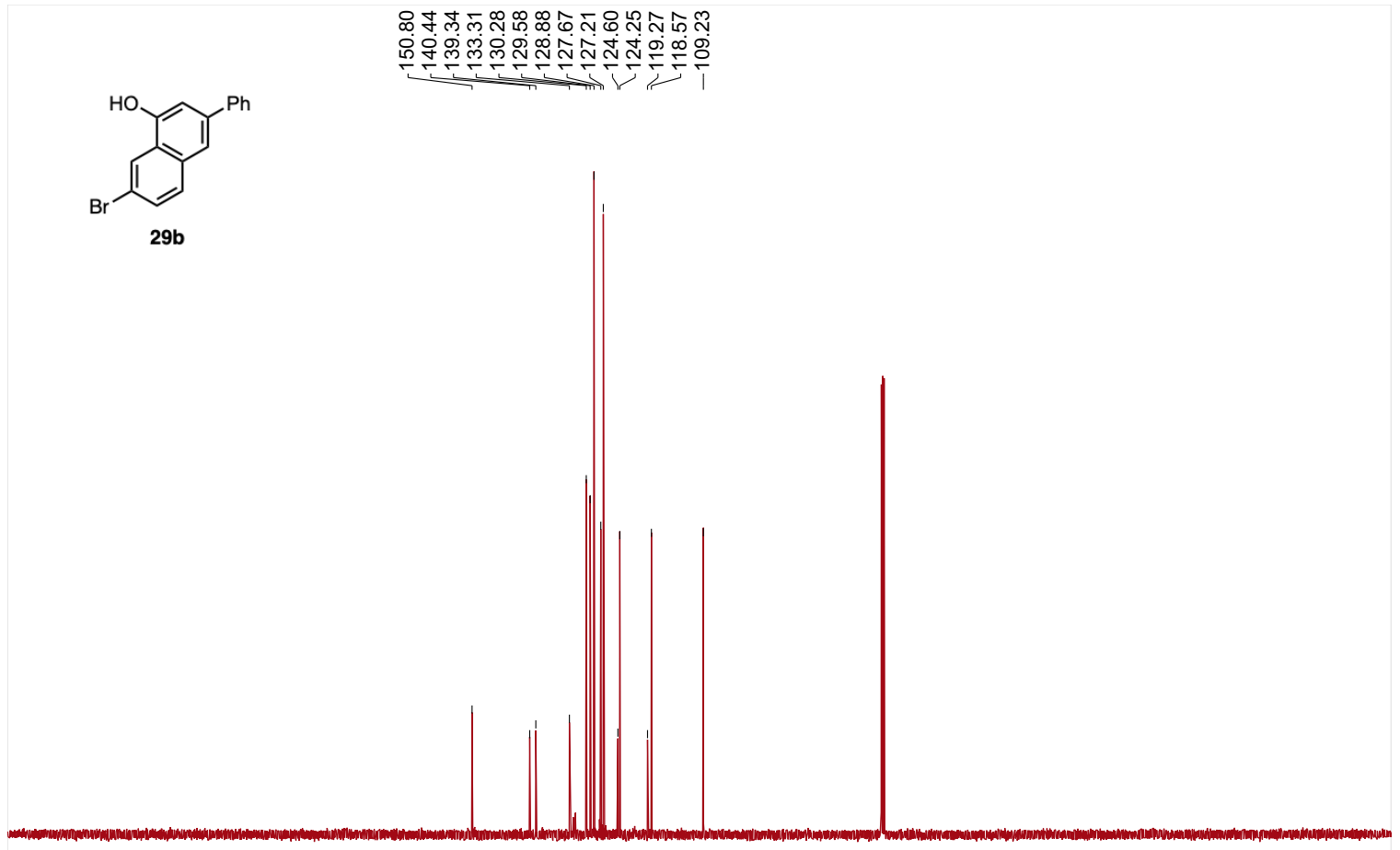

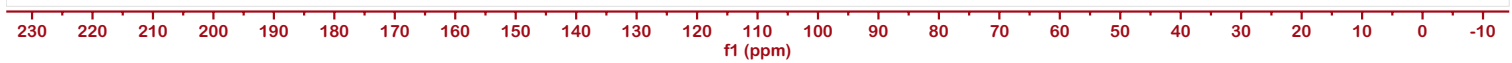


7,7'- $-\mathrm{Br}_{2}$ VANOL 13b:

${ }^{1} \mathrm{H}$ NMR $\left(500 \mathrm{MHz}, \mathrm{CDCl}_{3}\right)$

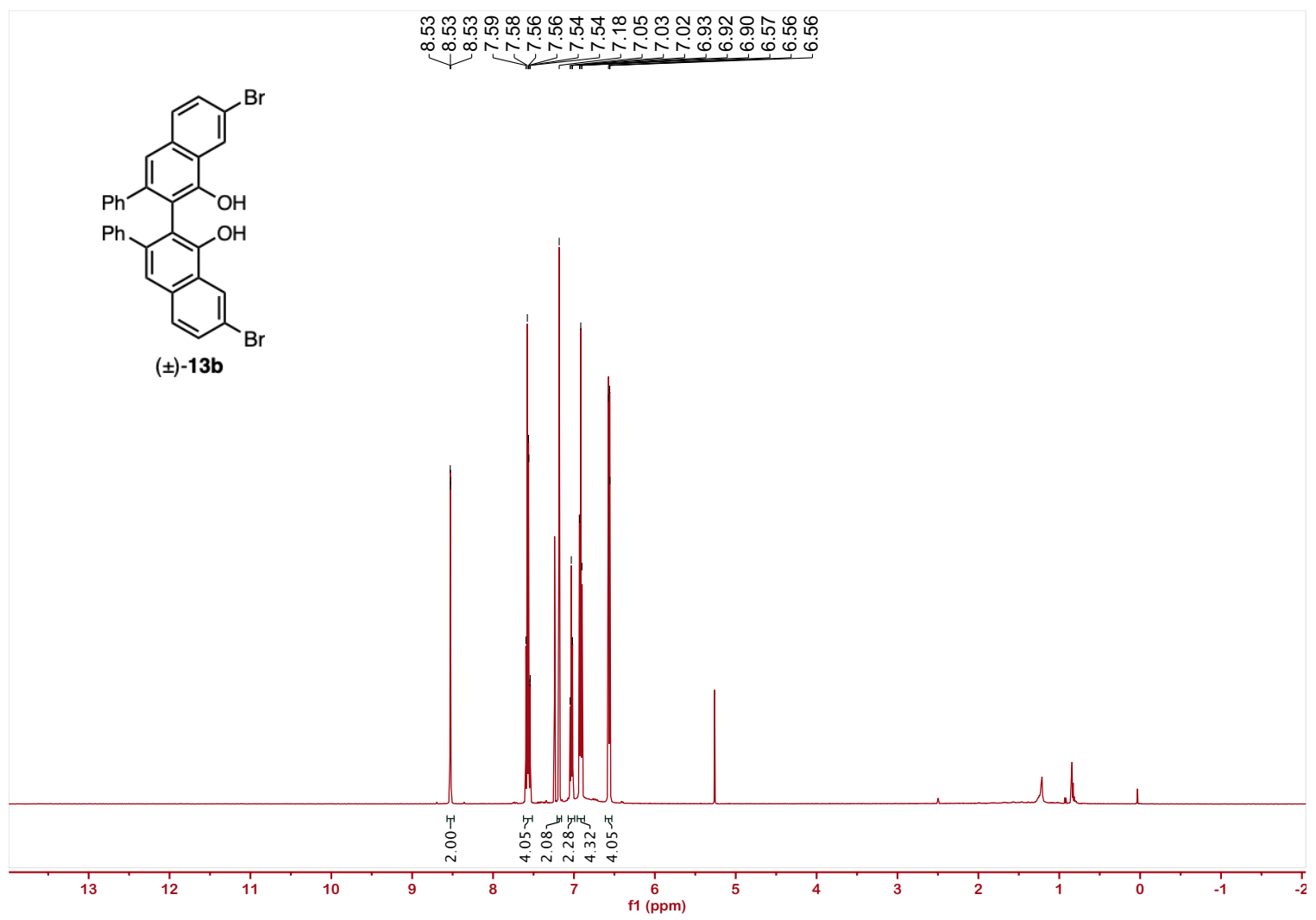

${ }^{13} \mathrm{C}\left\{{ }^{1} \mathrm{H}\right\}$ NMR $\left(126 \mathrm{MHz}, \mathrm{CDCl}_{3}\right)$

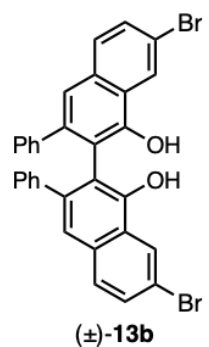

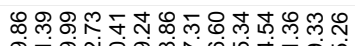

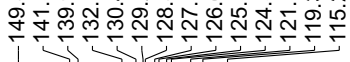

( \pm )-13b

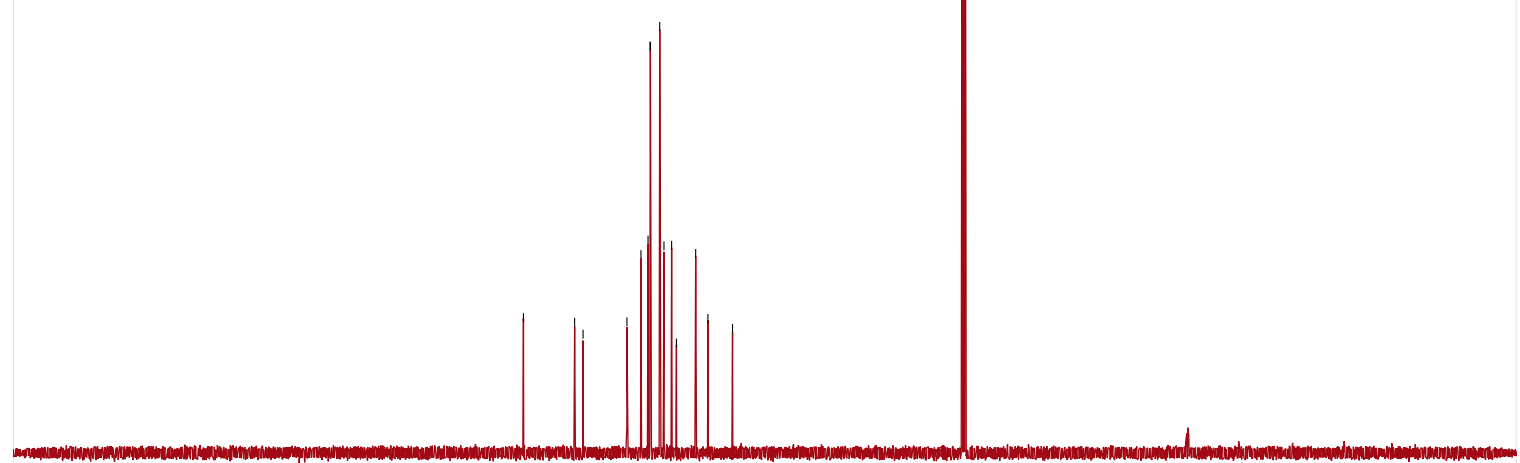

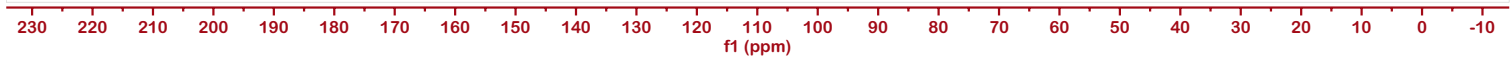


7-Adamantyl-3-phenyl-1-naphthol 29e:

${ }^{1} \mathrm{H}$ NMR $\left(500 \mathrm{MHz}, \mathrm{CDCl}_{3}\right.$ )

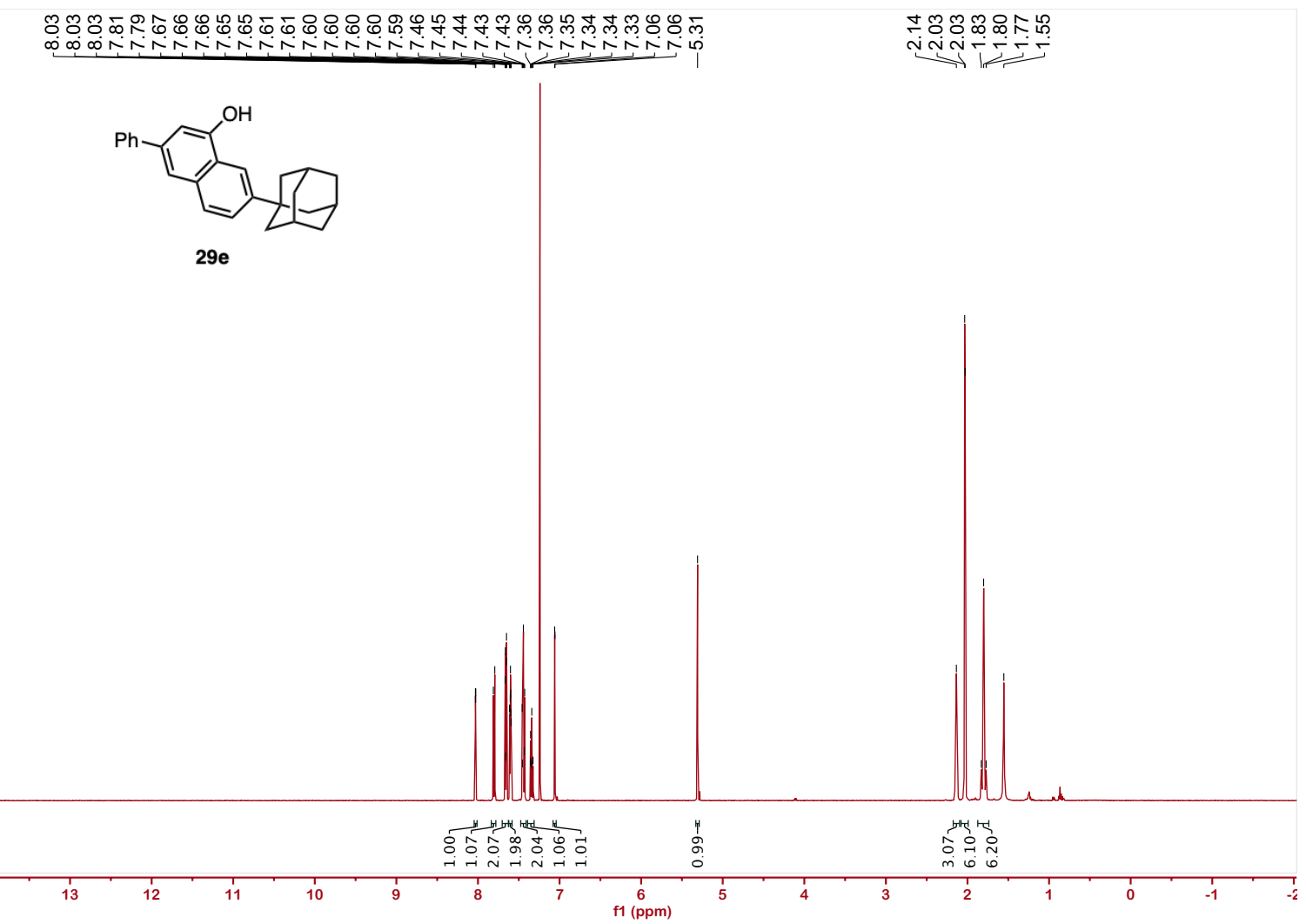

${ }^{13} \mathrm{C}\left\{{ }^{1} \mathrm{H}\right\}$ NMR $\left(126 \mathrm{MHz}, \mathrm{CDCl}_{3}\right)$

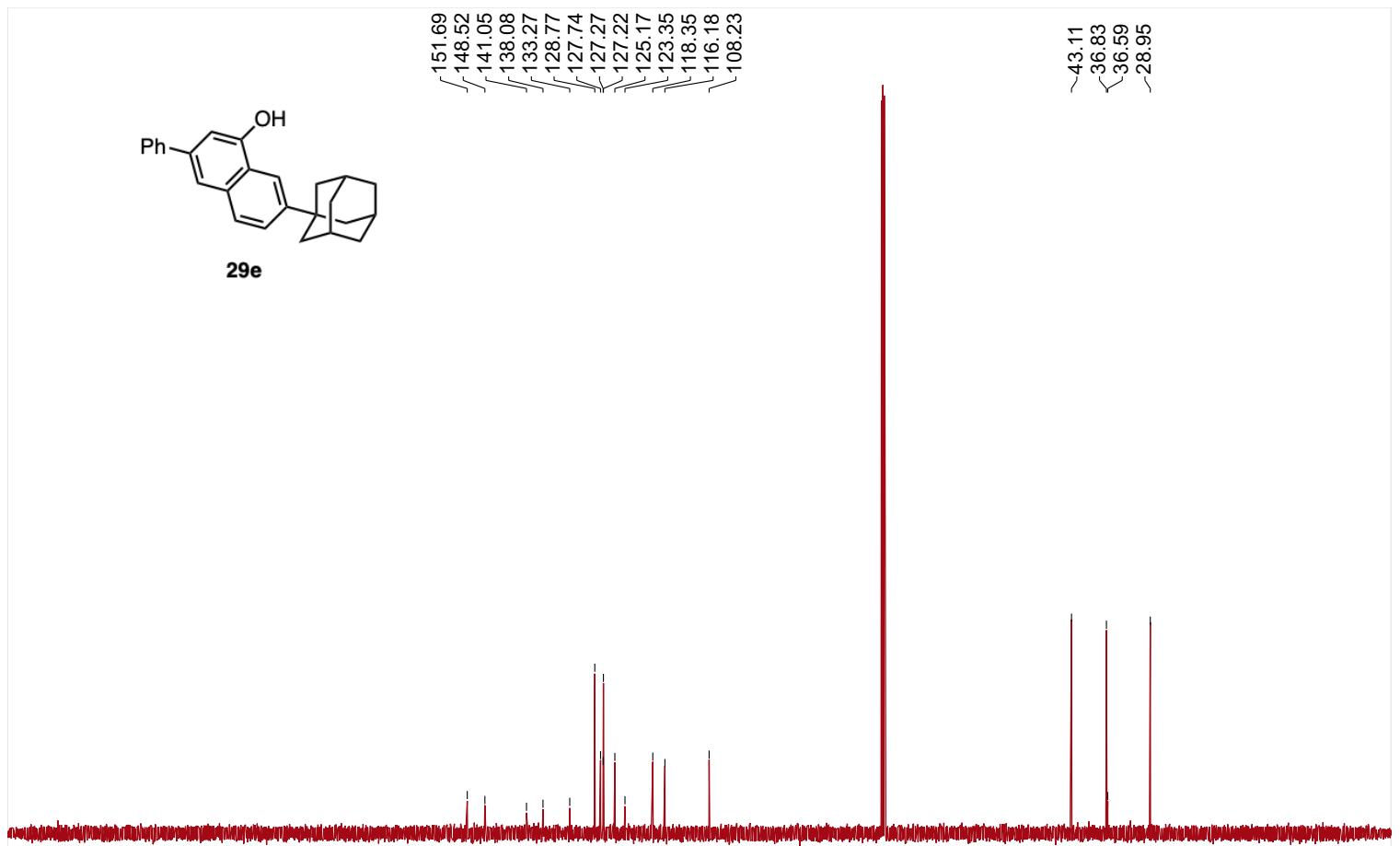

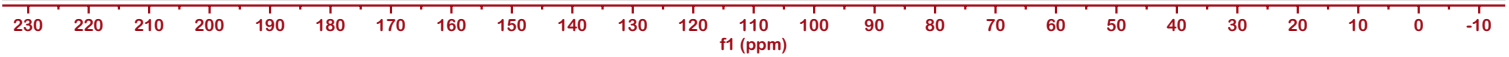


7,7'-Ad 2 VANOL 13e:

${ }^{1} \mathrm{H} \mathrm{NMR}\left(500 \mathrm{MHz}, \mathrm{CDCl}_{3}\right.$ )

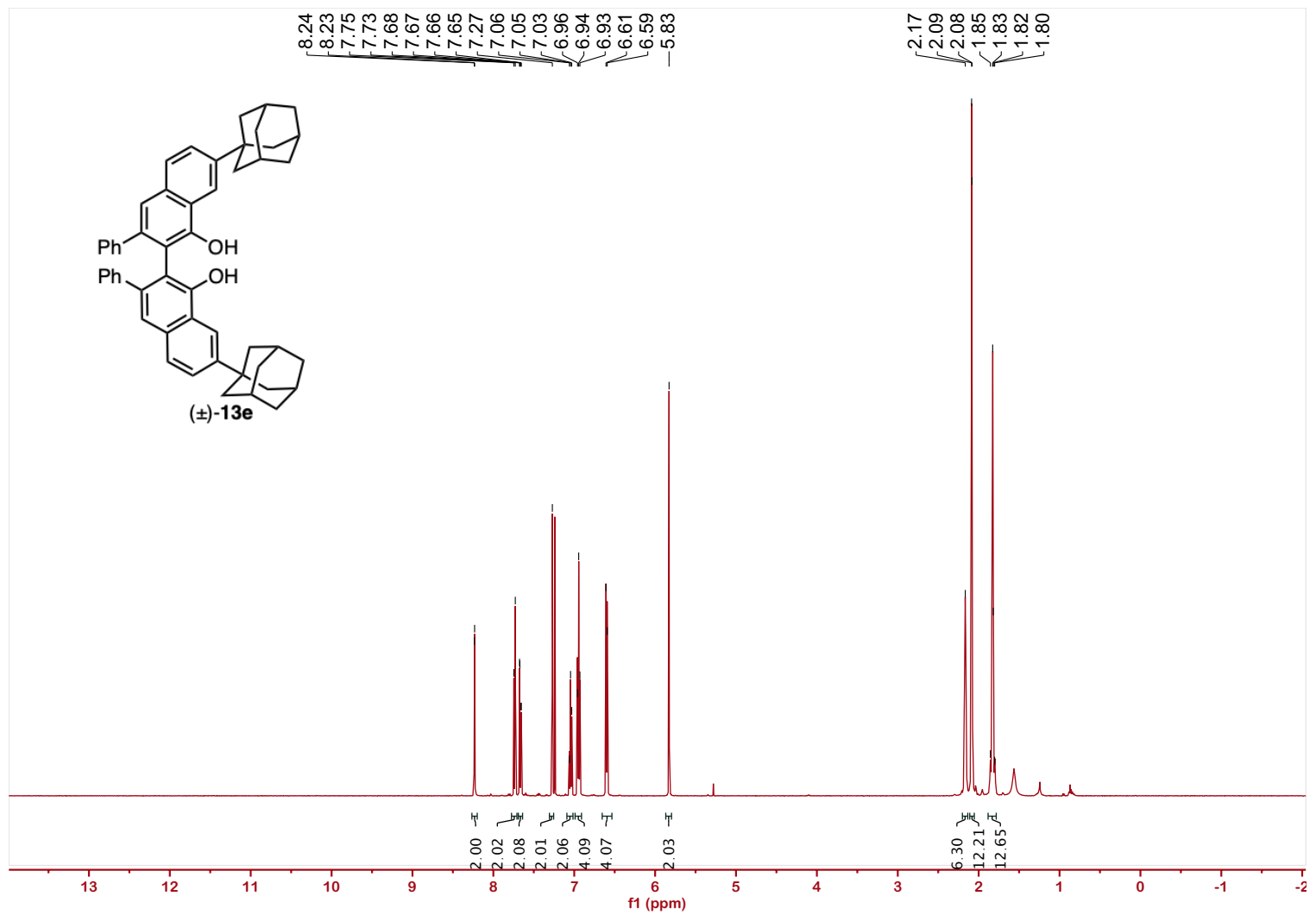

${ }^{13} \mathrm{C}\left\{{ }^{1} \mathrm{H}\right\}$ NMR $\left(126 \mathrm{MHz}, \mathrm{CDCl}_{3}\right)$

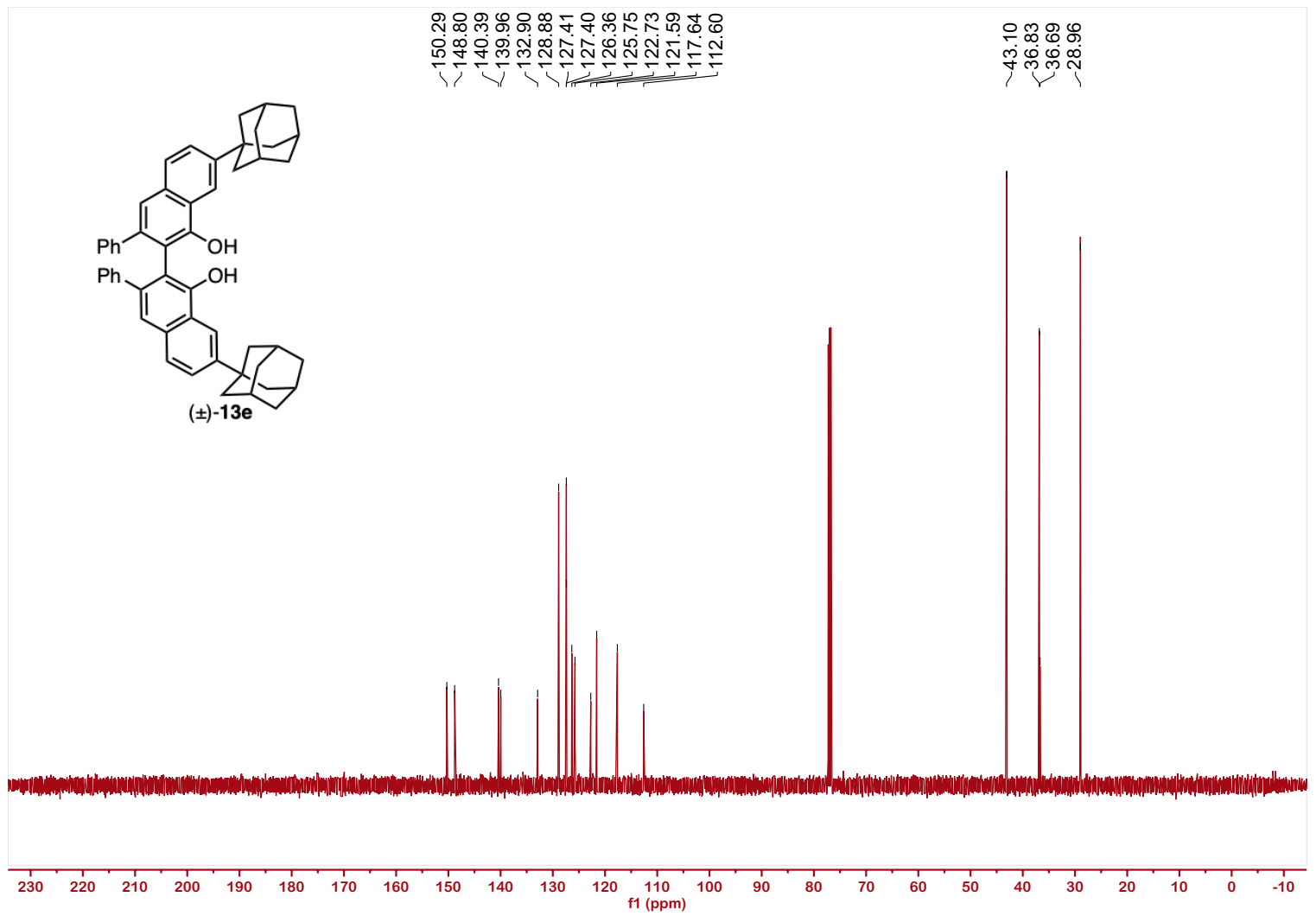


7,7'-BrVANOL-MOM 2 30:

${ }^{1} \mathrm{H} \mathrm{NMR}\left(500 \mathrm{MHz}, \mathrm{CDCl}_{3}\right.$ )

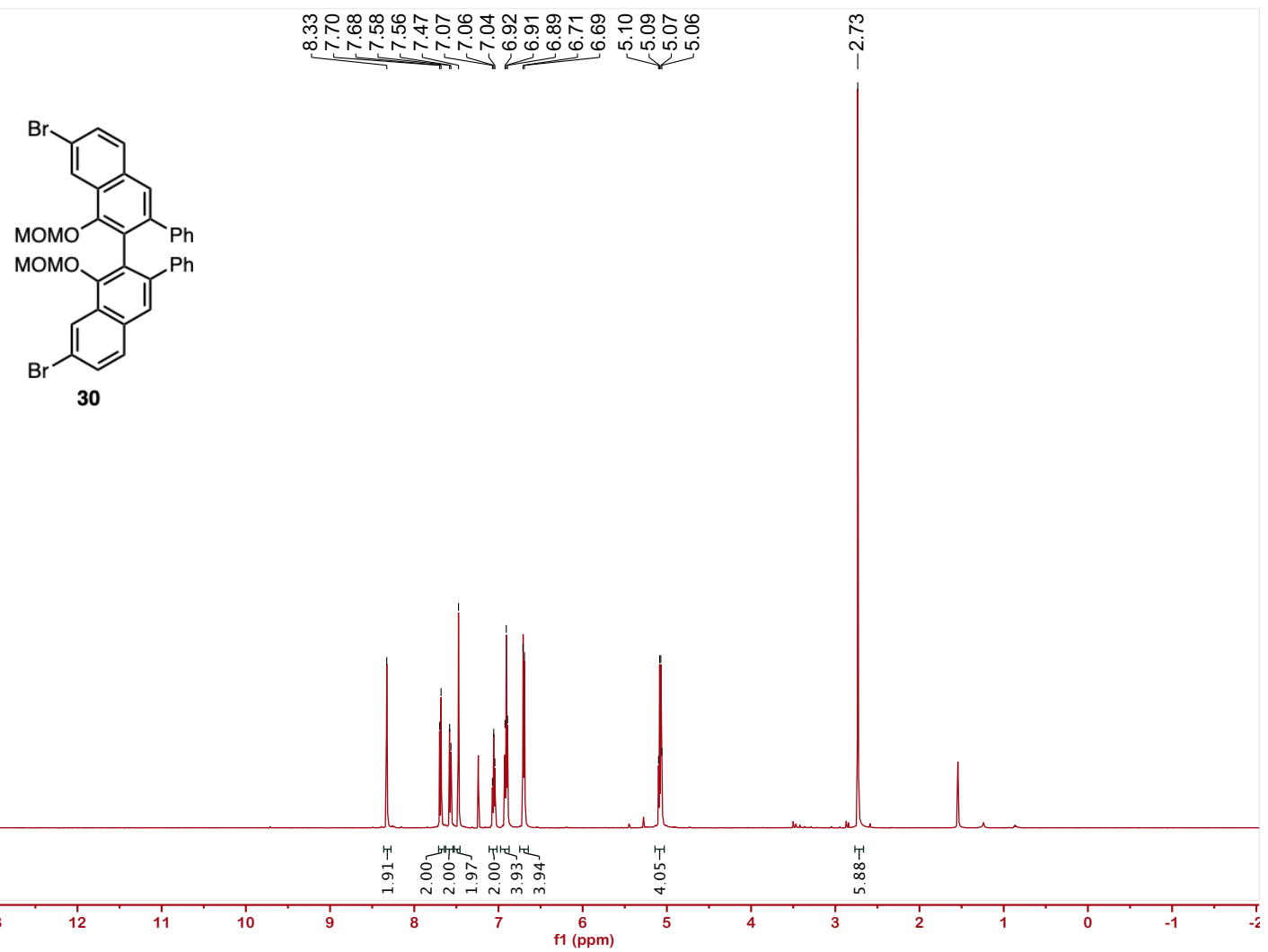

${ }^{13} \mathrm{C}\left\{{ }^{1} \mathrm{H}\right\}$ NMR (126 MHz, $\left.\mathrm{CDCl}_{3}\right)$

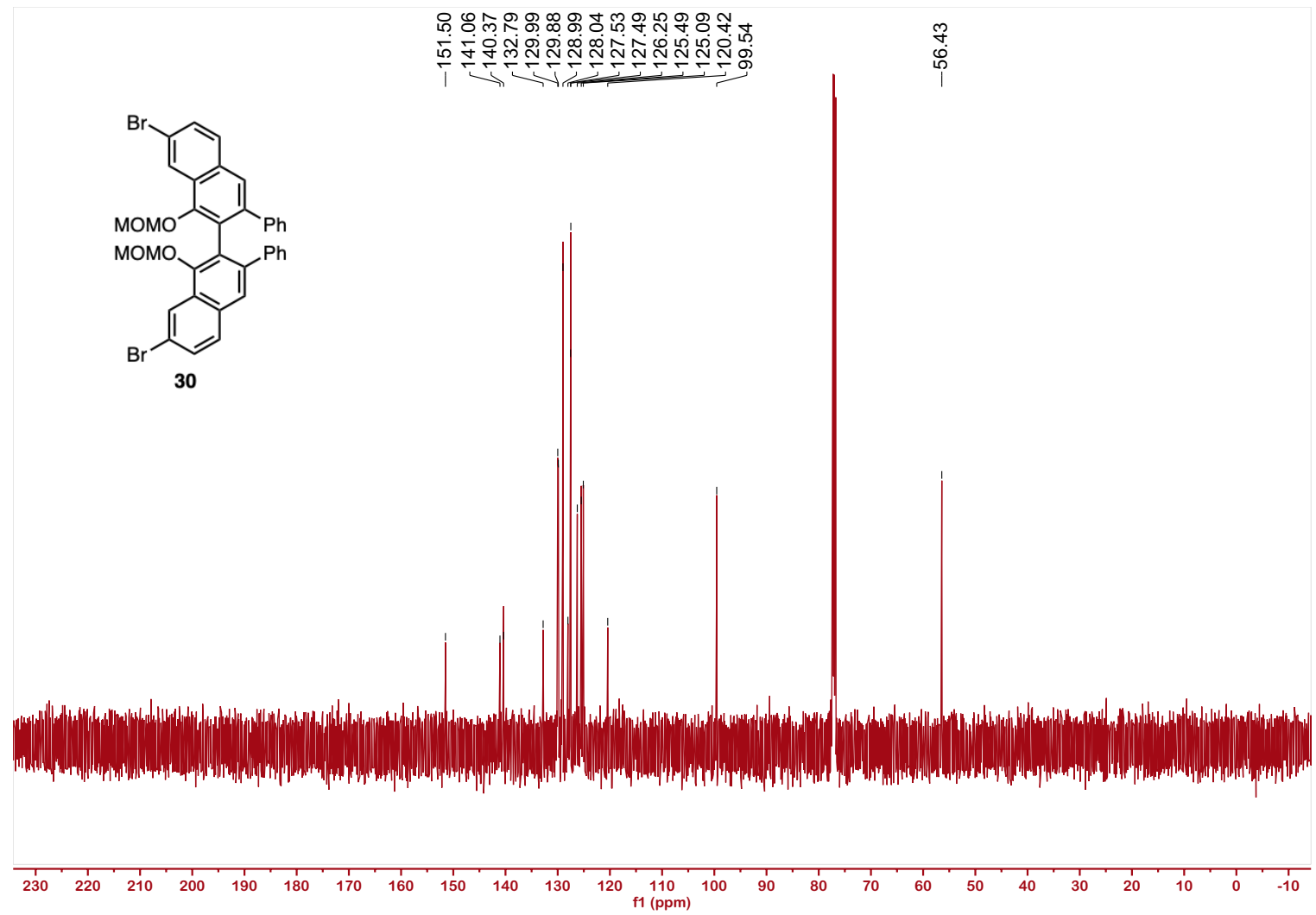


7,7'-isoamyl ${ }_{2}$ VANOL 13d:

${ }^{1} \mathrm{H}$ NMR $\left(500 \mathrm{MHz}, \mathrm{CDCl}_{3}\right)$

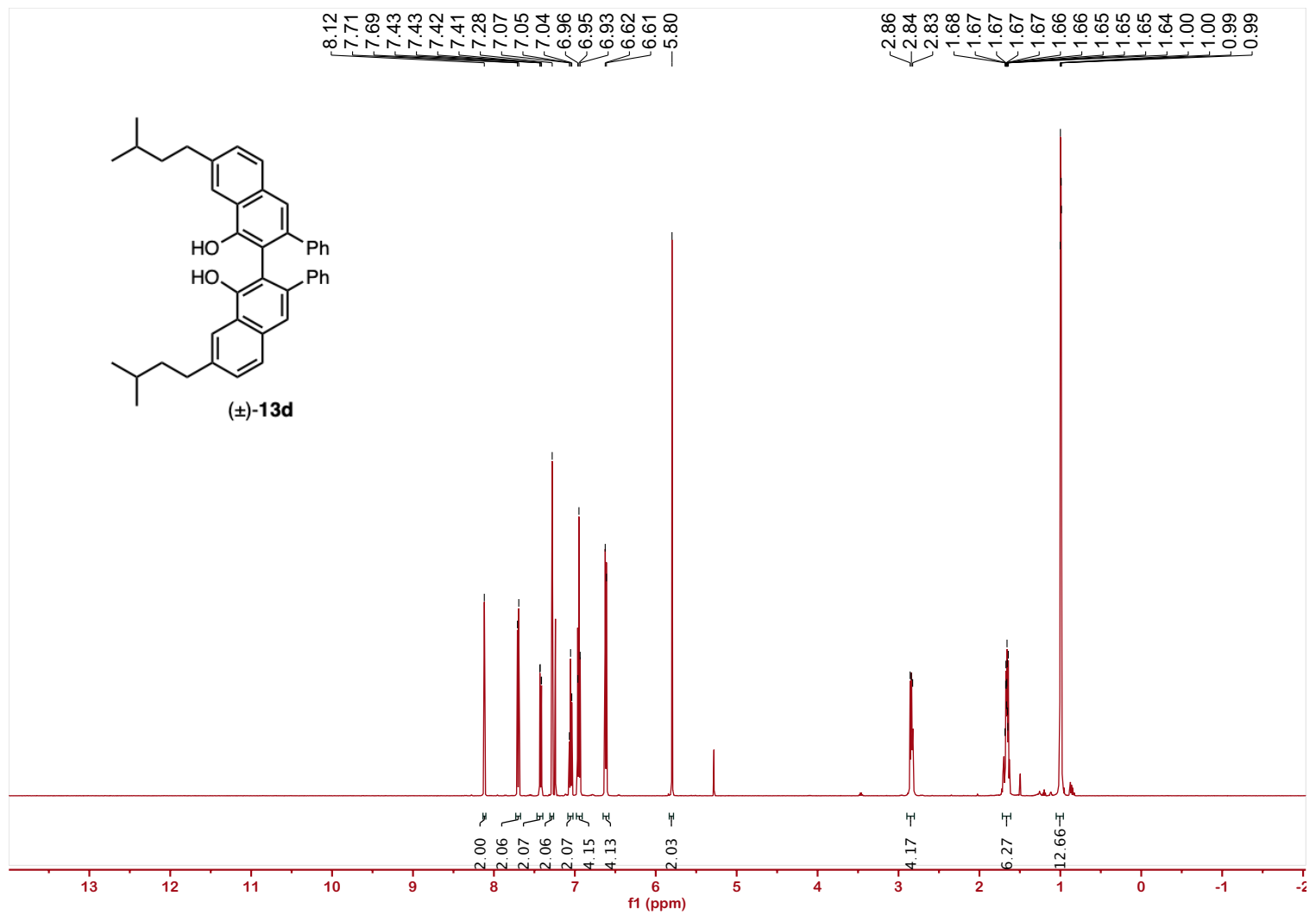

${ }^{13} \mathrm{C}\left\{{ }^{1} \mathrm{H}\right\}$ NMR $\left(126 \mathrm{MHz}, \mathrm{CDCl}_{3}\right)$

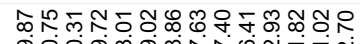

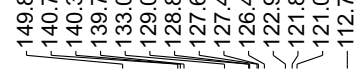

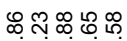

ํำกำ

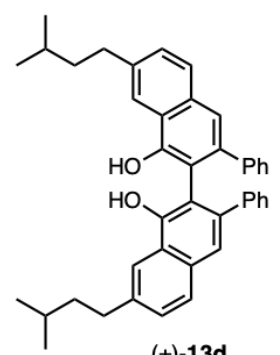

(士)-13d

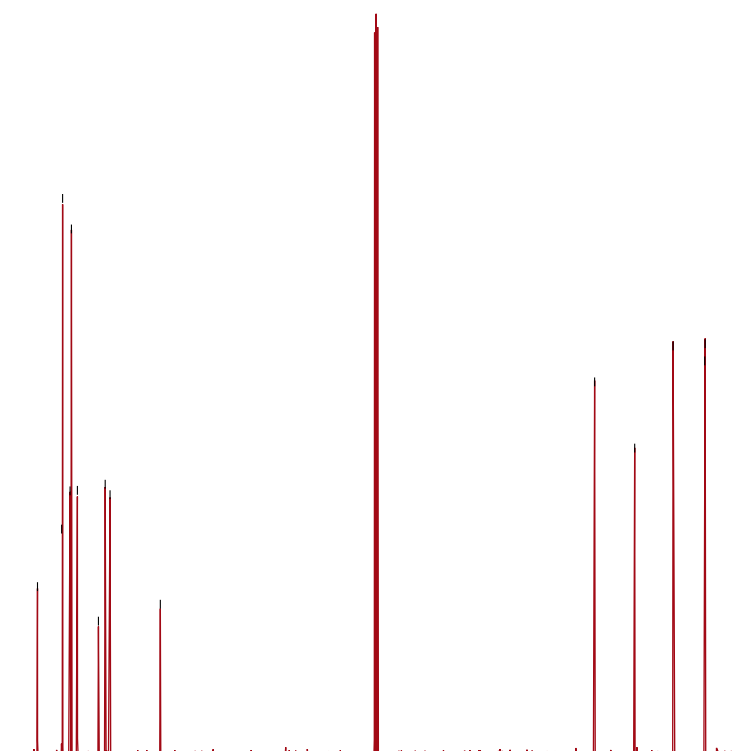

\begin{tabular}{lllllllllllll}
\hline 230 & 220 & 210 & 200 & 190 & 180 & 170 & 160 & 150 & 140 & 130 & 120 & 110 \\
$\mathrm{f} 1(\mathrm{ppm})$ & 100
\end{tabular} 


\section{7,7'-- $\mathrm{Cy}_{2}$ VANOL 13c:}

${ }^{1} \mathrm{H}$ NMR $\left(500 \mathrm{MHz}, \mathrm{CDCl}_{3}\right)$

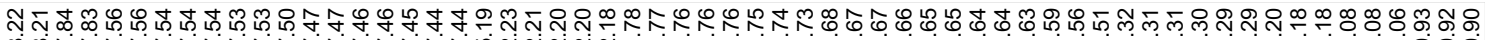

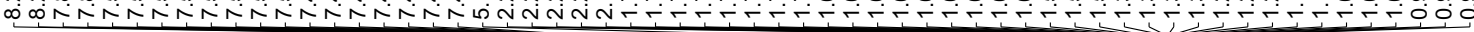

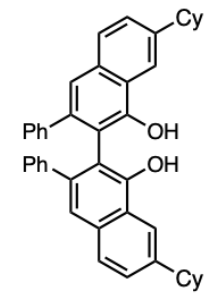

$( \pm)-13 c$

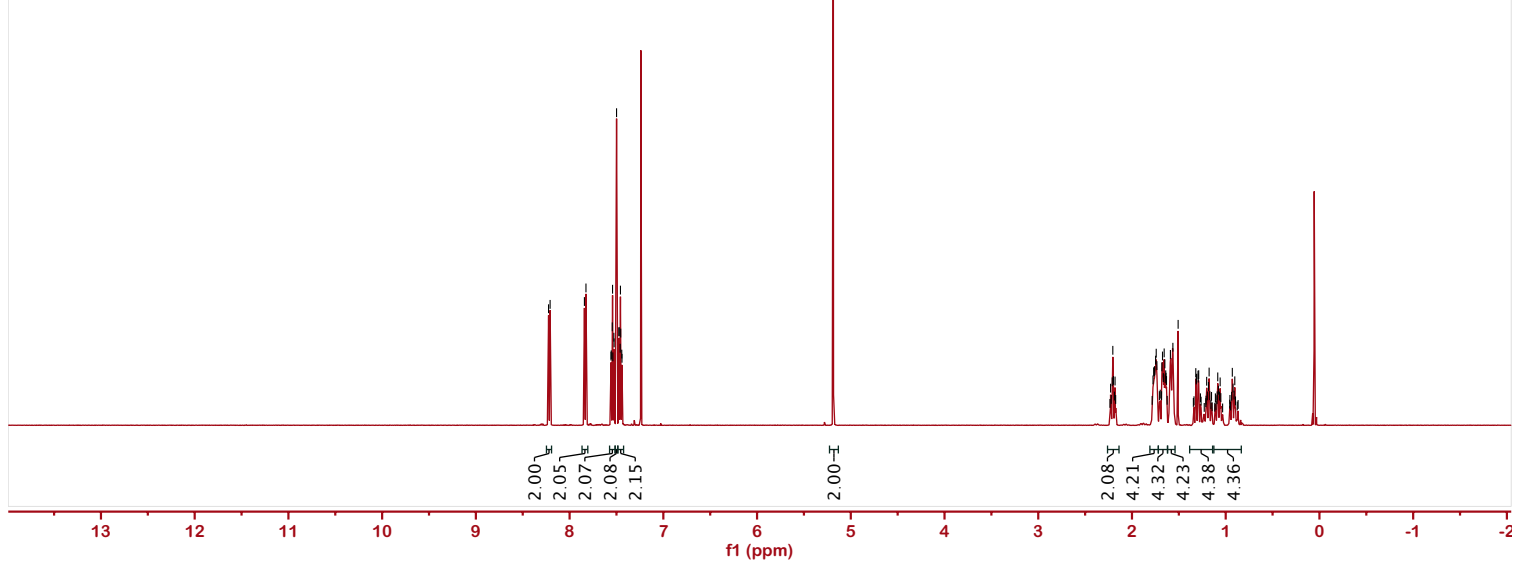

${ }^{13} \mathrm{C}\left\{{ }^{1} \mathrm{H}\right\}$ NMR (126 MHz, $\left.\mathrm{CDCl}_{3}\right)$

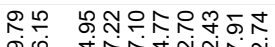

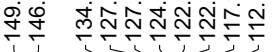

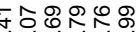

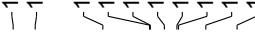

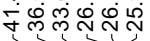

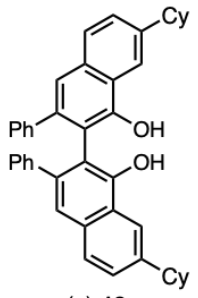

$( \pm)-13 c$

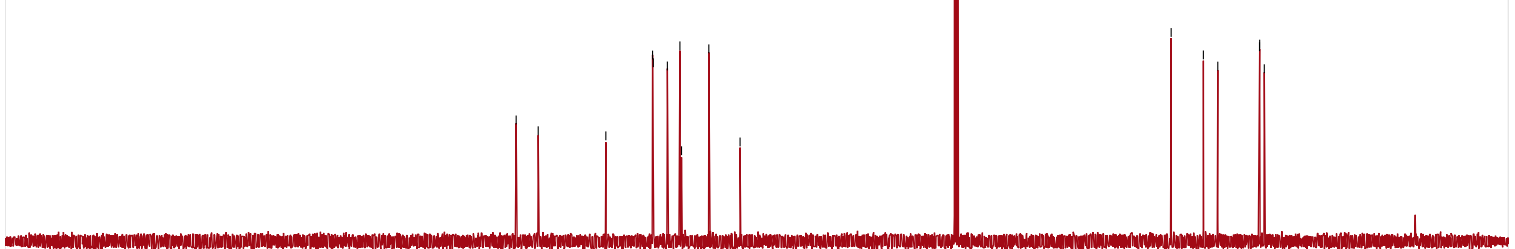

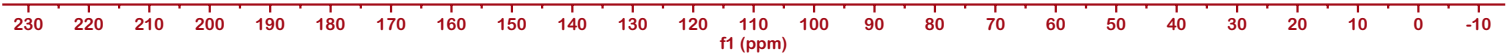

